\title{
Espalhamento Raman em pontos quânticos de InGaAs
}

\section{Alfredo Rodrigues Vaz}

Tese apresentada ao Instituto de Física da Universidade de São Paulo para a Obtenção do Título de Mestre em Ciências

\section{Munuliti}

Orientadora:

Profa. Dra. Vólia Lemos Crivelenti

Membros da Banca Examinadora:

Profa. Dra. Vólia Lemos Crivelenti - UFC

Prof(a). Dr(a). Maria Cecília Barbosa da Silveira Salvadori - IFUSP

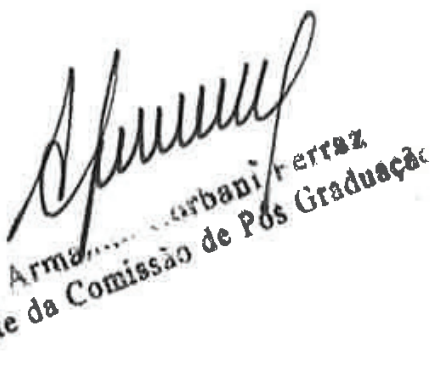

Prof. Dr. Fernando Cerdeira - UNICAMP

$$
\text { SÃO PAULO }
$$

1999

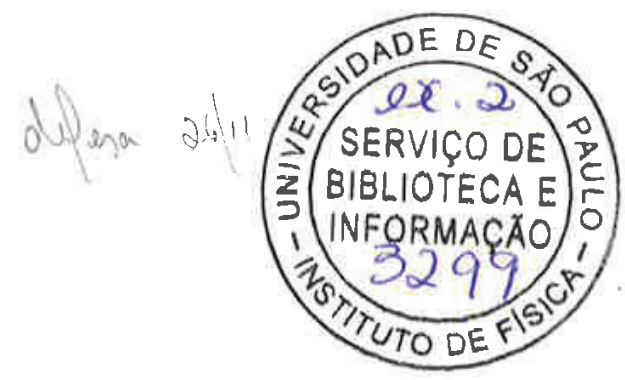


FICHA CATALOGRÁFICA

Preparada pelo Serviço de Biblioteca e Informação do Instituto de Física da Universidade de São Paulo

Vaz, Alfredo Rodrigues

Espalhamento Raman em pontos quânticos de InGaAs. São Paulo. 1999

Dissertação (Mestrado) - Universidade de São Paulo. Instituto de Física - Departamento de Física dos Materiais e Mecânica

Orientador: Profa. Dra. Vólia Lemos Crivelenti Área de Concentração: Fisica do Estado Sólido

Unitermos: 1. Propriedades ópticas de materiais; 2. Espalhamento Raman; 3. Pontos quânticos; 4. Efeitos de tensão. 


\section{Agradecimentos}

Agradeço muito à Professora Vólia pela orientação deste trabalho e por toda a sua compreensão, dedicação e apoio nessa fase tão importante da minha vida.

Agradeço também ao Professor Alain A. Quivy pelo trabalho de crescimento das amostras.

Gostaria também de agradecer à Professora Mônica Cotta do Departamento de Física Aplicada da UNICAMP pela ajuda nas medidas de AFM.

Agradeço à acolhida do pessoal do Laboratório de Novos Materiais Semicondutores do Departamento de Física da USP.

Ao grupo GPO da UNICAMP pelo uso dos laboratórios e ao desenhista Charles pela ajuda com as figuras.

Aos meus pais por todo apoio e carinho e ao meu falecido tio Lelo pela troca de idéias e abertura dos caminhos que me permitiu chegar até aqui.

Aos moradores, anexos, agregados e transeuntes da G-1 pelo apoio moral por todos esses anos de amizade.

Aos Solidários pela amizade e experiências. 


\section{Abstract}

$I n_{x} G a_{1-x} A s$ islands are interesting for use in Laser diode and light-emitting diode technology. The $I n_{x} G a_{1-x} A s$ islands investigated in this work were grown on semi-insulating (001) GaAs substrates by the self-organization method using molecular beam epitaxy. This type of island, when isolated and of small size, is considered as a quantum dot or zero-dimensional system. The samples were characterized by use of atomic force microscopy. The dot density and size were seen to increase as the In molar fraction decreased, resulting in a large dotcoverage in the case of $x=0.25$. The Raman spectra main features were the peaks corresponding to the LO and TO modes of GaAs-substrate. Second order structures were also present around $520 \mathrm{~cm}^{-1}\left(160 \mathrm{~cm}^{-1}\right)$ for optical (acoustic) vibration of GaAs. Two additional structures appear as a sharp peak at $222 \mathrm{~cm}^{-1}$ and higher energy broad band, which is resolved only for $x=0.25$, at $245 \mathrm{~cm}^{-1}$. The peak in $222 \mathrm{~cm}^{-1}$ is probably due to the normally forbidden GaAs LA(X) phonon induced by defects. To assign the broad band a model was constructed that considers: (i) the Raman frequency of the InAs-like mode with LO character as constant with $x$ in bulk InGaAs; (ii) confinement effects for the large dots formed has negligible effects in the quantum dot Raman frequency; (iii) The strain scale with $x$, the maximun value corresponds to that obtained for InAs. This model allowed to predict a range of frequencies for the dots. The value measured, $245 \mathrm{~cm}^{-1}$, fit into this range and is, thus, attributed to the InAs-like mode of the $I n_{0.25} G a_{0.75} A s$ quantum dots. Selection rules arguments reinforces this assignment. Several additional contributions in the frequency range of interest were considered. In order to analyze those contributions, a detailed study of disorder induced phonons in GaAs, and Raman scattering of As-crystaline and amorphous, was realized. The disorder was produced by laser ablation and the As sample was formed by an oxidation process of an AlAs film. Comparison of the Raman spectra allowed to conclude that neither As or GaAs disorder induced phonons contribute to the quantum-dot spectrum. 


\section{Resumo}

Ilhas de $I n_{x} G a_{1-x} A s$ são de grande interesse no desenvolvimento tecnológico de lasers de diodos e diodos emissores de luz. As ilhas de $I n_{x} G a_{1-x} A s$ investigadas neste trabalho foram crescidas sobre um substrato semi-isolante de GaAs (001) pelo método de auto-organização usando epitaxia de feixe molecular. Este tipo de ilha, quando isolada e de pequeno tamanho, é considerada um ponto quântico ou sistema zero-dimensional. As amostras foram caracterizadas através do uso da microscopia de força atômica. A densidade e o tamanho dos pontos aumenta com a diminuição da fração molar de In, resultando em uma maior cobertura para o caso de $x=0,25$. As características principais dos espectros Raman são os picos que correspondem aos modos LO e TO do substrato de GaAs. Duas estruturas adicionais aparecem no espectro: um pico estreito em $222 \mathrm{~cm}^{-1}$ e uma banda larga de mais alta energia, que só é resolvida para $x=0,25$, centrada em $245 \mathrm{~cm}^{-1}$. O pico em $222 \mathrm{~cm}^{-1}$ é provavelmente devido ao fônon LA(X) do GaAs normalmente proibido, induzido por defeitos. Para identificar a banda larga foi construído um modelo que considera: (i) a frequência Raman do modo tipo-InAs com caráter de LO como constante com a variação de $x$ no InGaAs 3-D; (ii) efeitos de confinamento não afetam a frequência Raman dado ao tamanho dos pontos quânticos das amostras deste trabalho; (iii) A tensão escala com $x$ e o valor máximo ocorre para o composto binário InAs. Este modelo permite prever um intervalo de frequências para os pontos quânticos. O valor medido, $245 \mathrm{~cm}^{-1}$, está dentro deste intervalo e portanto foi atribuído ao modo tipo- $I n A s$ dos pontos quânticos de $I n_{0,25} G a_{0,75} A s$. Considerações de simetria reforçam esta designação. Contribuições adicionais de fônons foram consideradas no intervalo de energia de interesse. Para analisar estas contribuições, foi feito um estudo detalhado dos fônons induzidos por desordem em camadas de GaAs, e espalhamento Raman de As cristalino e amorfo. A desordem foi produzida através da erosão por laser e a amostra de As foi formada por um processo de oxidação de um filme de AlAs. Comparação dos espectros Raman permitiu concluir que não houve contribuição de fônons induzidos por desordem no espectro do ponto quântico, seja de GaAs ou arsênio. 


\section{Sumário}

1 Introdução $\quad 9$

2 Sobre o Experimento 13

2.1 Montagem Experimental .............. . 13

2.2 Dificuldades Experimentais . . . . . . . . . . . . 17

2.3 Regras de Seleção . . . . . . . . . . . . . 18

3 Vibrações ópticas polares em pontos quânticos esféricos 21

3.1 Introdução . . . . . . . . . . . . . . . . . . . 21

3.2 Equações Gerais . . . . . . . . . . . . . . 22

3.3 Soluções Gerais . . . . . . . . . . . . . . . . 23

3.4 Ponto quântico esférico com interface abrupta . . . . . . . 26

3.5 Regras de seleção . . . . . . . . . . . . . 30

3.6 Conclusões . . . . . . . . . . . . . . . . . 31

4 Espalhamento Raman em ilhas de InAsGa auto-organizadas 33

4.1 Introdução . . . . . . . . . . . . . . . 33

4.2 Crescimento e Caracterização das Amostras . . . . . . . 34

4.3 Resultados e discussões . . . . . . . . . . . . . . . 37

4.3.1 Espectros Raman . . . . . . . . . . . . 37

4.3.2 Contribuições Adicionais e Regras de Seleção Correspondentes ................... . . . 42

4.3.3 Distribuições de Tensão nos Pontos . . . . . . . . . 43

4.3.4 Comparação com resultados experimentais da literatura 46 4.4 Conclusões . . . . . . . . . . . . . . . . 48

5 Espalhamento Raman de camadas de GaAs e AlAs com erosão na superfície 
5.1 Introdução . . . . . . . . . . . . . . . 49 49

5.2 Procedimento Experimental e Amostras . . . . . . . . . . 50

5.3 Resultados e Discussões . . . . . . . . . . . . 52

5.4 Conclusões . . . . . . . . . . . . . . . 63

6 Conclusões $\quad 65$

$\begin{array}{ll}\text { A Detectores } & \mathbf{6 9}\end{array}$

A.1 Medidas de Energia . . . . . . . . . . . . . . . 69

A.2 Detectores de Estado Sólido . . . . . . . . . . 70

A.3 Sobre as Fotomultiplicadoras . . . . . . . . . . . . . 72

A.4 Sobre o CCD . . . . . . . . . . . . . 74

B Espalhamento Raman Ativado por desordem $\quad 77$

B.1 Introdução . . . . . . . . . . . . . . . 77

B.2 Observação prévia de modos ativados por desordem . . . . 78

B.3 Conclusões . . . . . . . . . . . . . . . 81 


\section{Lista de Figuras}

2.1 Configurações do espectrômetro. . . . . . . . . . . . . . 14

2.2 Montagem Experimental. . . . . . . . . . . . . . . 15

2.3 Esquema do espectrômetro com enumeração dos elementos

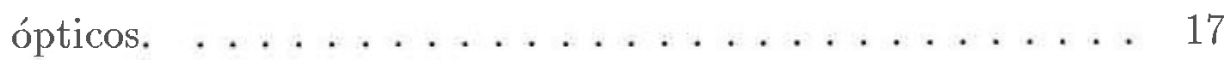

3.1 Energia dos três primeiros modos ópticos vibracionais para $l=0$ de um ponto quântico esférico de GaAs dentro de uma matriz de AlAs. . . . . . . . . . . . . . . .

4.1 Imagem da superfície das amostras com diferentes concentrações de In. . . . . . . . . . . . . . . . . . 35

4.2 Imagem da superfície da amostra obtida por AFM. A concentração de In é de $x=0,25 \ldots \ldots \ldots \ldots \ldots$

4.3 Imagem da superfície da amostra obtida por AFM. A concentração de In é de $x=0,50 \ldots \ldots \ldots \ldots \ldots \ldots$

4.4 Imagem da superfície da amostra obtida por AFM. A concentração de In é de $x=0,75 \ldots \ldots \ldots \ldots \ldots \ldots$

4.5 Espectros Raman dos pontos quânticos de InGaAs sobre o substrato de GaAs. . . . . . . . . . . . . . . . 38

4.6 Espectros Raman dos pontos quânticos de InGaAs sobre o substrato de GaAs a baixa temperatura. . . . . . . . . . . 39

4.7 Distribuição da tensão no plano (010) da pirâmide ao longo

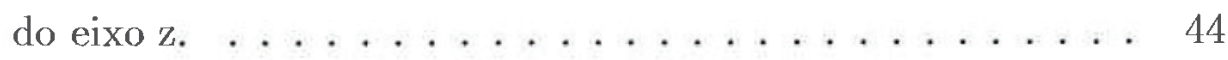

4.8 Tensão hidrostática e biaxial ao longo do eixo z da pirâmide. 45

5.1 Fotografia do furo produzido pela erosão com o laser. . . . . 51

5.2 Espectro Raman da amostra 911 (GaAs/GaAs). . . . . . . 53

5.3 Espectro Raman da amostra 923 (AlAs/GaAs). . . . . . . 54 
5.4 Curva de dispersão de fônons para o GaAs (vermelha) e para o AlAs (preta). [34] . . . . . . . . . . . . 57

5.5 Superfície da amostra \# 921 (AlAs/GaAs). . . . . . . 58

5.6 Espectro Raman da amostra \# 921 (casquinha). . . . . . . . 59

5.7 Espectro Raman do Arsênio na forma cristalina e amorfa. . . 62

5.8 Superposição do espectro Raman do GaAs (\#911) e AlAs/GaAs (\#923) com a lasca do filme de GaAs+As. . . . . . . 63

A.1 Diagrama de bandas de um detector de estado sólido. . . . . 71

A.2 Eficiência Quântica de uma fotomultiplicadora com catodos fabricados a partir de materiais bi-alcalinos. . . . . . . . 72

A.3 Curva de sensibilidade espectral típica de um fotocatodo, modelo S 20 F. . . . . . . . . . . . . . . 73

A.4 Eficiência Quântica do CCD. . . . . . . . . . 75

B.1 Variação da frequência versus composição das linhas Raman de primeira ordem em ligas de $\mathrm{Ga}_{1-x} \mathrm{Al}_{x} \mathrm{As} \ldots$. . . . . . . 81

B.2 Perfil do modo $\mathrm{LO}$ em $\mathrm{Ga}_{1-x} \mathrm{Al}_{x} \mathrm{As}$, com diversas composições. 82 


\section{Lista de Tabelas}

2.1 Regras de seleção Raman para a face (001) do GaAs. . . . . 19

4.1 Sumário das características dos pontos quânticos obtidos por AFM. ..................... 36

4.2 Posição dos modos Raman da liga $\operatorname{In}_{x} G a_{1-x} A s$ sem tensão

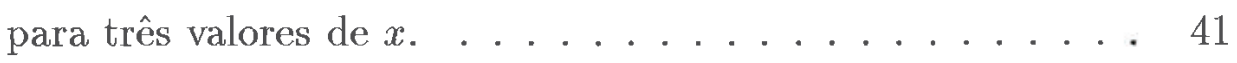

4.3 Frequências dos modos LO e TO do cristal 3-D, $w_{s 1}(c a l)$, e medido $w_{s 1}(\exp )$ para o modo de superfície de número quântico $l=1$. Dimensão das ilhas investigadas na ref. [9]: h: altura, $\emptyset$ : diâmetro. . . . . . . . . . . 47

4.4 Valores das frequências dos modos tipo-InAs no composto $I n_{x} G a_{1-x} A s 3-\mathrm{D}$ e valores calculados para as frequências dos modos de superfície dos pontos quânticos. . . . . . . 47

5.1 Valores nominais das espessuras características das camadas. 50

5.2 Comparação dos resultados obtidos dos ajustes das curvas referentes à amostra 911 (GaAs/GaAs). . . . . . . 56

5.3 Comparação dos resultados obtidos dos ajustes das curvas referentes à amostra $923(\mathrm{AlAs} / \mathrm{GaAs}) \ldots \ldots . \ldots 56$ 


\section{Capítulo 1}

\section{Introdução}

Existe um interesse recente nas heteroestruturas de baixa dimensionalidade em decorrência de sua ampla aplicação em dispositivos. Diodos emissores de luz (LEDs) e laser de diodos (LDs) semicondutores emitindo no visível já estão sendo usados em cartazes e sinalização. A vantagem deste tipo de dispositivo é um consumo menor de energia e longa durabilidade em comparação com os sistemas convencionais. [1] A alta qualidade dos dispositivos mais recentes resulta de propriedades ópticas e eletrônicas superiores devido ao confinamento dos portadores. Um modelo teórico mostra que o confinamento em uma dimensão causa aumento de ganho óptico por efeitos excitônicos. [2] Ganhos maiores geram expectativas de economia, por exemplo, na redução da corrente de disparo em lasers semicondutores e consequente aumento da vida média. Baseado neste tipo de expectativa a busca por dispositivos semicondutores com portadores confinados é frenética. O confinamento é máximo em materiais zero-dimensionais, designados na literatura por pontos quânticos. Recentemente, foi demonstrado que a camada ativa de vários dispositivos emissores de luz fabricados pela companhia japonesa Nichia Chemical, continha sequências de pontos quânticos isotrópicos formados espontaneamente durante o crescimento epitaxial. [3] A emissão ocorre por transições entre estados de energia dos pontos quânticos, justificando a eficiência dos dispositivos. [4]

Para observar efeitos de confinamento zero-dimensional o tamanho das partículas devem estar na escala nanométrica. As primeiras tentativas de produzir nanopartículas, pelo processo de litografia, esbarraram no problema de degradação nas proximidades das dimensões requeridas. Um 
dos primeiros sucessos foi a deposição epitaxial pelo processo de StranskiKrastanov vastamente empregado para obtenção de pontos quânticos de semicondutores III-V, incluindo InP/InGaP, GaSb/GaAs, InGaAs/GaAs, InAlAs/GaAs, InSb/GaAs, AlSb/GaAs, etc. [5-7] O processo consiste em depositar uma camada tensionada, a qual, a partir de uma espessura crítica (da ordem de 2 monocamadas) é seguida de relaxação elástica através da formação de ilhas. A caracterização estrutural destas ilhas tem sido feita usando-se técnicas de microscopia de força atômica (AFM) e/ou microscopia eletrônica de transmissão (TEM).

$O$ confinamento de portadores é investigado através da análise de resultados de fotoluminescência (PL), fotoluminescência de excitação (PLE), fotorefletância (PR), e outras.

Embora o conhecimento atingido nos últimos anos seja considerável, questões fundamentais sobre os mecanismos de formação das nanoestruturas não foram resolvidas ainda. Entre elas, cita-se: (a) a temperatura de formação dos pontos é muito inferior ao ponto de fusão $\left(T_{M}\right)$ do material constituinte; (b) a existência e dimensão de espessura crítica de formação dos pontos; (c) a interdifusão nas interfaces e a segregação em constituintes de compostos mistos; (d) a distribuição de tensões internas, etc.

Uma explicação da fusão em lâminas finas tensionadas a temperaturas abaixo de $T_{M}$ foi proposta, recentemente por Bottomley. [8] Neste trabalho a tensão é escrita em termos do acréscimo de energia (livre de Gibbs) necessária para ocorrer a fusão. Como o acréscimo depende da temperatura, a uma dada temperatura corresponde uma tensão crítica de fusão. O modelo ignora efeitos de interdifusão e segregação. Por outro lado, evidências de interdifusão e segregação foram recentemente encontradas através de estudo de espalhamento Raman Ressonante em sistemas semicondutores III-V. $[9,10]$ A expectativa de informações similares para pontos quânticos de InGaAs gera grande interesse na sua investigação utilizando espectroscopia Raman.

Neste trabalho foram realizadas medições Raman em pontos quânticos de $I n_{x} G a_{1-x} A s / G a A s$ crescidos por MBE com fração molar de In $x=$ $0,25, x=0,50$ e $x=0,75$. As experiências foram realizadas tanto a temperatura ambiente quanto a baixas temperaturas.

As amostras, caracterizadas estruturalmente através de AFM, continham densidades e tamanhos de pontos diferentes. Para os pontos formados de 
In $n_{0,25} G a_{0,75} A s$ a densidade, bem como tamanho médio dos pontos, era maior. Neste caso, foi observado um pico em $245 \mathrm{~cm}^{-1}$ o qual foi indentificado como vibração tipo radial, em comparação com modelo teórico desenvolvido para pontos esféricos. [11] Foi utilizado o resultado de um cálculo númerico de tensão para prever o valor da energia de vibração correspondente. [12]

No processo de identificação do pico Raman várias hipóteses foram consideradas. Uma delas foi ativação de modos proibidos do GaAs - substrato por desordem superficial gerada pelos pontos. Para explorar melhor esta hipótese foram realizadas experiências em camadas de GaAs onde a desordem era produzida por erosão com laser. No desenvolvimento desta parte do trabalho foi feita uma tentativa de isolar uma camada de AlAs para estudar os fônons deste material. Embora a tentativa tenha sido frustrada devido aos efeitos de oxidação, ela permitiu estudar modos de As puro tanto na forma cristalina como amorfa. Com estes dados foi classificado todo tipo de contribuição possivel ao espectro Raman na região de energia onde ocorre o pico relativo ao modo de vibração do ponto quântico. A informação foi útil para confirmar a identificação prévia. 


\section{Capítulo 2}

\section{Sobre o Experimento}

\subsection{Montagem Experimental}

Os espectros Raman foram obtidos no laboratório de MicroRaman do Grupo de Propriedades Ópticas (GPO) do Departamento de Física do Estado Sólido da UNICAMP. Foi utilizado um espectrômetro da Jobin Ivon (modelo T64000) na configuração dúplo-subtrativo com detecção usando CCD (Charge Coupled Device), e focalização através da técnica de MicroRaman. Esse equipamento é implementado com um dos mais altos desempenhos dentre os equipamentos Raman encontrados no mercado. Ele está baseado em um monocromador triplo com comprimento focal de $0.64 \mathrm{~m}$. Ele pode trabalhar com várias configurações, conforme a necessidade requerida: Como um espectrômetro simples, duplo ou triplo. Como um espectrômetro duplo, o monocromador dianteiro é usado como um filtro, na configuração chamada "subtrativo", ou como um sistema dispersivo duplo aditivo em que o caminho óptico é acrescido. O equipamento também possibilitou visualizar as amostras através de um monitor de TV onde foi possível determinar o ponto exato de focalização. As medidas foram realizadas à temperatura ambiente e $T=16 \mathrm{~K}$. Como radiação de excitação foi utilizada a linha $514,5 \mathrm{~nm}$ de um Laser de argônio $\left(\mathrm{Ar}^{+}\right)$modelo 2016 da Spectra-Physics. Para a focalização da luz do laser foi utilizado um microscópio modelo Olympus BH-2 UMA. Não foi utilizado nenhum polarizador no trajeto da luz espalhada mas a grade apresenta uma eficiência cerca de 10 vezes maior quando a polarização da luz espalhada é paralela à fenda. Então a geometria resultante é aproximadamente $z(x, x) \bar{z}$. Como ilustração, o esquema óptico básico do 
espectrômetro é apresentado na Figura-2.1. O espectrômetro deve ser es-

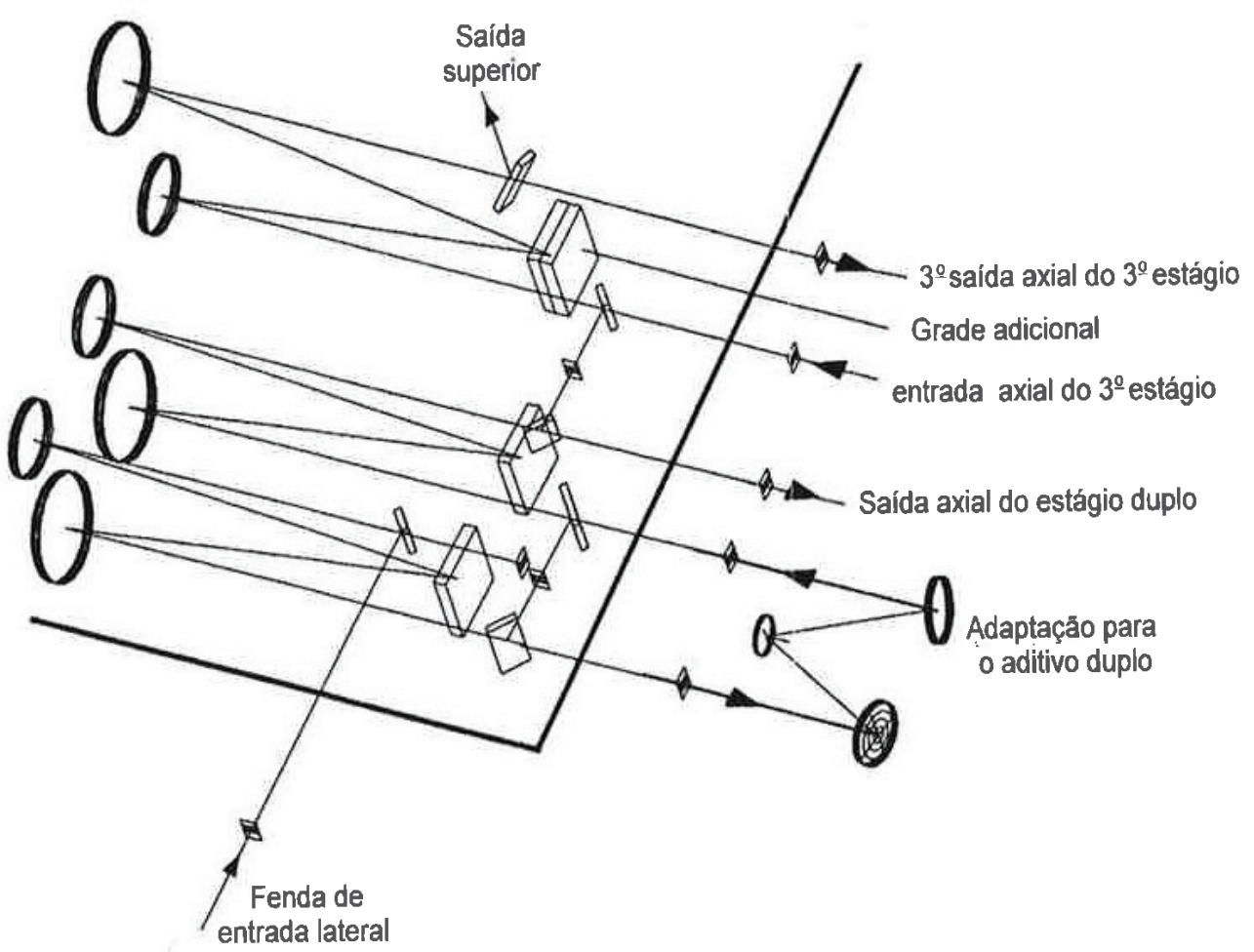

Figura 2.1: Possíveis configurações do espectrômetro. Esquema extraído do catálogo do equipamento T64000 da Jobin-Yvon.

colhido com base no seu poder de resolução, na capacidade de rejeição da luz espúria, ou ainda no ganho oferecido (relação sinal/ruído). A resolução depende da rede de difração empregada e da abertura das fendas de entrada e saída do espectrômetro. O Jobin-Yvon é um dos modelos modernos de espectrômetro em que a resolução e rejeição são preteridos em favor do ganho excepcional oferecido. Outro ponto importante em uma montagem Raman são os elementos ópticos empregados pois geralmente são utilizados filtros espaciais que permitem aumentar o caminho óptico com a luz passando através de prismas de forma que o comprimento de onda desejado é melhor selecionado. Normalmente em montagens como estas são utilizados no caminho óptico filtros interferenciais que permitem passar apenas o comprimento de onda desejado devido a sua largura de banda, mas esse tipo de filtro geralmente queima quando a potência incidente é muito alta (cerca de $300 \mathrm{~mW}$ ). A montagem experimental com os elementos ópticos 
constituintes é apresentada na Figura-2.2.
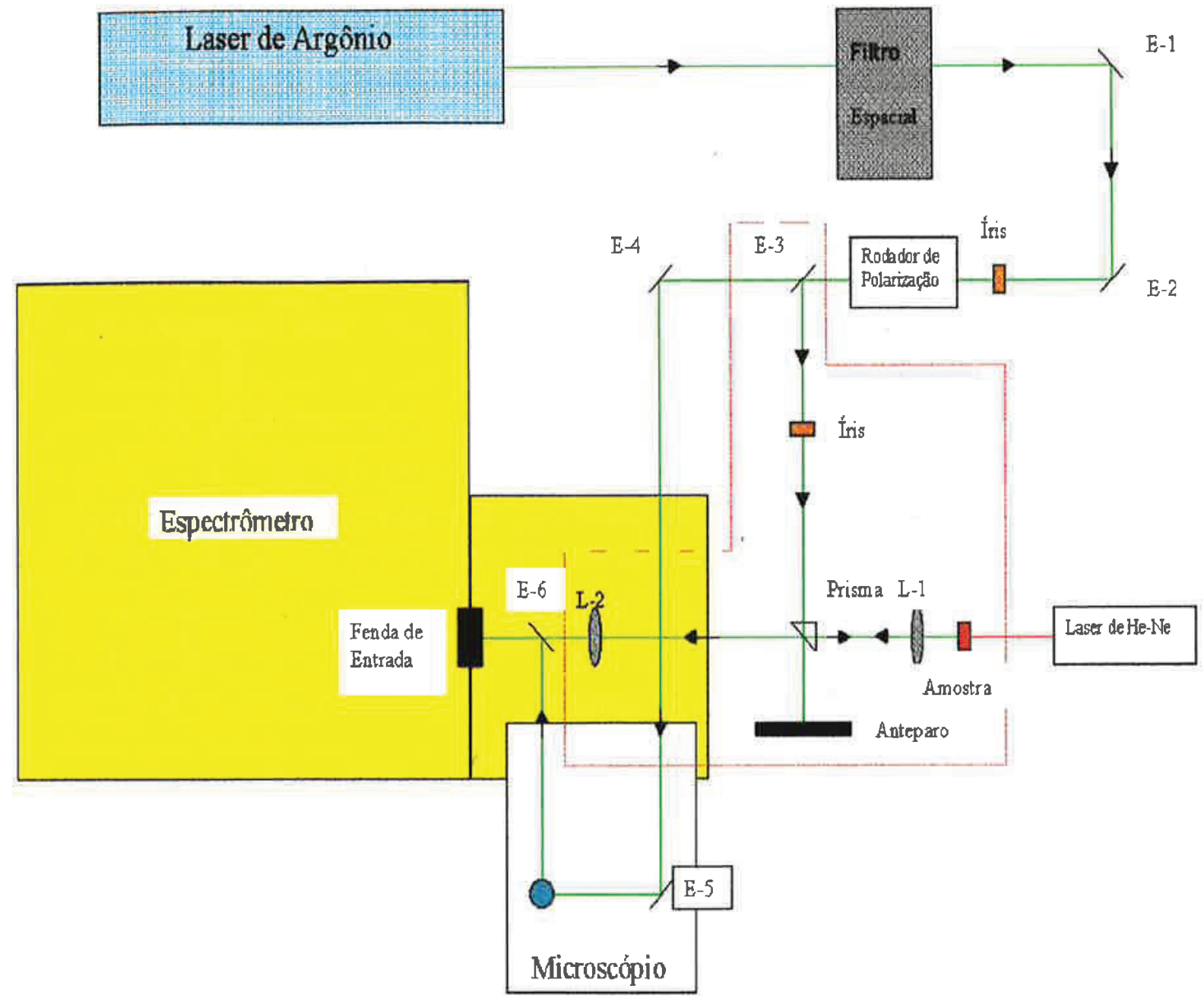

Figura 2.2: Montagem Experimental.

O sistema permite realizar medidas tanto na configuração de Macro como MicroRaman. Na configuração de MicroRaman a luz é focalizada na amostra através de um microscópio fornecendo um ponto focal com uma densidade de energia bem maior que no caso do MacroRaman. O espelho $\mathrm{E}-4$ permite que a luz seja levada até o microscópio e incida na amostra. A luz incidente na amostra é retroespalhada e em seguida é desviada através de um prisma em direção ao espelho E-6 que leva a luz até a fenda de entrada do espectrômetro. Para eliminar as linhas de plasma do Laser há necessidade de um caminho óptico aumentado e filtrar antes que o Laser atinja a amostra, tanto na configuração de Macro como MicroRaman. Para isso são utilizados 
elementos ópticos como o filtro espacial e as íris. A configuração de MicroRaman não necessita de uma montagem externa para a focalização da luz na amostra, pois ela aproveita os próprios elementos ópticos do microscópio e espectrômetro. Ao contrário, a configuração MacroRaman precisa de uma montagem externa que está localizada dentro da região pontilhada em vermelho na Figura-2.2. O espelho E-3 permite que a luz se desvie para a montagem confocal composta do prisma e das lentes L-1 e L-2. O laser de He-Ne é utilizado para auxiliar o alinhamento confocal com a fenda de entrada. Tanto as lentes como o prisma são montados sobre bases que permitem um deslocamento nas três direçôes cartesianas. Os espectros foram medidos na configuração de pré-monocromador duplo subtrativo que apresenta uma dispersão de $0,7 \mathrm{~nm} / \mathrm{mm}$ para $500 \mathrm{~nm}$ com a rede de difração de 1800 linhas/mm. A Figura-2.3 apresenta os elementos ópticos do espectrômetro, com numeração, para facilitar a indentificação. Nos experimentos feitos nesta tese foram utilizadas apenas duas grades, caracterizando-se como um espectrômetro duplo. As duas grades utilizadas na montagem (elementos 2 e 6) são redes de difração holográficas com correção de aberrações de 1800 linhas/mm. Este sistema, duplo subtrativo, apresenta ainda, uma fenda de entrada que é movimentada manualmente e varia de 0 até $2 \mathrm{~mm}$ (1), uma fenda intermediária que varia até $50 \mathrm{~mm}(4), 2$ espelhos fixos que se encontram cada um de um lado da fenda intermediária (3 e 5), e finalmente um elemento muito importante que é o espelho de número 7. Este espelho é móvel, e através dele podemos definir o tipo de detecção que será realizada. A luz emergente da segunda grade pode tomar dois destinos, conforme a movimentação do espelho 7: ou o espelho é retirado do caminho da luz, após ela passar pela segunda grade permitindo o uso de uma fotomultiplicadora ou o espelho é posicionado de forma que ele possa desviar a luz emergente da grade em direção ao CCD que está colocado perpendicularmente em relação ao plano do espectrômetro. O desempenho do CCD é comentado no Apêndice-A. Todas as fendas variam até $15 \mathrm{~mm}$ de altura. Os espelhos circulares que aparecem no diagrama são todos esféricos. É possível também controlar através de "software" a área do CCD que será sensibilizada, dessa forma durante a calibração do sistema devemos reduzir ao máximo essa área para que qualquer sinal devido à luz espúria seja eliminado. 


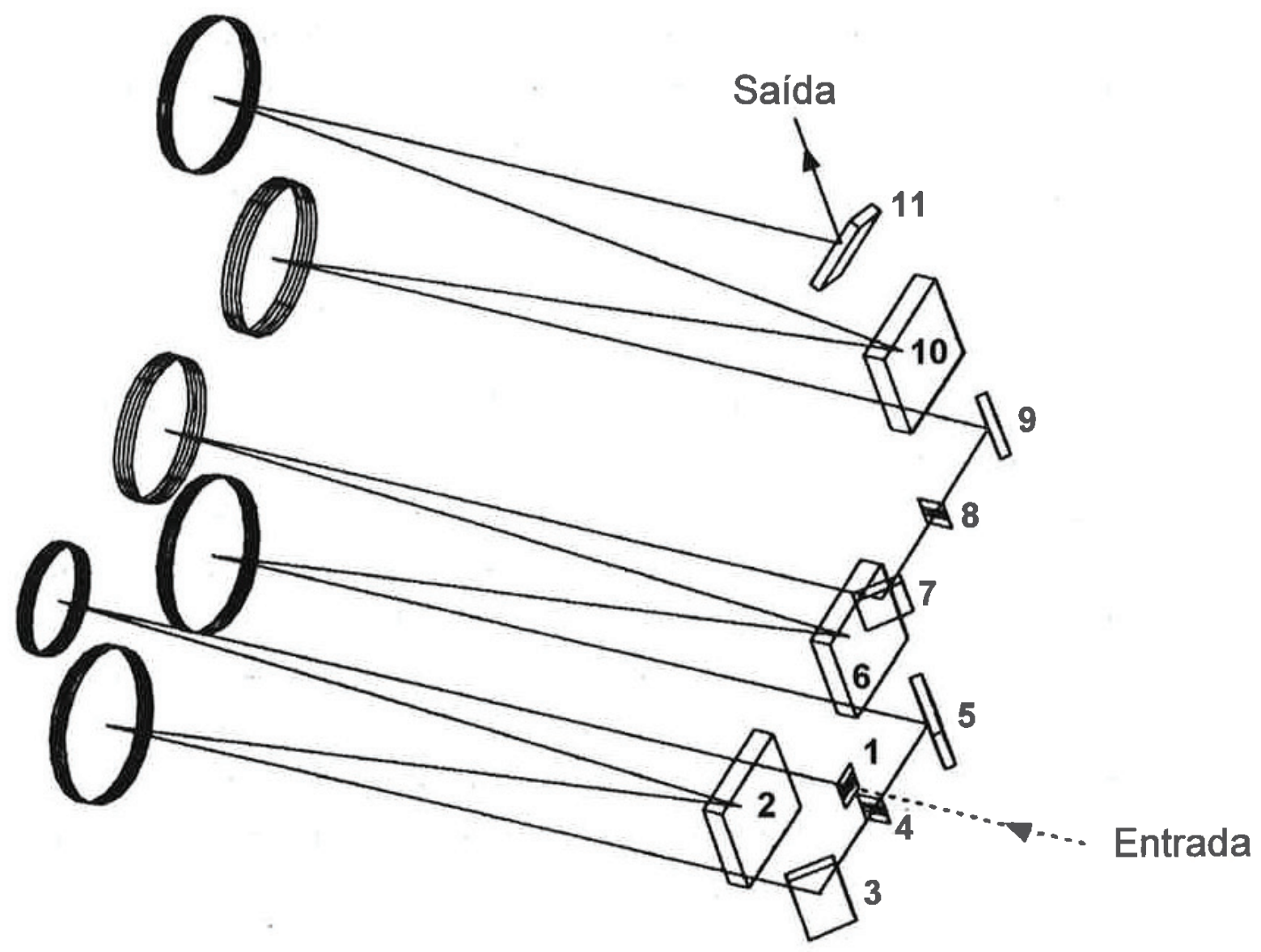

Figura 2.3: Esquema do espectrômetro com enumeração dos elementos ópticos. Figura extraída do catálogo do equipamento T64000 da JobinYvon.

\subsection{Dificuldades Experimentais}

Em qualquer sistema óptico como este, que envolve uma grande quantidade de elementos ópticos há a necessidade de um ótimo alinhamento dos elementos para que a eficiência do sistema seja máxima. Esse ajuste é feito de forma interativa com cada um dos elementos ópticos. Os dois modos de medidas (Macro e MicroRaman) apresentam formas de alinhamento distintas. Após o alinhamento mais grosseiro é usada alguma amostra padrão para verificar o nível de sinal. Em geral foi usado, em primeira instância, o GaP e em segunda instância, o silício, como padrão. Após o ajuste do 
sistema óptico, é feito um ajuste da área iluminada do CCD.

Devido ao pequeno volume dos pontos quânticos sua contribuição para o espectro Raman é pequena comparada com a do substrato. Assim, geralmente, o tempo de integração de cada espectro é elevado variando entre duas e oito horas conforme o nível de sinal. Inicialmente são realizadas medidas rápidas (poucos segundos) para estimar a relação sinal/ruído e em seguida é estipulado o número de vezes que as medidas devem ser repetidas. Um grande número de medidas permite que o ruído de fundo diminua evidenciando mais as estruturas presentes nos espectros. Devido ao longo tempo de exposição muitas vezes as medidas são prejudicadas e até perdidas devido a algumas dificuldades inerentes à física experimental tais como: sobrecargas no sistema, queda de corrente, diminuição da potência do Laser, queima da amostra, qualidade da amostra, etc. Esse tipo de dificuldade torna o trabalho muitas vezes lento pois dentre as várias medidas realizadas foi possível o aproveitamento de poucos espectros que são apresentados no decorrer da tese. Mediu-se também os espectros na região Anti-Stokes de algumas amostras para verificar a temperatura local durante as medidas (Capítulo-5). Essa região apresenta um nível de sinal mais fraco que a região Stokes, devido ao termo populacional na seção de choque.

\subsection{Regras de Seleção}

O material usado como substrato (GaAs) apresenta uma estrutura cristalina cúbica do tipo zincblende $(\mathrm{ZnS})$. Com geometria de retroespalhamento da face (001) o espalhamento Raman fornece informaçóes sobre a orientação do plano e eixos cristalinos no plano do substrato. Assim, podemos utilizar as regras de seleção Raman para verificar quais são os modos vibracionais permitidos e proibidos nos experimentos realizados. Para isso utilizaremos a analogia da polarizabilidade com o tensor Raman $\overleftrightarrow{R}$, o qual descreve mudanças na polarização elétrica produzida por uma excitação do material. O termo que devemos considerar nesta situação é:

$$
\left|\widehat{e}_{i} \cdot \overleftrightarrow{R} \cdot \widehat{e}_{s}\right|
$$

onde $\widehat{e}_{i}$ e $\widehat{e}_{s}$ são as polarizações de incidência e espalhada respectivamente, e $\overleftrightarrow{R}$ e o tensor Raman associado à simetria do cristal. Com base na equação acima podemos calcular quais são os modos permitidos e proibidos para 
Tabela 2.1: Regras de seleção para retroespalhamento por fônons em cristais de estrutura zincblende ( $\mathrm{ZnS})$ para a face (001).

\begin{tabular}{cccc}
\hline \hline Face & Polarização incidente & Polarização espalhada & Fator de Intensidade \\
\hline$[001]$ & {$[1 \overline{1} 0]$} & {$[1 \overline{1} 0]$} & $\mathrm{d}^{2}(L O)$ \\
{$[001]$} & {$[110]$} & {$[1 \overline{1} 0]$} & - \\
{$[001]$} & {$[010]$} & {$[100]$} & $\mathrm{d}^{2}(L O)$ \\
{$[001]$} & {$[010]$} & {$[010]$} & - \\
\hline \hline
\end{tabular}

a geometria escolhida. A geometria de retroespalhamento da face (001), permite apenas a componente longitudinal óptica, LO. A observação de contribuição transversal óptica, TO, nestas condições indicaria uma má orientação do cristal em relação a face (001) ou algum tipo de desordem estrutural que pudesse quebrar as regras de seleção para o espalhamento Raman. A Tabela-2.1 fornece as regras de seleção para o substrato de GaAs com relação à face (001). A tabela indica as geometrias nas quais a intensidade do pico devido ao espalhamento por fônons longitudinais é nula. Estas geometrias são: (i) Polarizações cruzadas, quando a polarização incidente é ao longo de uma direção cristalina [110]; (ii) Polarizações paralelas, quando a incidência é ao longo de uma direção cristalina, principal. Usando uma tal geometria (escolhida para que $I_{L O}=0$ ), é possível minimizar a contribuição do substrato e desta forma evidenciar a contribuição dos pontos quânticos ao espectro. Estes, dado ao confinamento em dimensões da ordem de alguns nanômetros, estão sujeitos a outras regras de seleção as quais dependem inclusive, da forma geométrica em que os pontos são formados (no próximo capítulo é apresentada a discussão relativa a pontos quânticos com geometria esférica conforme resultado da referência [11]). Observando os espectros apresentados na tese, é possível ver que em todos eles aparecem o LO permitido e o TO proibido para o GaAs, evidenciando quebra de regras de seleção. Para um melhor entendimento das causas deste efeito foi realizado um estudo da superfície de GaAs e AlAs sob a ação do Laser para potências variáveis. Camadas de AlAs foram estudadas neste contexto, porque a observação dos fônons proibidos em GaAs, gerou a idéia de obter informações sobre as curvas de dispersão do AlAs usando espalhamento Raman. 


\section{Capítulo 3}

\section{Vibrações ópticas polares em pontos quânticos esféricos}

\subsection{Introdução}

Atualmente, com o avanço das novas tecnologias de crescimento, é possivel crescer cristais semicondutores com propriedades quasi-zero-dimensionais, os chamados pontos quânticos com dimensões na escala de nanômetros. A investigação dos modos vibracionais de nanoestruturas semicondutoras é um dos objetos de estudo atual da Física do Estado Sólido.

O intuito nesta sessão é discutir as modificações em frequência dos fônons dos pontos quânticos em função do tamanho da partícula. O ideal, seria produzir um cálculo analítico, para confinamento na forma de pirâmide, como ocorre na formação de pontos quânticos de InAs. [12] A complexidade de cálculo, porém seria muito grande, e foge ao escopo de uma tese de mestrado. Para o ponto quântico esférico o tratamento ainda é complexo, porém já tem sido desenvolvido na literatura, através de aproximações diferentes. $[11,13]$ As vibrações ópticas em materiais polares, foram bem descritas por Roca e colaboradores [11] dentro de algumas restrições: (i) O ponto quântico é um material de estrutura zincblende, dentro de uma matriz também tipo zincblende, cujas curvas de dispersão não se sobrepõem; (ii) A dispersão dos ramos ópticos é levada em consideração com uma aproximação de $2_{-}^{a}$ ordem em vetor de onda e considerada isótrópica (direção $\Gamma \longrightarrow L$ foi escolhida como representativa da dispersão). Com estas restrições, foi desenvolvido um cálculo para as frequências e auto-vetores de pontos quânticos esféricos 
de GaAs em matriz de AlAs. [11] Usando este resultado é possivel discutir qualitativamente o exemplo de vibrações em pontos quânticos de InAs crescido sobre GaAs que serve aos propósitos de elucidar a influência do confinamento nas frequências dos fônons, e portanto será incluído aqui. A descrição a seguir, será truncada em relação ao tratamento rico em detalhes da ref.[11], no sentido de analizar apenas as soluções relacionadas com os fônons possíveis de observação em pontos quânticos do tipo descrito no exemplo citado acima.

A descrição consta da definição das equações e condições de contorno mais genéricas, e da solução considerando apenas a simetria esférica. A solução particular decorrente da condição de contorno $\vec{u}(R)=0$ será apenas citada e a justificativa fornecida oportunamente. A solução a ser detalhada neste capítulo, é aquela apropriada a modos que têm um potencial eletrostático associado, ou seja, a situações que envolvem uma interação elétron-fônon tipo-Fröhlich.

\subsection{Equações Gerais}

Para um ponto quântico de raio $R$ em meio isotrópico e homogêneo, a equação de movimento é escrita em termos do vetor deslocamento, como [14]:

$$
\mu \vec{u}=-\mu w_{0}^{2} \vec{u}+e \vec{E}_{l o c} .
$$

Levando em consideração vibrações polares e a dispersão de fônons, esta equação pode ser reescrita, como:

$$
\begin{aligned}
\rho(r)\left[w^{2}-w_{T O}^{2}(r)\right] \vec{u}= & \vec{\nabla}\left[\rho(r) \beta_{L}^{2}(r) \vec{\nabla} \cdot \vec{u}\right]- \\
& \vec{\nabla} \times\left[\rho(r) \beta_{T}^{2}(r) \vec{\nabla} \times \vec{u}\right] \\
& +\alpha(r) \vec{\nabla} \Phi
\end{aligned}
$$

onde, $w_{T O}$ é a frequência do fônon transversal do cristal-3D, $\rho$ é a densidade de massa reduzida, $\beta_{L}$ e $\beta_{T}$ são parâmetros que descrevem a dispersão dos fônons no cristal-3D correspondente, assumindo ramos parabólicos e isotrópicos. O coeficiente $\alpha$ é dado por: 


$$
\alpha=\left(\frac{\left(\varepsilon_{0}-\varepsilon_{\infty}\right) \rho w_{T O}^{2}}{4 \pi}\right)^{\frac{1}{2}}
$$

$\operatorname{com} \varepsilon_{0}$ e $\varepsilon_{\infty}$ sendo as constantes dielétricas estática e de altas frequências, respectivamente. $\mathrm{Na}$ equação (3.2) o potencial, $\Phi$, está associado a um campo elétrico, $\vec{E},(\vec{E}=-\vec{\nabla} \Phi)$ o qual impõe a igualdade:

$$
\vec{\nabla} \cdot\left(\varepsilon_{\infty} \vec{\nabla} \Phi\right)=4 \pi \vec{\nabla} \cdot(\alpha \vec{u})
$$

As equações (3.2) e (3.4) descrevem um sistema genérico para o qual os parâmetros são função da coordenada $\vec{r}$. Tais equações compõem um sistema de quatro equações diferenciais parciais de $2_{-}^{a}$ ordem, acopladas. Para obter uma solução é necessário introduzir condições de contorno apropriadas. No caso do ponto quântico esférico, estas condições são a continuidade das três componentes de $\vec{u}$ e $\Phi$ na interface esférica $(r=R)$.

O teorema de Gauss impõe novas condições, que são a continuidade da componente normal do tensor de tensóes e a continuidade do deslocamento elétrico na interface. [11]

As equações fundamentais, com tais condiçốes de contorno, produzem soluções de caráter longitudinal e transversal acoplados, como apresentado a seguir.

\subsection{Soluções Gerais}

Para resolver o sistema das quatro equações diferenciais acopladas, foi conveniente introduzir uma função escalar $\Lambda$, e uma função vetorial, $\vec{\Gamma}$, tal que:

$$
\Lambda=\vec{\nabla} \cdot \vec{u} \quad \text { e } \quad \vec{\Gamma}=\vec{\nabla} \times \vec{u} .
$$

Aplicando-se o rotacional a equação (3.2), obtêm-se

$$
\left(\vec{\nabla}^{2}+Q^{2}\right) \vec{\Gamma}=0
$$


onde,

$$
Q^{2}=\frac{w_{T O}^{2}-w^{2}}{\beta_{T}^{2}} .
$$

O divergente da equação (3.2), leva ao resultado:

$$
\left(\overrightarrow{\nabla^{2}}+q^{2}\right) \Lambda=0
$$

$\operatorname{com} q^{2}$ escrito em termos de $w_{L O}$, através de:

$$
q^{2}=\frac{w_{L O}^{2}-w^{2}}{\beta_{L}^{2}},
$$

onde, $w_{L O}^{2}=\left(\varepsilon_{0} / \varepsilon_{\infty}\right) w_{T O}^{2}$ é a equação conhecida como relação de LydaneSachs-Teller.

Substituindo, as funções definidas em (3.5) na equação (3.4), obtêm-se:

$$
\overrightarrow{\nabla^{2}} \Phi=\frac{4 \pi \alpha}{\varepsilon_{\infty}} \Lambda
$$

A solução geral para o potencial escalar é obtida por comparação das equações (3.8) e (3.10) como:

$$
\Phi=\Phi_{H}-\frac{4 \pi \alpha}{\varepsilon_{\infty} q^{2}} \Lambda
$$

onde $\Phi_{H}$ é a solução da equação de Laplace

$$
\vec{\nabla}^{2} \Phi_{H}=0
$$

Desta forma o segundo termo em (3.11) é uma solução particular de (3.10). A solução para o vetor deslocamento pode ser obtida substituindo (3.5) e (3.11) em (3.12): 


$$
\vec{u}=-\vec{\nabla}\left[\frac{\alpha}{\rho \beta_{T}^{2} Q^{2}} \Phi_{H}+\frac{\Lambda}{q^{2}}\right]+\frac{1}{Q^{2}} \vec{\nabla} \times \vec{\Gamma} .
$$

Estas soluçôes gerais, independem do particular formato geométrico definido pela interface. Para cada caso particular, é necessário escrever equações adequadas para $\Lambda, \vec{\Gamma}$ e $\Phi_{H}$, obtendo assim equações gerais para cada meio levando em conta as condições de continuidade na interface.

Para o ponto quântico esférico, é conveniente utilizar funções associadas à simetria esférica, como: as funções harmônicas esféricas, $Y_{l m}(\theta, \varphi)$ com $m=-l, \ldots l$ e $l=0,1, \ldots$; as funções de Bessel esféricas, $j_{l}$, e as funções de Hankel esféricas, $h_{l}$. Para o ponto quântico de raio $R$, as funções podem ser escritas como:

$$
\Phi_{H}=Y_{l m}(\theta, \varphi) \begin{cases}C_{1} r^{l} & r<R \\ C_{2} r^{-l-1} & r>R\end{cases}
$$

e

$$
\Lambda=Y_{l m}(\theta, \varphi) \begin{cases}A_{1} j_{l}(q r) & r<R \\ A_{2} h_{l}^{(1)}(q r) & r>R\end{cases}
$$

onde, $\mathrm{C}_{i}$ e $\mathrm{A}_{i}(i=1,2)$ são constantes a serem obtidas através de ajustes. Levando estas expressões na equação do potencial escalar (3.11), obtêm-se:

$$
\Phi(r, \theta, \varphi)=Y_{l m}(\theta, \varphi)\left\{-\frac{4 \pi \alpha_{1}}{\varepsilon_{\infty}^{(1)} q^{2}} A_{1} j_{l}\left(q_{1} r\right)+C_{1} r^{l}, \quad r<R\right.
$$

e

$$
\Phi(r, \theta, \varphi)=Y_{l m}(\theta, \varphi)\left\{-\frac{4 \pi \alpha_{2}}{\varepsilon_{\infty}^{(2)} q^{2}} A_{2} h_{l}^{(1)}(q r)+C_{2} r^{-l-1}, \quad r>R\right.
$$

$\mathrm{O}$ índice $i$ utilizado nas equações acima se refere ao constituinte de cada meio, o ponto quântico dentro da esfera e a matriz fora da esfera. Escolhendo o sistema de coordenadas, cujos vetores de base são: $\overrightarrow{e_{r}}$, na direção radial 
da esfera e $\vec{X}_{l m}$ e $\overrightarrow{e_{r}} \times \vec{X}_{l m}$ em direções tangenciais e perpendiculares entre si, o vetor deslocamento é dado por:

$$
\vec{u}=K_{1} \overrightarrow{e_{r}}+K_{2} \vec{X}_{l m}+K_{3}\left(\vec{e}_{r} \times \vec{X}_{l m}\right) \quad r<R
$$

onde os coeficientes são dados por:

$$
\begin{gathered}
K_{1}=\left[-\frac{A_{1}}{q^{2}} \frac{d}{d r}\left(j_{l}\right)+\frac{B_{1} l(l+1)}{r Q^{2}} g_{l}-\frac{\alpha C_{1}}{\rho \beta_{T}^{2} Q^{2}} l r^{l-1}\right] Y_{l m}, \\
K_{2}=-i \frac{D_{1}}{Q} \sqrt{l(l+1)} g_{l} e \\
K_{3}=-i \frac{\sqrt{l(l+1)}}{r}\left[-\frac{\alpha C_{1}}{\rho \beta_{T}^{2} Q^{2}} r^{l}-\frac{A_{1}}{q^{2}} j_{l}+\frac{B_{1}}{Q^{2}} \frac{d}{d r}\left(r g_{l}\right)\right] .
\end{gathered}
$$

A função $g_{l}$ e a expressão para $\left|X_{l m}\right|$ são encontradas nos apêndices da ref. [11]. As constantes $B_{1}$ e $D_{1}$ são parâmetros ajustáveis. A expressão para o meio fora da esfera é similar.

A aplicação das condições de continuidade à equação (3.18), levariam a soluções acopladas descrevendo modos de caráter misto. Para simplificar a solução, é possível escolher um caso limite de interface abrupta que serve para descrever sistemas derivados de cristais-3D em que as curvas de dispersão são bem separadas. Este é o caso do exemplo que será discutido a seguir, onde os pontos são de GaAs e a matriz é de AlAs.

\subsection{Ponto quântico esférico com interface abrupt}

A condição de continuidade para o deslocamento, no caso de interface abrupta, deve ser substituída pela condição de contorno, escrita como:

$$
\vec{u} / r=R=0
$$

A condição de continuidade para o potencial ainda é necessária neste caso, sendo expressa por: 


$$
\varepsilon_{\infty}^{(1)} \frac{\partial \Phi}{\partial r} /_{r=R_{-}}=\varepsilon_{\infty}^{(2)} \frac{\partial \Phi}{\partial r} /_{r=R_{+}}
$$

Impondo a condição de contorno mecânica, $\vec{u}(R)=0$, a equação (3.18), resulta em duas soluções, uma acoplada e uma pura. A solução pura define um deslocamento ao longo da componente $\vec{X}_{l m}$, o que representa um caráter transversal em relação à direção principal $\overrightarrow{e_{r}}$ ao longo do raio da esfera. No caso do ponto de GaAs em AlAs, os modos de vibração deste tipo são Raman inativos, por consideração de simetria. Portanto, não interessa discutir estes modos no contexto deste trabalho.

A solução acoplada fornece o deslocamento com duas componentes nas direções $\overrightarrow{e_{r}}$ e $\overrightarrow{e_{r}} \times \vec{X}_{l m}$, respectivamente (Ela é obtida para condições opostas àquelas dando origem ao modo transversal puro na direção $\vec{X}_{l m}$, citada acima). Neste caso, a constante D1 é nula e consequentemente não há vibração na direção $\vec{X}_{l m}$.

Porém, não há uma observação experimental que possa ser descrita em termos deste modelo tão restrito baseado nas condiçôes de contorno mecânicas apenas.

Para tornar o modelo mais realístico, é necessário levar em conta simultaneamente o potencial elétrico. Considerando o potencial como expresso na equação (3.11), com as funções $\Phi_{H}$ e $\Lambda$, descritas nas equações (3.14) e (3.15), respectivamente, obtêm-se o termo de interação elétron-fônon tipo Fröhlich. O Hamiltoniano da interação elétron-fônon tipo Fröhlich é descrito como. [11]

$$
\begin{gathered}
H_{i n t}=\sum_{n} \sum_{l=0}^{\infty} \sum_{n=-l}^{l} C_{F} \frac{R}{\nu_{n}}(2 l+1) i^{-l} \sqrt{2 \pi} \\
\times \bar{\Phi}_{\nu_{n, l}}(r) \cdot Y_{l m}(\theta, \varphi)\left(\widehat{b}_{\nu_{n}}+\widehat{b}_{-\nu_{n}}^{\dagger}\right)
\end{gathered}
$$

onde $\bar{\Phi}_{\nu_{n, l}}(r)$ é dado em termos das funções esféricas especiais (ver equação (43) da ref. [11]), e a constante de Fröhlich, $C_{F}$, é escrita como:

$$
C_{F}=e \sqrt{\frac{2 \pi \hbar w_{L O}}{V_{0}}\left(\varepsilon_{\infty}^{-1}-\varepsilon_{0}^{-1}\right)}
$$


Os operadores $\widehat{b}_{\nu_{n}}$ e $\widehat{b}_{\nu}^{\dagger}$ são operadores de criação e aniquilação e $V_{0}$ é o volume do cristal. Por espalhamento Raman ressonante os modos, esférico, $(l=0)$, e quadripolar esferoidal, $(l=2)$, podem, em princípio, ser observados. Os modos esféricos são excitados em polarizações da luz incidente e espalhada paralelas. A contribuição mais importante para o espalhamento Raman de um fônon, corresponde a $l=0$. Neste caso a componente $\vec{X}_{00}$ é ausente, consequentemente, somente os modos radiais são obtidos. A equação de auto-valores correspondente, pode ser obtida, fixando o deslocamento mecânico igual a zero:

$$
\vec{u}_{l=0}=A j_{1}\left(\nu_{n} \frac{r}{R}\right) \vec{e}_{r}
$$

Usando as propriedades bem conhecidas das funções de Bessel esféricas, a equação anterior pode ser escrita como:

$$
\operatorname{tg} \nu_{n}=\nu, \quad n=1,2, \ldots
$$

As frequências de vibração correspondentes são do tipo longitudinal, dadas por [veja equação (3.9)]:

$$
w^{2}=w_{L O}^{2}-\beta_{L}^{2}\left(\frac{\nu_{n}}{R}\right)^{2}
$$

O Hamiltoniano da interação elétron-fônon tipo Fröhlich é:

$$
\begin{gathered}
H_{i n t}^{l=0}=\sum_{n} C_{F} \frac{R}{\nu_{n}} \frac{\varepsilon_{\infty}^{(2)}}{\varepsilon_{\infty}^{(1)}}\left[j_{0}\left(\nu_{n}\right)-j_{0}\left(\nu_{n} \frac{r}{R}\right)\right] \\
\times\left(b \gamma_{n}+\widehat{b}-\gamma_{n}\right)
\end{gathered} .
$$

A Figura-3.1 mostra a energia dos fônons dos três primeiros modos de um ponto de GaAs em uma matriz de AlAs como uma função do raio do ponto quântico. Note que o modo $n=1$ ocorre basicamente para a frequência $w_{L O}$ do material do ponto, exceto para raios $R \lesssim 2,5 \mathrm{~nm}$. A figura mostra que a curva para $\mathrm{n}=1$ é paralela ao eixo horizontal até $R \sim 1,5 \mathrm{~nm}$. 


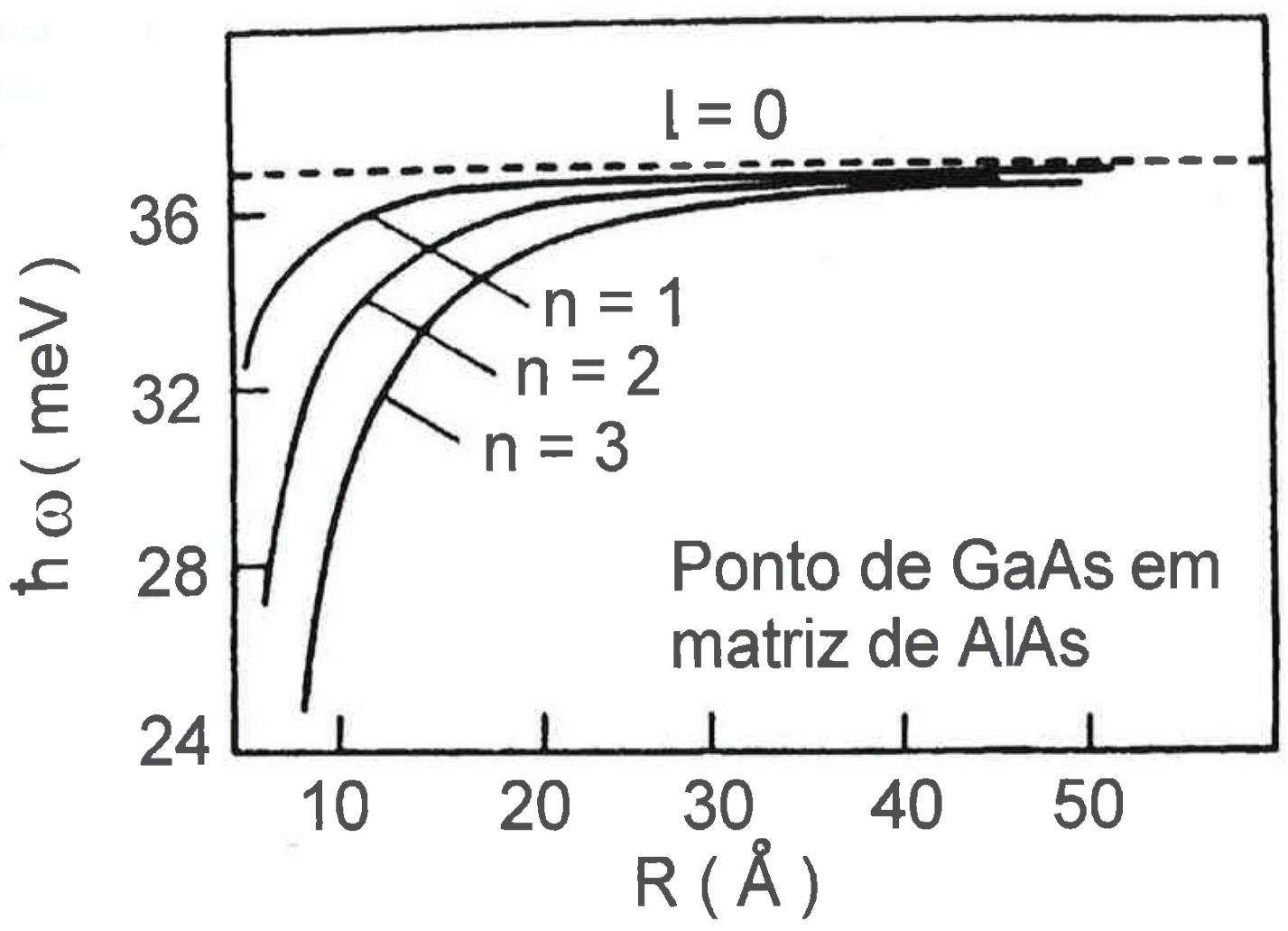

Figura 3.1: Energia dos três primeiros modos ópticos vibracionais para $l=0$ de um ponto quântico esférico de GaAs dentro de uma matriz de AlAs como função do raio R. O gráfico foi extraído da ref. [11].

As frequências dos modos acoplados são mais difíceis de serem obtidas pois elas requerem a solução de uma equação até certo ponto complicada (veja a equação (30) da ref.[11]). Para o caso limite, onde o raio $R$ é muito grande os modos de vibração são independentes do raio e obtidos através da seguinte equação:

$$
w^{2}=w_{T O}^{2}\left[\frac{\varepsilon_{0} l+\varepsilon_{\infty}^{(2)}(l+1)}{\varepsilon_{\infty}^{(1)} l+\varepsilon_{\infty}^{(2)}(l+1)}\right] .
$$

Assim, com a equação (3.28) é possível obter uma série de modos com frequências entre $w_{T O}$ e $w_{L O}$. Para $l=1$ a então chamada frequência de Fröhlich $w_{F}^{2}=w_{T O}^{2}\left(\varepsilon_{0}^{(2)}+2 \varepsilon_{\infty}^{(2)}\right) /\left(\varepsilon_{\infty}^{(1)}+2 \varepsilon_{\infty}^{(2)}\right)$ é derivada. O três modos degenerados de Fröhlich correspondem a uma polarização uniforme da esfera. Os modos com $l>1$ são usualmente chamados modos de superfície. 
Note-se que os modos da equação (3.28), obtidos no limite de $R \rightarrow \infty$ não são afetados pelas condições de contorno mecânicas: elas são basicamente as mesmas obtidas somente pela imposição das condições de contorno eletrostática sobre $\Phi$. Se $R$ não é muito maior que $Q^{-1}$ e $q^{-1}$ os efeitos das condições de contorno mecânicas tornam-se importantes e a equação (3.28) não é mais válida.

\subsection{Regras de seleção}

As regras de seleção são estabelecidas baseando-se em considerações de simetria. Para a esfera de GaAs em matriz de AlAs, as soluções da equação de movimento devem pertencer ao grupo de rotação-inversão $\mathrm{O}(3)$ cujas representações são seletivamente par ou ímpar frente à operação de inversão. Estas representações são designadas como: $D_{l}^{g}$ quando pares ou $D_{l}^{\mu}$ quando ímpares, para $l=1,2,3, \ldots$ : O operador de momento de dipolo elétrico que governa processos de absorção no infravermelho pertence à representação irredutível $D_{1}^{\mu}$. O operador na seção de choque de espalhamento Raman é um tensor de segunda ordem e transforma como as representações irredutíveis $D_{0}^{g}$ e $D_{2}^{g}$. Desta forma, as vibrações que dão origem a modos ativos em absorção infravermelha são ímpares e aquelas que permitem modos Raman são pares. Analisando as soluções discutidas na seção anterior sob o ponto de vista de simetria, é possível distinguir os modos ativos em Raman. Os modos não acoplados, cujos deslocamentos ocorrem na direção $\vec{X}_{l m}$, são pares frente à inversão para $l=1,3, \ldots$ e ímpar para $l=2,4, \ldots$, e portanto se transformam como as representações: $D_{1}^{g}, D_{2}^{\mu}, D_{3}^{g}$, etc. Assim, estes modos são inativos seja por espalhamento Raman seja por absorção infravermelha no sistema considerado. Os modos acoplados pertencem às representações $D_{0}^{g}, D_{1}^{\mu}, D_{2}^{g}$, etc permitindo atividade óptica. Um caso particular de interesse é a solução para o deslocamento dos modos acoplados, tomando $l=0$ e $m=0$. Neste caso, ocorre um desacoplamento acidental porque o vetor $\vec{X}_{00}$ é nulo. Como consequência, o modo radial é a solução restante, e o deslocamento correspondente é na direção $\overrightarrow{e_{r}}$. Este tipo de modo pertence à representação $D_{0}^{g}$ e é ativo em Raman. Além disso, os auto-valores (descritos na seção anterior) são funções das raízes $\nu_{n}$ das funções de Bessel e compõem um conjunto discreto, cuja ordem é designada por $n$. Os modos de ordem superior devem ter baixa intensidade devido a cancelamentos na 
amplitude de espalhamento advindos do caráter oscilatório destes modos. O modo $l=0, n=1$, então, deve aparecer no espectro como o pico mais intenso. É necessário reforçar a idéia de que a frequência dos modos $l=0$, $n=1,2, \ldots$, é a mesma que a do modo $l=0, n=1$, quando o raio do ponto quântico é grande (Unidades $R>1,5 \mathrm{~nm}$ no exemplo considerado).

\subsection{Conclusões}

O ponto esférico de GaAs em AlAs em espalhamento Raman dá origem a modos descritos pela interação elétron-fônon tipo Fröhlich. O modo mais intenso tem frequência muito próxima ao valor $w_{L O}$ para o cristal $3-\mathrm{D}$ constituinte do ponto. A observação da série dos modos $l=0, n=1,2, \ldots$, é difícil porque a intensidade cai com o aumento de $n$, e também as frequências são resolvidas apenas para raios muito pequenos. Então, o espalhamento Raman de um ponto quântico similar deve constar de um único pico, com frequência aproximadamente igual à do cristal 3-D, exceto quando a partícula for muito pequena. Omitimos a discussão dos modos superficiais por conveniência. O modo superficial $l=0$ ocorre em $231 \mathrm{~cm}^{-1}$ para pontos de $I n_{x} G a_{1-x} A s \operatorname{com} x=0,25$. 
São apresentados dados sobre a observação dos pontos quânticos no material estudado e os efeitos que podem contribir no deslocamento dos modos vibracionais. É feita também uma comparação com a teoria introduzida no capítulo anterior.

\subsection{Crescimento e Caracterização das Amostras}

As amostras estudadas foram crescidas por epitaxia de feixe molecular, MBE ("Molecular Beam Epitaxy") no Laboratório de Novos Materiais Semicondutores do Departamento de Física do Estado Sólido no Instituto de Física da USP. As medidas de AFM (Atomic Force Microscopy) foram realizadas no Departamento de Física Aplicada do Instituto de Física da UNICAMP pelo Prof. Dr. Alain A. Quivy e pela Profa. Dra. Mônica A. Cotta. As medidas de espalhamento Raman das amostras foram realizadas no laboratório de MicroRaman do Grupo de Propriedades Óticas (GPO) do Instituto de Física da UNICAMP.

As ilhas crescidas pela técnica de MBE pelo método de auto-organização são formadas a partir da liga de $\operatorname{In}_{x} G a_{1-x} A s$ crescidas sobre um substrato semi-isolante de GaAs (001). Sobre o substrato foi depositada uma camada intermediária (buffer layer) de $1 \mu m$ de espessura à temperatura de $580^{\circ} \mathrm{C}$ e sobre esta, a camada de InGaAs à temperatura de $480^{\circ} \mathrm{C}$. O processo de formação das ilhas auto-organizadas ocorre da seguinte forma: (i) primeiramente sobre o substrato de GaAs é crescida uma camada inicial de $I n_{x} G a_{1-x} A s$. As primeiras camadas atômicas depositadas são tensionadas para que haja um casamento com o parâmetro de rede do substrato formando uma estrutura 2D chamada de camada de molhagem. As próximas camadas que são depositadas sobre a camada tensionada sofrem um processo de relaxação, formando então pequenas ilhas coerentes sobre as primeiras camadas depositadas ( $\approx 2$ monocamadas) de $I n_{x} G a_{1-x} A s$. (ii) $\mathrm{O} \operatorname{InGaAs}$ usado no processo para formar as ilhas - 3D resulta na diminuição da espessura da camada de molhagem. (iii) Assim, ao exceder uma espessura crítica as últimas camadas depositadas sofrem uma relaxação plástica, através de um processo de descolagem ou formação de ilhas - 3D. Este tipo de ilha, quando isolada e de pequeno tamanho, é considerada como um ponto quântico ou sistema zero dimensional. Maiores detalhes de crescimento e formação das ilhas são dados na referência [17]. A caracterização estrutural 
foi feita através da Microscopia de Força Atômica (AFM) o que possibilitou um conhecimento da topologia da superfície. Uma imagem da superfície para as três frações molares de In é apresentada na Figura-4.1.

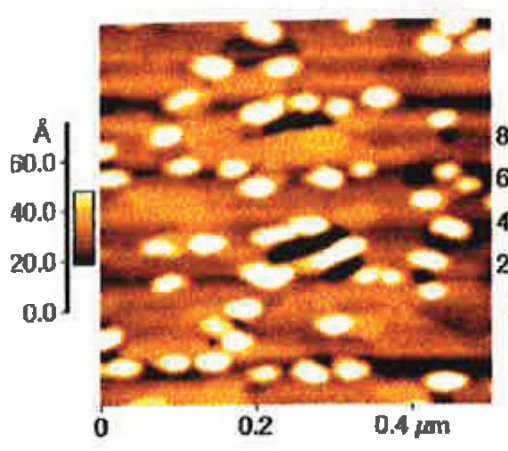

a)

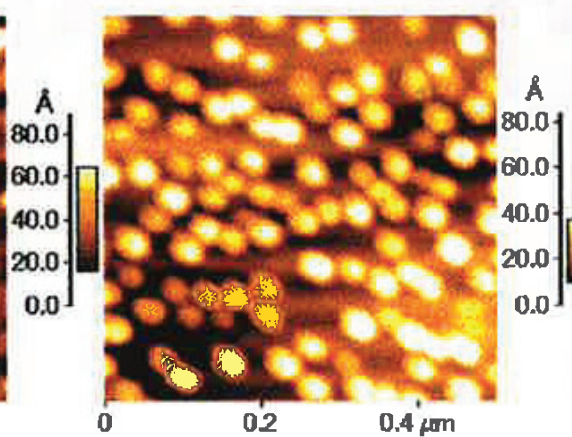

b)

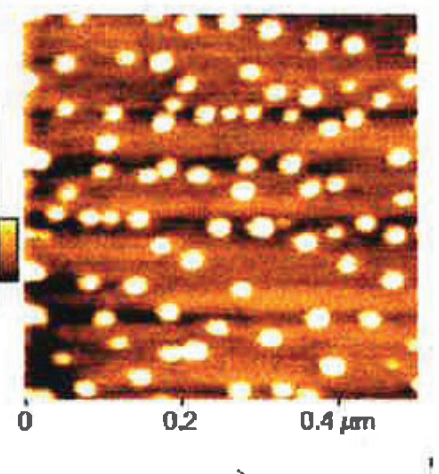

c)

Figura 4.1: Imagem da superfície das amostras com diferentes concentrações de In. a) $x=0,25$, b) $x=0,50$ e c) $x=0,75$.

Nas figuras 4.2, 4.3 e 4.4 são apresentadas imagens tridimensionais obtidas por AFM dos pontos quânticos de $I n_{x} G a_{1-x} A s$ para três concentrações molares de In. Os valores de $x$ para as três figuras são respectivamente: $0,25,0,50$ e 0,75 .

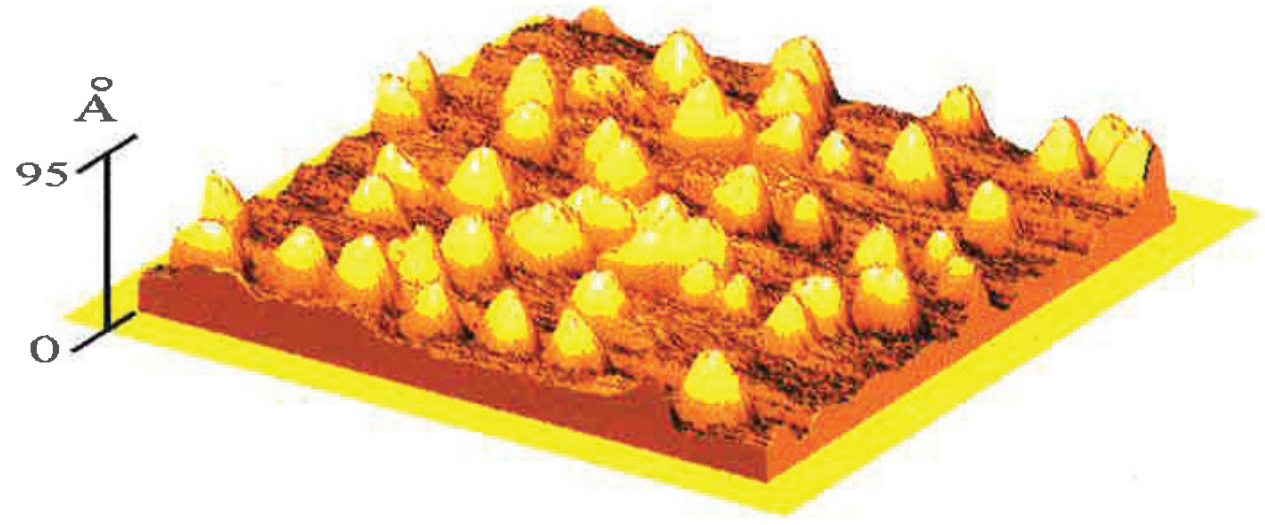

Figura 4.2: Imagem da superfície da amostra obtida por AFM. A concentração de In é de $x=0,25$. A área varrida foi de $0,5 \mu m$ por $0,5 \mu m$.

As características das amostras obtidas por Microscopia de Força Atômica são apresentada na Tabela-4.1. 


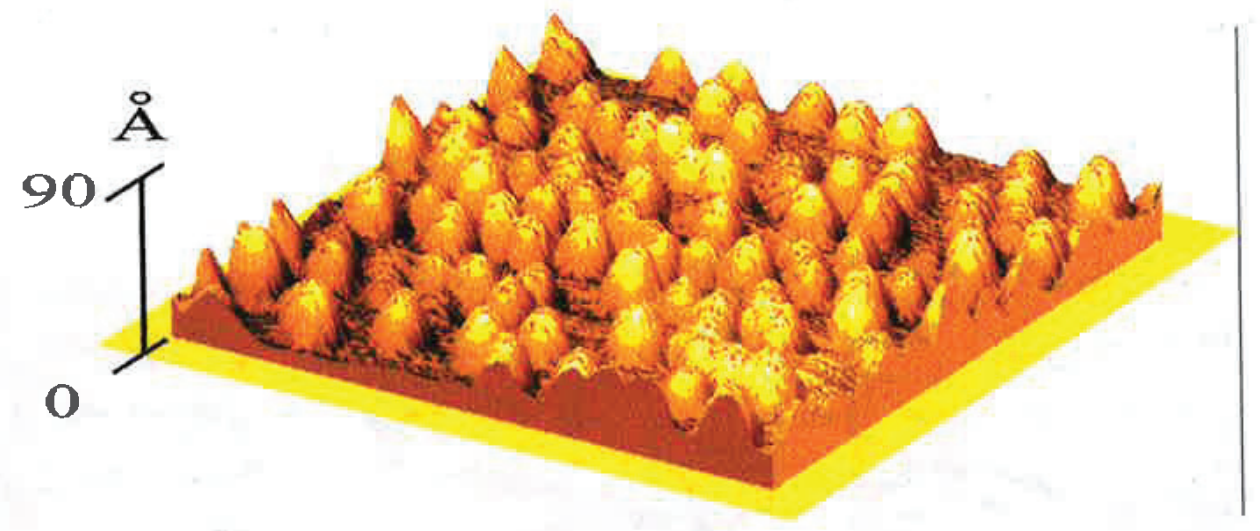

Figura 4.3: Imagem da superfície da amostra obtida por AFM. A concentração de In é de $x=0,50$. A área varrida foi de $0,5 \mu \mathrm{m}$ por $0,5 \mu \mathrm{m}$.

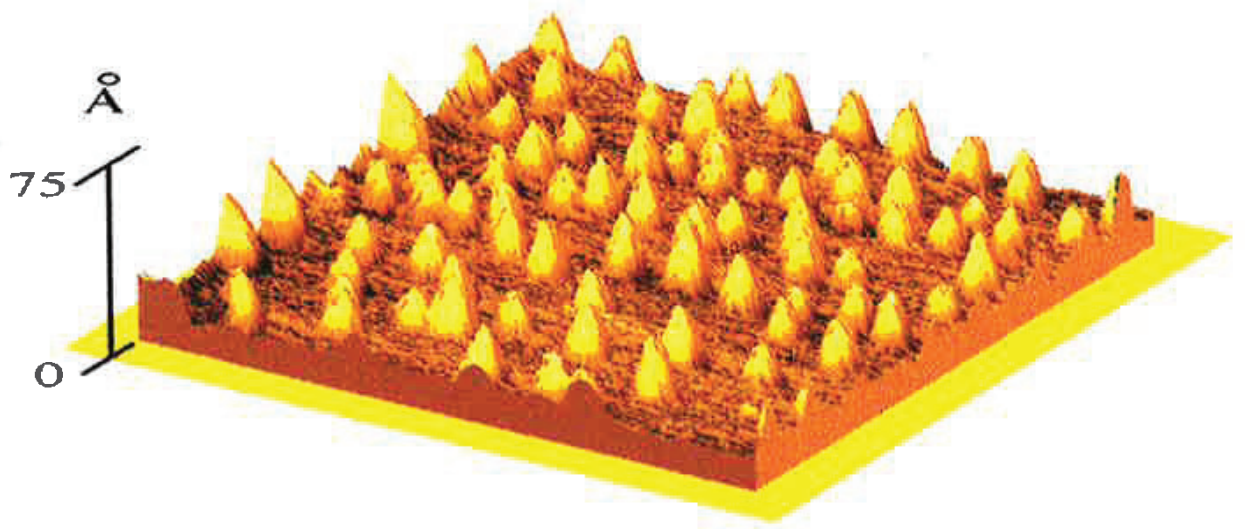

Figura 4.4: Imagem da superfície da amostra obtida por AFM. A concentração de In é de $x=0,75$. A área varrida foi de $0,5 \mu \mathrm{m}$ por $0,5 \mu \mathrm{m}$.

Tabela 4.1: A tabela apresenta as frações de In, $x$, e estimativa da densidade de pontos, $d$, comprimento médio da base, $l$, altura média, $h$, volume médio, $V$, e intensidade relativa dos fônons de GaAs. $V$ representa o volume médio estimado para um ponto quântico piramidal.

\begin{tabular}{cccccc}
\hline \hline$x$ & $d\left(\mathrm{~cm}^{-2}\right)$ & $l(\mathrm{~nm})$ & $h(\mathrm{~nm})$ & $V\left(\mathrm{~nm}^{3}\right)$ & $I_{T O} / I_{L O}$ \\
\hline 0,75 & $3 \times 10^{10}$ & 22 & 5 & 807 & $9 \%$ \\
0,50 & $4 \times 10^{10}$ & 37 & 5 & 2282 & $13 \%$ \\
0,25 & - & 46 & 6 & 4232 & $20 \%$ \\
\hline \hline
\end{tabular}


Note-se que a densidade e o tamanho das ilhas aumenta com a diminuição do conteúdo de In até $x=0,25$. Para este valor de $x$, as ilhas tendem a se alinhar lado a lado ao longo de uma direção preferencial. [17] A formação de aglomerados de ilhas torna difícil a contagem destas e por essa razão a densidade de pontos para $I n_{0,25} G a_{0,75} A s$ está faltando na Tabela-4.1.

Embora a estimativa de volume seja rude, dependendo da leitura da escala de cores nas imagens de AFM, ela permite estabelecer o escalonamento de volume total das ilhas com o valor de $x$. É possível concluir que quando o conteúdo de In diminui, o volume total das ilhas de InGaAs aumenta.

\subsection{Resultados e discussões}

\subsubsection{Espectros Raman}

A morfologia de pontos quânticos de InAs/GaAs, conforme análise através da microscopia eletrônica de transmissão, apresenta uma forma piramidal. Informações sobre esta morfologia são apresentadas na referência [18]. Os espectros Raman das ilhas são apresentados nas Figuras-4.5 e 4.6 para os três valores da fração molar de In, como indicado.

A medida à baixa temperatura $(16 \mathrm{~K})$ foi feita na tentativa de separar o pico do ponto quântico do restante do espectro pois à baixa temperatura a largura de linha diminui. Porém, a Figura-4.6 mostra que o espalhamento proveniente dos pontos contribui com um ombro do lado de baixas energias do pico TO do GaAs.

As características principais nos espectros da Figura-4.5 são os picos em $292 \mathrm{~cm}^{-1}$ e $268 \mathrm{~cm}^{-1}$, correspondendo aos modos LO permitido e TO proibido de GaAs do substrato. A razão de intensidades $I_{T O} / I_{L O}$, aumenta de $9 \%$ para $x=0,75$ até $20 \%$ para $x=0,25$, provavelmente devido a presença de defeitos em maior escala para baixos valores de tensão. Linhas características de espalhamento de segunda ordem foram observadas em torno de $520 \mathrm{~cm}^{-1}$ e $160 \mathrm{~cm}^{-1}$ correspondentes respectivamente aos modos vibracionais ópticos e acústicos do GaAs. Além disso, aparecem duas estruturas adicionais, um pico bem definido em $222 \mathrm{~cm}^{-1}$ e uma banda larga de mais alta energia que é resolvida somente para $x=0,25$ em 245 $\mathrm{cm}^{-1}$. O pico a $222 \mathrm{~cm}^{-1}$ permanece na mesma posição dentro do erro experimental para as três quantidades de In examinadas aqui. Existe então a 


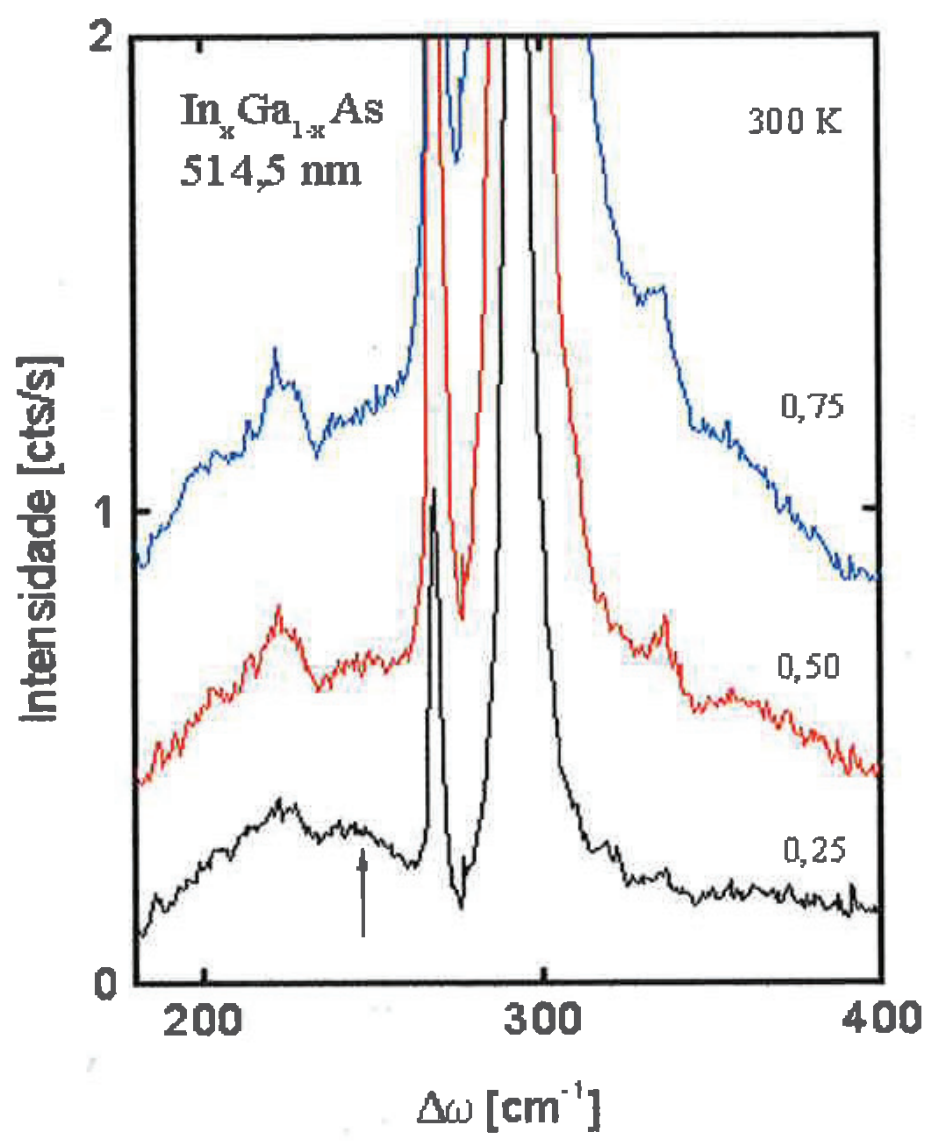

Figura 4.5: Espectros Raman dos pontos quânticos de InGaAs sobre o substrato de GaAs, com a variação da fração molar de In.

possibilidade desse pico ser proveniente do espalhamento por dois fônons que correspondem a termos de segunda ordem no momento de dipolo elétrico. A observação da densidade de estados permite inferir essa atribuição. O pico em $222 \mathrm{~cm}^{-1}$ nos espectros, é provavelmente devido ao fônon LA(X) normalmente proibido, induzido por defeitos.

A banda larga, em contraste, desloca em direção às altas energias com o aumento de $x$. A posição desta banda foi obtida através de ajuste usando a forma de linha lorentziana para cada pico do espectro. Como resultado foi obtido o valor de $\sim 249 \mathrm{~cm}^{-1}$ para $x=0,50$.

Para explicar a origem da banda larga em $\sim 245 \mathrm{~cm}^{-1}$ poderia ser considerada a hipótese de espalhamento Raman de 2 fônons do GaAs do 


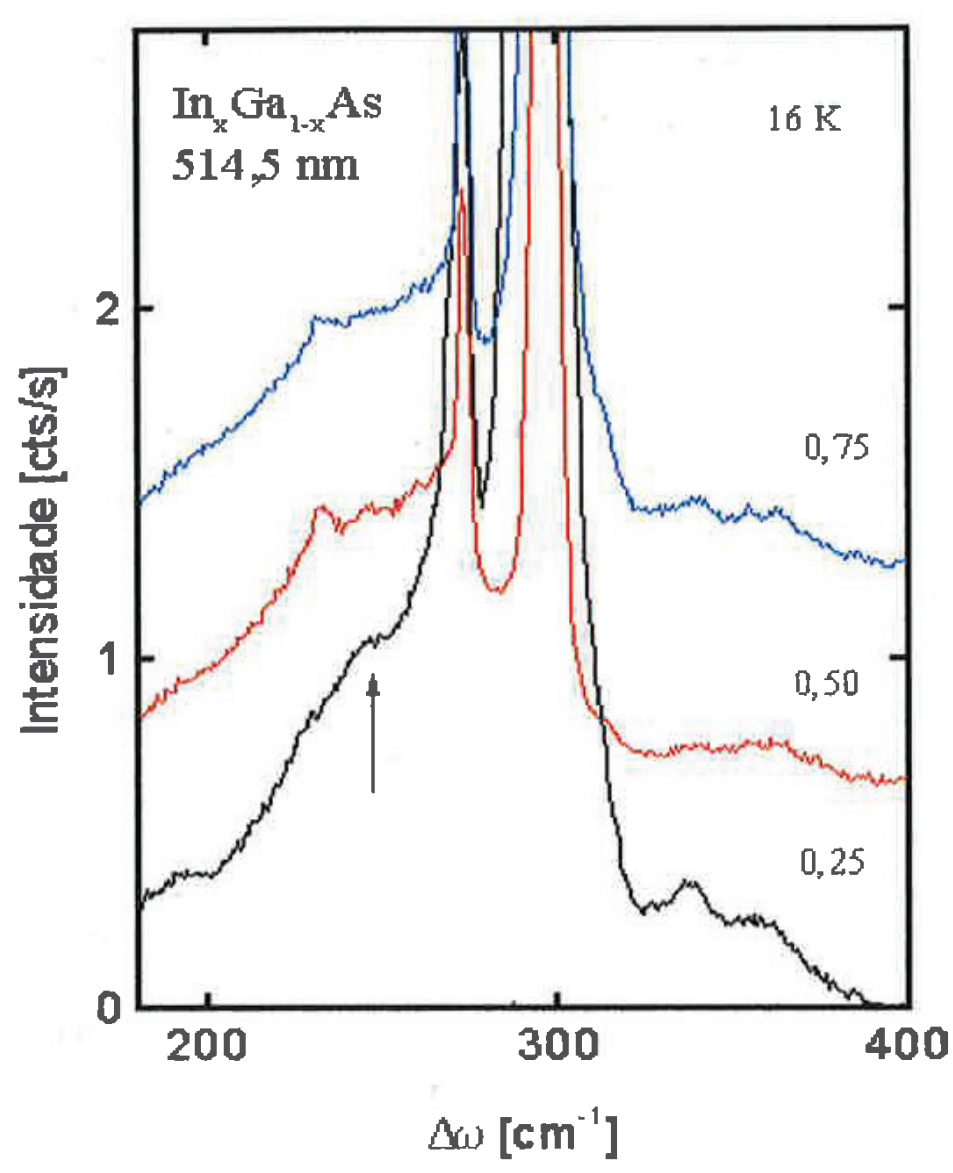

Figura 4.6: Espectros Raman dos pontos quânticos de InGaAs sobre o substrato de GaAs com a variação da fração molar de In. As medidas foram realizadas à baixa temperatura $(16 \mathrm{~K})$.

substrato, induzidos por desordem. Porém, o exame do perfil da densidade de estados, bem como o espectro Raman de segunda ordem na simetria predominante, $\Gamma_{1}$, se anula na região de frequências ao redor de $245 \mathrm{~cm}^{-1}$. [19] Então é pouco provável que este efeito seja responsável pelo aparecimento da banda em $245 \mathrm{~cm}^{-1}$. É necessário também, examinar a possibilidade de vibrações na lâmina de molhagem ocasionarem o aparecimento desta estrutura no espectro. A lâmina de molhagem é o depósito inicial de $I n_{x} G a_{1-x} A s$ para as três amostras com composição $x=0,25, x=0,50$ e $x=0,75$. Trabalhos anteriores sobre o crescimento do sistema In GaAs/GaAs, mostram que quando a diferença de parâmetro de rede é maior, a espessura da lâmina 
de molhagern é menor. [20,21] Medidas recentes de fotoluminescência e AFM em amostras com densidade de pontos variadas confirmam este fato mostrando que o sinal de PL relativo à emissão da camada de molhagem diminui com o aumento da densidade de pontos. [22] Desta forma, seria esperado um sinal Raman mais intenso para a amostra com $x=0,75$, em que tanto o descasamento de parâmetro de rede é maior, quanto a densidade de pontos é menor. A observação experimental mostra o inverso. Na figura-4.5, por exemplo, é visto um sinal mais forte para $x=0,25 \mathrm{em} \sim 245 \mathrm{~cm}^{-1}$, e perdendo intensidade em relação ao pico vizinho em $222 \mathrm{~cm}^{-1}$, com o aumento de $x$. Desta forma, é improvável que o pico seja proveniente de vibrações na lâmina de molhagem. As regras de seleção a serem discutidas em sessão subsequente corroboram esta conclusão.

Resta considerar que os pontos quânticos dão origem ao pico Raman em $245 \mathrm{~cm}^{-1}$. Nesta consideração é possível estimar a frequência de vibração radial da partícula de menores números quânticos, a partir do valor de frequência observado para o cristal 3-D, analizando os efeitos de confinamento e tensão interna sobre ele.

Vários compostos ternários de semicondutores III-V, incluindo InGaAs, exibem o comportamento de 2 modos. O espectro Raman do composto InGaAs apresenta três picos, dois deles relativos aos modos tipo-GaAs com frequências $w_{1}$ e $w_{2}$ e um modo tipo-InAs com frequência $w_{3}$. [23] $\mathrm{O}$ outro modo tipo-InAs, de frequência $w_{4}$, não contribui para o espalhamento Raman, tendo sido observado apenas por absorção no infravermelho.

Os modos da liga tem posições dependentes com a fração molar de In, dados pelas seguintes equações: [23]

$$
\begin{gathered}
w_{1}=-32,4 x^{2}-18,6 x+290,0 \\
w_{2}=-29,0 x^{2}-5,3 x+265,1 \\
w_{3}=8,92 x^{2}-7,7 x+234,9 \\
w_{4}=-16,5 x+233,7
\end{gathered}
$$


onde $w_{i}$ representa o número de onda em unidades de $\mathrm{cm}^{-1}$ para o modo i. Usando estas expressões, é possível calcular as posições para compostos $\operatorname{In}_{x} G a_{1-x} A s$ (3-D), sem tensão, com composição $x=0,25, x=0,50 \mathrm{e}$ $x=0,75$. Os resultados estão apresentados na tabela-4.2.

Tabela 4.2: Posição dos modos Raman da liga $I n_{x} G a_{1-x} A s$ sem tensão para três valores de $x$.

\begin{tabular}{ccccc}
\hline \hline$x$ & $w_{1}\left(\mathrm{~cm}^{-1}\right)$ & $w_{2}\left(\mathrm{~cm}^{-1}\right)$ & $w_{3}\left(\mathrm{~cm}^{-1}\right)$ & $w_{4}\left(\mathrm{~cm}^{-1}\right)$ \\
\hline 0,25 & 283,3 & 265,6 & 233,5 & 229,6 \\
0,50 & 272,6 & 255,2 & 233,3 & 225,4 \\
0,75 & 257,8 & 244,8 & 234,1 & 221,3 \\
\hline \hline
\end{tabular}

Os modos de InGaAs de frequência $w_{2}$ e $w_{4}$ têm caráter transversal e não serão analisados porque não há equivalente a eles entre os modos de interesse dos pontos quânticos. Os modos de frequência $w_{1}$ e $w_{3}$ devem corresponder a modos do tipo Fröhlich dos pontos quânticos, pois têm caráter longitudinal. Porém as frequências $w_{1}$ ocorrem na região dos fônons do GaAs, que compõe o substrato. Como estes fônons dão origem a picos muito fortes, é provável que picos mais fracos sejam encobertos pela intensidade espalhada pelo substrato. Desta forma, o modo tipo-GaAs de frequência $w_{1}$ será omitido na análise. O modo tipo-InAs de caráter longitudinal tem frequência praticamente constante em função da concentração de In no composto InGaAs. Isto pode ser constatado pela equação (4.3) e por inspeção da Tabela-4.2. O valor médio dos números listados nesta tabela para $w_{3}$ é $233,6 \mathrm{~cm}^{-1}$.

Portanto, o valor $\overline{w_{3}}=233,6 \mathrm{~cm}^{-1}$ pode ser considerado como a frequência para o modo tipo-InAs da liga sem tensão, independente do valor de $x$. As diferenças observadas entre $\overline{w_{3}}$ e os valores listados na Tabela-4.2 estão dentro do erro experimental. Como a quantidade de In na liga não altera a frequência do modo 3-D, não deve alterar também a posição dos modos dos pontos quânticos. Para os pontos quânticos deste estudo, os efeitos de confinamento nas frequências de vibração podem ser desprezados por causa do tamanho das partículas. São partículas cujo volume é da ordem de grandeza de $1 \times 10^{3}-3 \times 10^{3} \mathrm{~nm}^{3}$. Comparando com resultados publicados para pontos quânticos de GaAs em matrizes de AlAs, para os 
quais os modos de menores números quânticos $(l=0, n=1)$ mudam significativamente a posição para raios $R<1,5 \mathrm{~nm}$, os volumes em questão são muito grandes para produzir modificações nas frequências dos fônons. Assim sendo, as frequências dos pontos quânticos serão consideradas independentes do tamanho da partícula. Então, as modificações de frequência devem advir exclusivamente dos efeitos de tensão nos pontos quânticos. A discussão destes efeitos vai ser abordada em sessão subsequente a título de simplificação. A seguir serão analizadas as possíveis contribuições adicionais ao espectro Raman e as correspondentes regras de seleção.

\subsubsection{Contribuições Adicionais e Regras de Seleção Correspondentes}

Nesta sessão serão consideradas duas contribuições importantes para os espectros Raman: (i) contribuição dos modos de vibração do substrato. (ii) contribuição dos modos de vibração provenientes da camada tensionada entre o substrato e os pontos quânticos.

Para o substrato crescido na direção [100] as regras de seleção são aquelas para o cristal cúbico (3-D) pertencente ao grupo Td conforme mostrado na Tabela-2.1. Para a superrede formada pela camada tensionada, as regras de seleção são referentes a um cristal 2-D. A deformação estrutural impõe um abaixamento da simetria pontual; assim o grupo pontual $T_{d}$, no cristal 3-D cúbico, abaixa para o grupo tetragonal $D_{2 d}$ na superrede. [24]

A seguir será apresentado de forma resumida a descrição das regras de seleção dos fônons ópticos confinados na camada de molhagem. O confinamento impõe a condição de contorno mecânica de que o deslocamento atômico tenha amplitude nula na interface. Considerando $z$ a posição do plano atômico ao longo do eixo da superrede e a origem $z=0$ no ponto médio da camada, a magnitude do deslocamento é descrita pelas funções envelope:

$$
u_{m}(z)=\cos K m z, \quad m=1,3,5 \ldots \quad \text { e } u_{m}(z)=\operatorname{sen} K m z, \quad m=2,4,6 \ldots
$$

Os fônons ópticos correspondentes, tem paridade ímpar ou par e são selecionados mediante o uso das regras de seleção. As regras de seleção para o 
sistema 2-D estabelecem que a observação de modos de simetria $B_{2}$ ocorre na geometria $z(y, x) \bar{z}$ e $A_{1}$ na configuração $z(x, x) \bar{z}$. Estas simetrias correspondem a modos ímpares e pares respectivamente. Os modos ímpares são sempre observados e os pares apenas em condições de ressonância. Os modos pares ocorrem devido à interação tipo Fröhlich de curto alcance no acoplamento elétron-fônon. [25]

$\mathrm{Na}$ geometria de espalhamento $z(x, x) \bar{z}$ os modos do GaAs-substrato e $B_{2}$ da camada 2-D de InGaAs são proibidos. Além disso, os modos $A_{1}$ da camada 2-D de InGaAs não devem aparecer em condições fora de ressonância. Então, a geometria $z(x, x) \bar{z}$ favorece a observação dos pontos quânticos, proibindo as contribuições adicionais. Ressalva seja feita, que esta é precisamente a geometria que permite a observação dos modos tipo radial, conforme descrito no capítulo anterior.

Não foi usada ressonância com os estados eletrônicos dos pontos quânticos, porque eles ocorrem em energias de $\sim 1,3 \mathrm{eV}$ e isto exigiria o uso de óptica especial para o laser de Titânio-Safira, a qual não estava disponível por ocasião do desenvolvimento deste trabalho.

\subsubsection{Distribuições de Tensão nos Pontos}

Um estudo da distribuição de tensão em pontos quânticos de InAs de forma piramidal com base de $12 \mathrm{~nm}$ de comprimento e altura de $6 \mathrm{~nm}$ foi publicado recentemente. [12] Os resultados são reproduzidos parcialmente aqui, pois foram usados na interpretação de nossos espectros.

A mudança na energia do fônon devido à tensão interna, foi estimada como 2,2 meV através deste cálculo da tensão média em um ponto quântico de InAs. [12] A variação da tensão local pode ser visualizada na Figura-4.7.

A figura-4.7 apresenta a variação das quatro componentes de tensão $\varepsilon_{x x}, \varepsilon_{y y}, \varepsilon_{z z}$ e $\varepsilon_{x z}$ através do plano $(010)$ cortando o topo da pirâmide. $\mathrm{O}$ caráter da tensão não é determinado pela separação das componentes do tensor de tensão, mas sim pela decomposição desse tensor em uma parte isotrópica (hidrostática) e outra anisotrópica. Uma pressão hidrostática aplicada a um semicondutor produz uma diminuição de seu parâmetro de rede, alterando sua estrutura de bandas e, portanto, levando a mudanças em suas propriedades eletrônicas e ópticas. Neste caso pode-se distinguir duas classes de efeitos provocados pela tensão: a) mudanças nas posições 

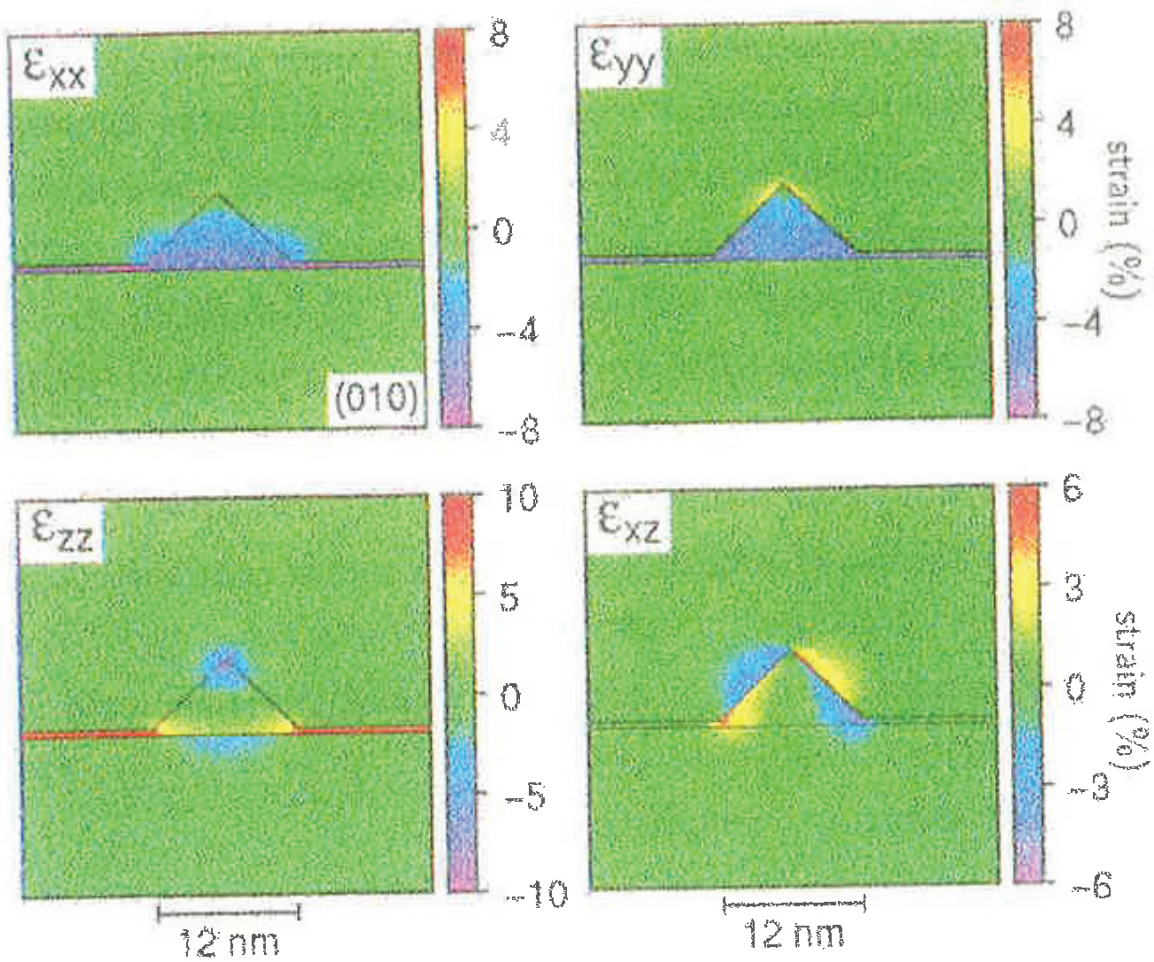

Figura 4.7: Distribuição da tensão no plano (010) da pirâmide ao longo do eixo z. Ref. [12].

relativas das bandas, o que influencia todas as propriedades determinadas por transições interbandas (função dielétrica e outras constantes ópticas); b) deformação de bandas individuais, o que altera a densidade de estados e, por conseguinte, a massa efetiva dos portadores. [26] Já urna tensão uniaxial teṃ como efeito principal uma redução na simetria do material (e consequentes modificações em sua estrutụra de bandas). Para semicondutores III-V polares com estrutura zincblende os efeitos de tensão provocam uma redução de simetria devido ao campo Coulombiano. Esse efeito leva à separação entre o modo óptico de vibração longitudinal, LO e os modos ópticos transversais (degenerados), TO. Uma tensão interfacial compressiva (sinal negativo), causa uma expansão ao longo da direção $z$ ( $\varepsilon_{z z}$ é poṣitivo). A camada de molhagem é afetada somente nas vizinhanças dos pontos, ao se afastar da base ou do topo da pirâmide ao longo da direção $z$ a tensão biaxial diminui. Na Figura-4.8 a parte hidrostática e a parte biaxial do tensor de tensão são comparadas.

Através da figura-4.8, nota-se que a tensão hidrostática (linha traceja- 


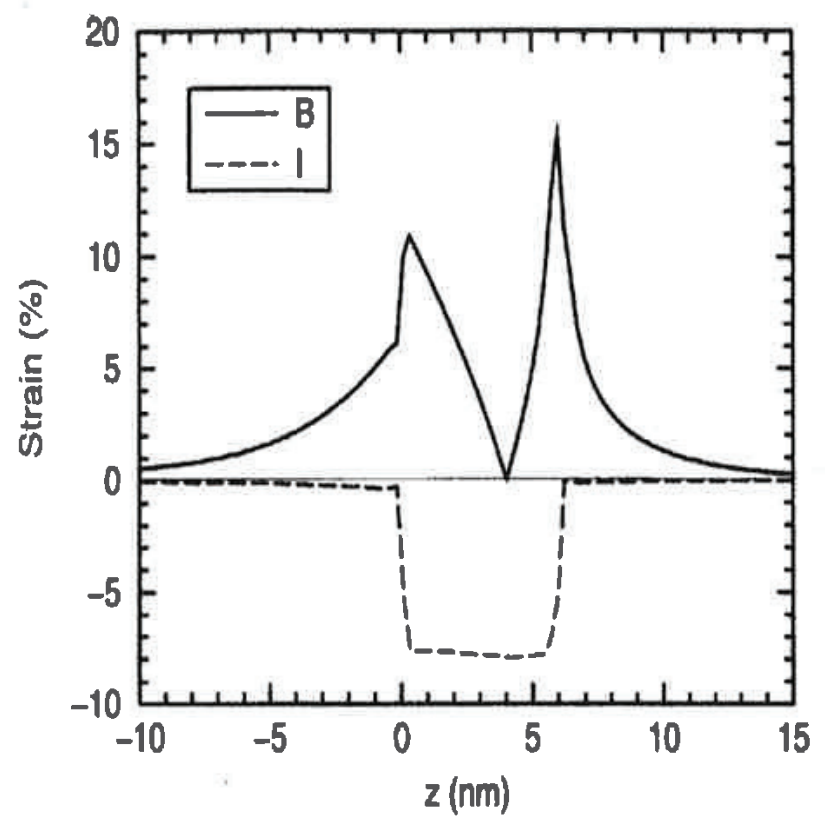

Figura 4.8: Tensão hidrostática (linha tracejada) e biaxial (linha sólida) ao longo da linha que liga o centro da base da pirâmide ao topo. Ref. [12]

da) ocorre somente dentro das dimensões do ponto ao longo da direção $z$. Enquanto que a tensão biaxial (linha sólida) apresenta uma variação bem maior, onde os máximos da tensão ocorrem na base e no topo da pirâmide, ela ainda ocorre ao longo da camada de molhagem. Usando a previsão $\Delta E=2,2$ meV dada na referência [12] , os pontos quânticos devem ter frequências contidas no intervalo entre $233,6 \mathrm{~cm}^{-1} \lesssim w_{i} \lesssim 251,3 \mathrm{~cm}^{-1}$, de acordo com a quantidade de In. As observações experimentais para a banda larga com frequência $w \approx 245 \mathrm{~cm}^{-1}$ estão de acordo com esta precisão. Por essa razão, nós interpretamos esta banda como um modo tipo-InAs dos pontos quânticos de InGaAs. Vale a pena mencionar que um valor experimental de fotoluminescência atribui à energia do fônon do ponto quântico o valor de $\approx 30 \mathrm{meV}$, estando em ótima concordância com os resultados obtidos neste trabalho. [27] 
Espalhamento Raman em ilhas de InAsGa auto-organizadas

\subsubsection{Comparação com resultados experimentais da literatura}

Ilhas tensionadas de InAs crescidas sobre $\operatorname{InP}(001)$ foram investigadas recentemente usando espectroscopia Raman. [28] As medidas foram realizadas em condições de ressonância na região dos níveis eletrônicos tipo $E_{1}$ do InAs. Um poço simples, com espessura de 2 monocamadas, foi estudado também a título de comparação. Para o poço, foi observado um pico em $\sim 250 \mathrm{~cm}^{-1}$ devido ao fônon LO do InAs tensionado. Para o sistema de ilhas, nas configurações $z(x, y) \bar{z} \mathrm{e} z(x, x) \bar{z}$ os picos são ligeiramente deslocados em sentido contrário, para baixas frequências no primeiro caso e para altas na configuração de polarizações paralelas. Usando argumentos de simetria, o pico em $\sim 250 \mathrm{~cm}^{-1}$ foi considerado como proveniente de vibrações internas às ilhas de InAs e o de frequência menor como devido a lâmina de molhagem, pelos autores da ref. [28].

Nossas observações para o sistema de ilhas $I n_{x} G a_{1-x} A s / G a A s$ com $x=0,25$ estão em concordância com estes resultados, no sentido de que as tensões internas nos pontos crescidos de interfaces com menor descasamento de rede, devem ser menores. Como consequência o deslocamento em frequência induzido por tensões é menor para $x=0,25$ que para $x=1$. Então, é de se esperar uma frequência menor para os modos vibracionais nas ilhas de InGaAs em comparação com aqueles de InAs puro. O valor medido por nós, $w \sim 245 \mathrm{~cm}^{-1}$, está plenamente de acordo com esta expectativa.

Um estudo de espalhamento Raman em sistemas de ilhas de ASb/GaAs, onde a letra A representa In, Ga ou Al, foi publicado recentemente. [9] Neste estudo, picos fracos no espectro Raman foram interpretados como modos de superfície das ilhas. As frequências observadas estão listadas na Tabela-4.3 junto com os valores calculados por nós para as frequências dos modos de superfície de número quântico $l=1, w_{s 1}$, usando a aproximação de raios grandes para pontos esféricos (equação 52 da ref. [11]). A comparação mostra uma concordância excelente entre os valores calculados e medidos, indicando que a interpretação fornecida na ref. [9] é correta. A Tabela-4.3 lista também dimensões das ilhas obtidas através de medições de AFM, em termos de altura, h, e diâmetro da base, $\varnothing$. Os autores deste trabalho não fazem menção aos modos tipo radial da esfera.

Nos espectros Raman obtidos por nós é possível distinguir apenas o 
Tabela 4.3: Frequências dos modos LO e TO do cristal 3-D, $w_{s 1}(c a l)$, e medido $w_{s 1}(e x p)$ para o modo de superfície de número quântico $l=1$. Dimensão das ilhas investigadas na ref. [9]: $\mathrm{h}$ : altura, $\varnothing$ : diâmetro.

\begin{tabular}{cccc}
\hline \hline$w_{i}$ & GaSb / GaAs & AlSb / GaAs & InSb / AlAs \\
\hline$w_{\text {TO }}\left(\mathrm{cm}^{-1}\right)$ & 228 & 323 & 182 \\
$w_{L O}\left(\mathrm{~cm}^{-1}\right)$ & 238 & 344 & 193 \\
$w_{s 1(\mathrm{cal})}\left(\mathrm{cm}^{-1}\right)$ & 231,4 & 330,1 & 185,7 \\
$w_{s 1(\text { exp })}\left(\mathrm{cm}^{-1}\right)$ & 234 & 331 & $182<w_{s 1}<193$ \\
$\mathrm{~h}(\mathrm{~nm}) / \varnothing(\mathrm{nm})$ & $3,2 / 28$ & $8,7 / 56$ & $21 / 170$ \\
\hline \hline
\end{tabular}

modo tipo radial da esfera. Os modos de superfície não foram observados isoladamente. As frequências destes modos foram estimadas utilizando os valores $w_{3}$ e $w_{4}$ obtidos das equações (4.3) e (4.4). Tais valores são listados na Tabela- 4.4 como $w_{s 1}$.

Tabela 4.4: Valores das frequências dos modos tipo-InAs no composto $I n_{x} G a_{1-x} A s$-D e valores calculados para as frequências dos modos de superfície dos pontos quânticos.

\begin{tabular}{cccc}
\hline \hline $\mathrm{x}$ & $w_{3}\left(\mathrm{~cm}^{-1}\right)$ & $w_{4}\left(\mathrm{~cm}^{-1}\right)$ & $w_{s 1}\left(\mathrm{~cm}^{-1}\right)$ \\
\hline 0,75 & 234,1 & 221,3 & 225,7 \\
0,50 & 233,3 & 225,4 & 228,1 \\
0,25 & 233,5 & 229,6 & 230,9 \\
\hline \hline
\end{tabular}

Nas posições onde deveriam ocorrer os modos de superfície, não foram observados picos independentes nos espectros, como pode ser verificado por inspeção da Figura-4.5. Como nas vizinhanças das frequências em questão $\left(w_{s 1}\right)$ existem estruturas de espalhamento do substrato, é difícil ser categórico a respeito desta questão. Porém, estruturas de intensidades comparáveis com aquelas observadas para os modos de superfície das ilhas de antimonetos, não foram vistas em nossos espectros. 


\subsection{Conclusões}

Foi mostrado neste capítulo que o modo de vibração dos pontos quânticos de $I n_{0,25} G a_{0,75}$ As consiste de uma banda centrada em $w=245 \mathrm{~cm}^{-1}$. Em adição a esta banda aparecem diversas características que foram associadas aos modos de vibração do substrato de GaAs. Dentre estas características aparecem os modos LO permitido e TO proibido do substrato de GaAs. Aparece também um pico centrado em $w=222 \mathrm{~cm}^{-1}$ para as três frações molares de In. A frequência deste pico permanece imutável dentro do erro experimental e em consequência disto ele foi interpretado como fônon da borda de zona de Brillouin ativado por desordem.

Dentre as possiveis origens do deslocamento da banda centrada em $w=245 \mathrm{~cm}^{-1}$, efeitos de confinamento foram considerados desprezíveis, pois os pontos estudados aqui são grandes. Para pontos quânticos esféricos os efeitos de confinamento são levados em conta quando as dimensões são da ordem de grandeza de poucos nm. Para pontos de GaAs em matriz de AlAs as mudanças em frequências ocorrem para $R \lesssim 1,5 \mathrm{~nm}$. Desta forma a origem dos deslocamentos foram associadas exclusivamente à efeitos de tensão. Assim, buscou-se na literatura um resultado conhecido para os efeitos de tensão em pontos quânticos de InAs/GaAs com a forma piramidal. Os pontos apresentados nesta tese possuem uma forma similar que permite comparações. O deslocamento da banda devido a pontos quânticos de $I n_{x} G a_{1-x} A s$ deve aumentar com a fração molar de In, deslocando-se para altas frequências. Assim, o máximo valor de deslocamento é esperado para $x=1$. Esse valor máximo produz uma mudança na energia do fônon estimada em 2,2 meV. [12] Com base nesse valor, conclui-se então que o modo de vibração para pontos quânticos de $I n_{x} G a_{1-x} A s$ está contido no intervalo $233,6 \mathrm{~cm}^{-1} \lesssim w_{i} \lesssim 251,3 \mathrm{~cm}^{-1}$. Como o valor medido para $I n_{0,25} G a_{0,75} A s, w=245 \mathrm{~cm}^{-1}$, está contido neste intervalo, e considerando que o pico observado para $I n_{0,50} G a_{0,50} A s$ se desloca para altas energias, foi possível identificar o modo de vibração dos pontos quânticos. Considerações de simetria confirmam esta identificação. 


\section{Capítulo 5}

\section{Espalhamento Raman de camadas de GaAs e AlAs com erosão na superfície}

\subsection{Introdução}

O GaAs é um dos semicondutores III-V de grande utilização em dispositivos e como substrato para fabricação de sistemas de baixa dimencionalidade. $\mathrm{O}$ estudo de superfícies deste material modificadas por ataque químico, erosão por laser, bombardeamento por íons, etc., tem despertado interesse sobretudo visando um melhor aproveitamento em aplicações. $[29,30]$

O AlAs é de difícil crescimento e manipulação, devido à rapidez de oxidação no ar. Para este material a literatura sobre vibrações da rede é muito precária. [24,31] O AlAs não é encontrado em tamanhos maiores, compatíveis com amostras exigidas em espectroscopia de nêutrons, e sua fabricação em laboratório só permite obter pequenos volumes. Para pequenos volumes é impossível obter uma curva de dispersão de fônons através da difração de nêutrons. A necessidade do conhecimento experimental da dispersão de fônons para o AlAs é um estímulo para o estudo do espalhamento Raman do material.

O cristal ordenado fornece informação sobre fônons, limitado por conservação de momento cristalino aos fônons do centro da zona de Brillouin. No intuito de obter uma rede cristalina com defeito, foi produzida uma erosão 
superficial nas camadas de GaAs e AlAs por queima com laser focalizado utilizando lente de microscópio. A espectativa, era induzir uma quebra das regras de conservação de momento cristalino e observar fônons da borda de zona os quais são proibidos na rede perfeita.

\subsection{Procedimento Experimental e Amostras}

As amostras estudadas foram crescidas por epitaxia de feixe molecular, MBE (Molecular Beam Epitaxy) no Laboratório de Novos Materiais Semicondutores do Departamento de Física dos Materiais e Mecânica no Instituto de Física da USP. Os dados experimentais de crescimento de cada amostra são apresentados na Tabela-5.1.

Tabela 5.1: Valores nominais das espessuras características das camadas. O substrato é GaAs para todas as amostras, com plano de orientação (001)

\begin{tabular}{lll}
\hline \hline$\#$ & $\begin{array}{l}\text { Estrutura depositada } \\
\text { e espessura }(\mu \mathrm{m})\end{array}$ & $\begin{array}{l}\text { Espessura do "Cap } \\
\text { Layer"de GaAs }(\AA)\end{array}$ \\
\hline 911 & GaAs -1.0 & - \\
923 & AlAs -0.5 & 100 \\
921 & AlAs -0.5 & 100 \\
\hline \hline
\end{tabular}

O tamanho do ponto focal foi determinado utilizando o critério de Reyleigh, como em trabalho publicado anteriormente. [29] O critério de Reyleigh

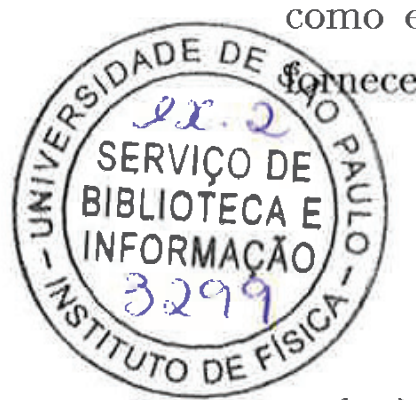

onde $\lambda$ é o comprimento de onda da radiação incidente $(514,5 \mathrm{~nm})$ e NA é a abertura da lente $(0,95)$. Com esses valores foi obtido um ponto focal de cerca de $2 \mu \mathrm{m}$ de diâmetro. Com a potência incidente na amostra sendo $\sim 3 \mathrm{~mW}$ foi possível determinar a densidade de potência incidente 
na amostra como $\sim 2 \cdot 10^{5} \mathrm{~W} / \mathrm{cm}^{2}$. Essa densidade de potência incidindo sobre a amostra durante cerca de 3 horas, foi suficiente para provocar uma erosão na superfície. A erosão foi registrada através de uma fotografia que é apresentada na Figura-5.1.

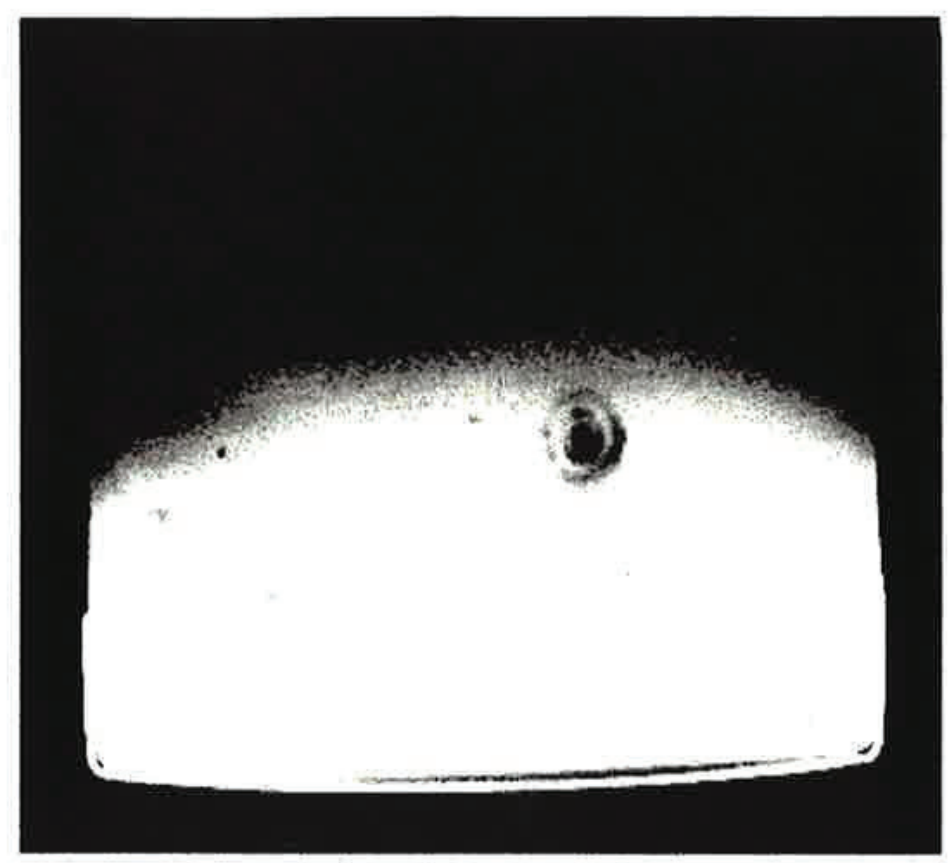

Figura 5.1: Fotografia do furo produzido pela erosão com o laser. O diâmetro do furo interno é de $\sim 2 \mu \mathrm{m}$.

Foi estimada também a profundidade de penetração da radiação incidente para ver se era possível atingir o substrato também. Para isso foi usada a seguinte expressão:

$$
I_{a}=I_{0} \exp ^{-\alpha z}
$$

onde $I_{a}$ é a intensidade da radiação absorvida, $I_{o}$ é a intensidade da radiação incidente, $\alpha$ é o coeficiente de absorção do AlAs para a linha $514,5 \mathrm{~nm}$ do laser de Argônio $\left(\alpha_{A l A s}=1,73 \cdot 10^{2} \mathrm{~cm}^{-1}\right)$ e $z$ é a profundidade que a radiação penetra. Assim, com um valor típico de $I_{a} / I_{o}=0,1$ a profundidade 
de penetração para essa radiação é de cerca de $z=133 \mu m$. Então, essa radiação atravessa o filme de AlAs e atinge o substrato. É possível que essa erosão não só cause a formação de uma cratera na amostra como também parte deste material é ejetado e se acumule nas bordas da cratera conforme indicado no trabalho de García e colaboradores. [29]

\subsection{Resultados e Discussões}

Num processo de espalhamento para um sólido cristalino perfeito os fônons viajam pela rede cristalina através de direções privilegiadas sem serem espalhados: Por exemplo quando a incidência ocorre ao longo da direção $x$ de um cristal puro, os átomos que estão ao longo deste eixo vibram longitudinalmente formando os modos longitudinais ópticos e acústicos (LO e LA) do cristal, enquanto os que vibram em direções perpendiculares, formam os modos transversais ópticos e acústicos (TO e TA). A situação de desordem local, é similar a de defeitos ou impurezas na estrutura cristalina (Apêndice-B). Os fônons são espalhados por esses defeitos implicando no surgimento dos modos ativados por desordem. [30,32] Defeitos e impurezas perturbam os estados eletrônicos e o momento cristalino não é conservado no processo de espalhamento. Na situação de desordem o momento cristalino não é conservado por perda de simetria translacional.

Foram realizadas várias medidas Raman das amostras descritas na Tabela5.1. Pelas regras de seleção, para a geometria de retroespalhamento de uma superfície (001) em materiais com estrutura zincblende, somente os modos LOs são permitidos. No entanto, os modos TOs que são proibidos nessa configuração, contribuem para o espectro, provavelmente devido à desordem local.

As Figuras 5.2 e 5.3 apresentam os espectros de duas amostras descritas na Tabela-5.1 onde aparecem os picos correspondentes a modos LO e TO de centro da zona de Brillouin do GaAs (911) e AlAs (923). Além dos picos referentes aos modos de vibração do material, aparecem também algumas linhas de plasma do laser. Uma linha de plasma, indicada pela letra $P$ na Figura-5.3, serviu de referência e foi útil para posicionar as frequências dos outros picos. A posição da linha de plasma foi tomada como $w_{p}=116,0$ $\mathrm{cm}^{-1}$, de acordo com uma publicação prévia [33]. A partir do conhecimento exato da frequência da linha de plasma $P$ foi possível encontrar a posição 
correta dos modos TOs e LOs no espectro apresentado na Figura-5.3. Usando este critério foi verificado que a posição do modo LO para o GaAs é $w_{L O}$ $=292 \mathrm{~cm}^{-1}$. O espectro da Fig. 5.2 foi deslocado no eixo de energias usando-se como referência o valor $w_{L O}$.

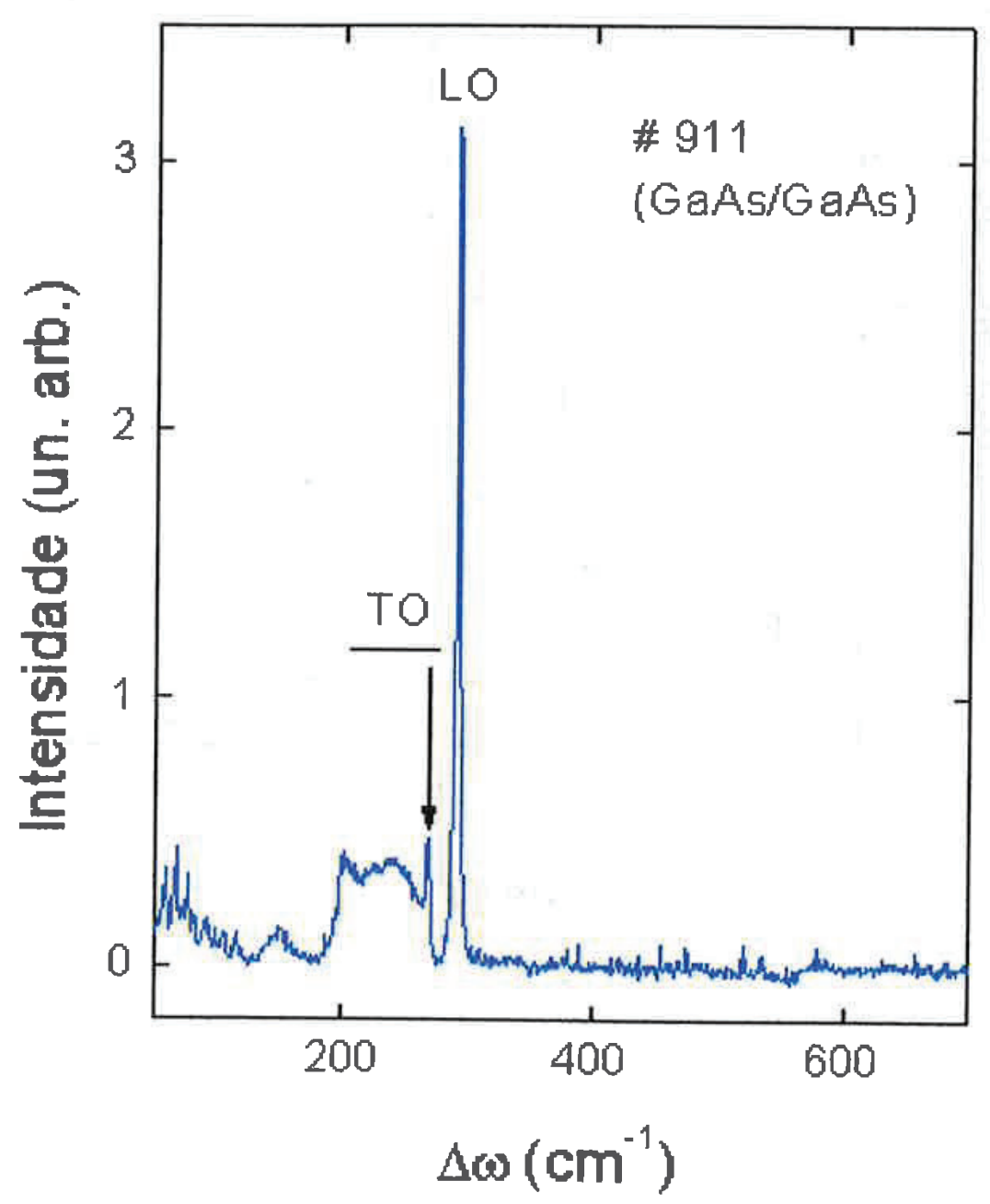

Figura 5.2: Espectro Raman da amostra 911 (GaAs/GaAs).

Nos espectros aparecem novas estruturas além daquelas permitidas por regra de seleção e dos modos transversais proibidos. Estas estruturas são: uma linha isolada em $w \approx 147 \mathrm{~cm}^{-1}$ e uma linha em $w \approx 200 \mathrm{~cm}^{-1}$ sobrepondo uma banda larga. Note-se a supreendente semelhança das estruturas adicionais nos espectros das Figuras 5.2 e 5.3. A banda larga pode ser 


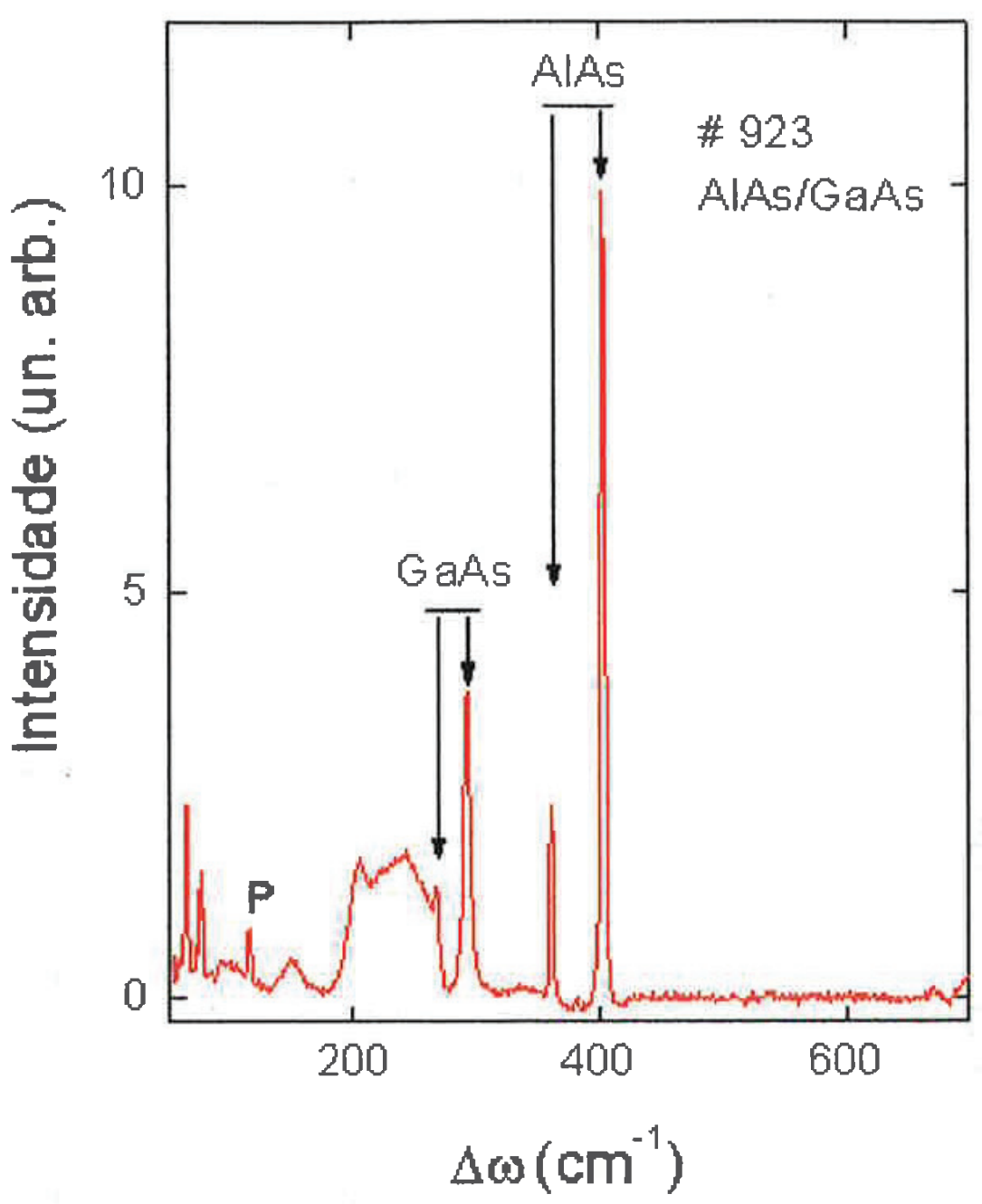

Figura 5.3: Espectro Raman da amostra 923 (AlAs/GaAs).

resultado da superposição de diversas linhas ou espalhamento de material amorfo. Essa banda larga pode ter sido induzida por defeito local devido à erosão da amostra por queima produzida pelo laser durante a medida. Foram realizadas algumas medições Raman sob baixa potência e utilizando um tempo menor de exposição das amostras aos efeitos do laser. Nesse caso não apareceu a banda larga, indicando que a erosão pelo laser foi responsável pelo seu aparecimento. Para interpretar os espectros foi considerada a hipótese de que a erosão produz deformação da rede cristalina induzindo quebra das regras de conservação de momento. Neste caso, é 
possível observar fônons de borda da zona de Brillouin.

O próximo passo foi obter alguns dados quantitativos com respeito aos espectros apresentados acima, tais como as posições e larguras das linhas finas isoladas. Para isso foi utilizado um programa gráfico que permitiu os ajustes dos picos através de Lorentzianas superpostas. Os resultados são apresentados nas Tabelas-5.2 e 5.3. Quanto às bandas largas que aparecem nos dois espectros, estas também foram ajustadas por quatro curvas Lorentzianas. Os dados quantitativos à respeito da posição e largura de linha para a região da banda larga também são apresentados nas Tabelas5.2 e 5.3, terceira coluna. Juntamente com os dados experimentais estão listados também os resultados de cálculos publicados para os fônons do GaAs e AlAs por Giannozzi e colaboradores [34]. A Tabela-5.2 apresenta os resultados para a amostra 911 que contém apenas GaAs e a Tabela-5.3 apresenta os resultados para a amostra 923 que contém AlAs sobre GaAs.

A título de clareza, é incluída a Figura-5.4 com a superposição das curvas de dispersão para GaAs e AlAs, também obtidas da ref. [34]. Os pontos nas curvas foram obtidos por difração de nêutrons enquanto as linhas sólidas representam resultados de cálculo através de um método $A b$ initio. Os poucos pontos experimentais existentes para as frequências dos fônons em AlAs, obtidos por medidas de absorção, são indicados com círculos cheios na Figura-5.4. Note-se na Figura-5.4 que na região dos fônons acústicos, as curvas para o GaAs e AlAs se sobrepõem, enquanto que para fônons ópticos elas são completamente separadas. A sobreposição dos ramos acústicos explicaria parcialmente a semelhança das bandas largas nos espectros Raman das Figuras 5.2 e 5.3, dentro da hipótese supra citada. Então, esta semelhança constitui uma indicação de que há contribuição de fônons de borda da zona de Brillouin nos espectros.

As Tabelas-5.2 e 5.3, contém também a comparação percentual entre as frequências calculadas e as obtidas pelos ajustes dos dados experimentais (ver colunas 4). Os números são todos inferiores a $2 \%$ exceto pelo valor $3 \%$ obtido para o pico observado em $w \approx 147 \mathrm{~cm}^{-1}$. O pico que aparece na posição $145 \mathrm{~cm}^{-1}$ na segunda coluna da Tabela-5.2 é devido a espalhamento de segunda ordem, proveniente de uma combinação de modos acústicos. A perfeita concordância entre os valores publicados e os nossos resultados induz à credibilidade na hipótese formulada. Note-se na Figura-5.4 que os pontos experimentais para o AlAs se limitam a 2 pontos no centro de zona 
Tabela 5.2: Comparação dos resultados obtidos dos ajustes das curvas referentes à amostra 911 (GaAs/GaAs), $w_{\text {exp., com frequências calculadas }}$ conforme publicado na ref.[34], $w_{\text {cal. }}$.

\begin{tabular}{cccccc}
\hline \hline Modos & $w_{\text {calc }} \cdot\left(\mathrm{cm}^{-1}\right)$ & $w_{\text {exp }} \cdot\left(\mathrm{cm}^{-1}\right)$ & $(\Delta w / w) \%$ & $\Gamma_{\text {exp }} \cdot\left(\mathrm{cm}^{-1}\right)$ & Área \\
\hline$T A(X)+T A(L)$ & 145 & 147 & 1,7 & 25 & 4 \\
$L A(K, L, W)$ & 204 & 202 & 0,7 & 12 & 7 \\
$L A(X)$ & 223 & 220 & 1,0 & 32 & 12 \\
$L O(L, X)$ & 239 & 238 & 0,2 & 27 & 11 \\
$T O(W, X, L)$ & 258 & 253 & 2,0 & 17 & 6 \\
$T O(\Gamma)$ & 271 & 268 & 1,0 & 4 & 2 \\
$L O(\Gamma)$ & 291 & 292 & 0,3 & 4 & 19 \\
\hline \hline
\end{tabular}

Tabela 5.3: Comparação dos resultados obtidos dos ajustes das curvas referentes à amostra 923 (AlAs/GaAs), $w_{\exp .,}$ com frequências calculadas conforme publicados na ref.[34], $w_{\text {cal. }}$.

\begin{tabular}{cccccc}
\hline \hline Modos & $w_{\text {calc }}\left(\mathrm{cm}^{-1}\right)$ & $w_{\text {exp }} \cdot\left(\mathrm{cm}^{-1}\right)$ & $(\Delta w / w) \%$ & $\Gamma_{\text {exp }} \cdot\left(\mathrm{cm}^{-1}\right)$ & Área \\
\hline $\mathrm{TA}(\mathrm{X})+\mathrm{TA}(\mathrm{L})$ & 155,5 & 151 & 3,0 & 17 & 8 \\
$\mathrm{LA}(\mathrm{K}, \mathrm{W}, \mathrm{L})$ & 204,5 & 202 & 0,1 & 19 & 31 \\
$\mathrm{LA}(\mathrm{X})$ & 219,5 & 221 & 0,6 & 19 & 29 \\
$L O(L, X)_{G a A s}$ & 239 & 242 & 1,4 & 32 & 58 \\
$T O(W, X, L)_{G a A s}$ & 258 & 255 & 1,0 & 22 & 32 \\
$T O(\Gamma)_{G a A s}$ & 271 & 268 & 1,2 & 3 & 5 \\
$L O(\Gamma)_{G a A s}$ & 291 & 292 & 0,4 & 6 & 36 \\
$T O(\Gamma)_{A l A s}$ & 363 & 361 & 0,6 & 2 & 14 \\
$L O(\Gamma)_{A l A s}$ & 400 & 403 & 0,7 & 4 & 45 \\
\hline \hline
\end{tabular}

e 4 pontos no ponto $X$ da zona de Brillouin. Os pontos experimentais são poucos e sendo obtidos por medição indireta não fornecem a precisão das técnicas de difração de nêutrons ou da espectroscopia Raman. Tais pontos são resultados de medições de absorção. [31] No processo de absorção, quando um elétron passa da banda de valência para a banda de condução ele 


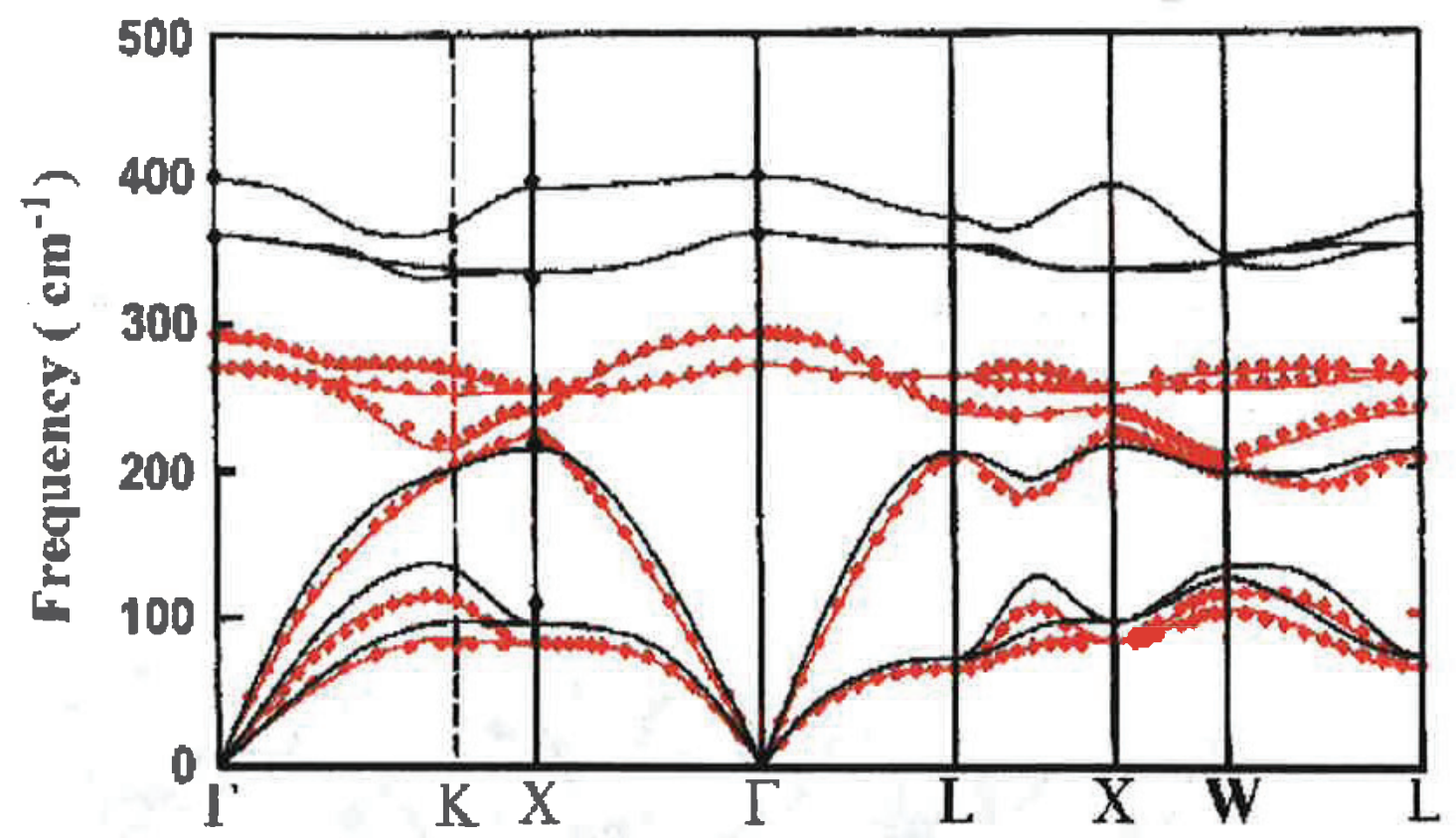

Figura 5.4: Curva de dispersão de fônons para o GaAs (vermelha) e para o AlAs (preta). [34]

absorve um fóton de energia $\hbar w_{a}$. Em alguns materiais existem transições diretas proibidas para $\mathrm{q}=0$ devido às regras de seleção, mas permitidas para $q \neq 0$. Quando a transição requer uma mudança tanto na energia quanto no momento, o processo é de transição indireta. O processo ocorre em dois passos, pois o fóton não pode mudar o momento. O momento é conservado via interação com os fônons. Os fônons devem ter vetor de onda apropriados para garantir a conservação do momento. Cada fônon tem uma energia característica $E_{p}$. Assim no processo de transição entre as bandas de valência e condução a equação de conservação de energia para a absorção de um fônon é:

$$
\hbar \omega_{a}=E_{f}-E_{i}-E_{p},
$$

onde $E_{f}-E_{i}$ é a energia da banda proibida. Dessa forma sabendo a energia da banda proibida e da radiação de excitação, é possível medir a energia do fônon. Maiores detalhes sobre o processo descrito acima pode ser obtido na ref. [35]. 
As curvas de dispersão para o AlAs e o GaAs da Figuras-5.4 apresentam regiões de sobreposição perfeita e regiões onde as curvas estão bem separadas. Então, é díficil estabelecer um critério de análise que permita isolar a contribuição do AlAs.

Com o intuito de isolar fisicamente a camada de AlAs foi escolhida uma outra amostra crescida nas mesmas condições, (amostra \#921). Essa amostra examinada no microscópio é um filme todo quebradiço sobre o substrato. A imagem da superfície foi obtida através de uma fotografia, e é apresentada na Figura-5.5.

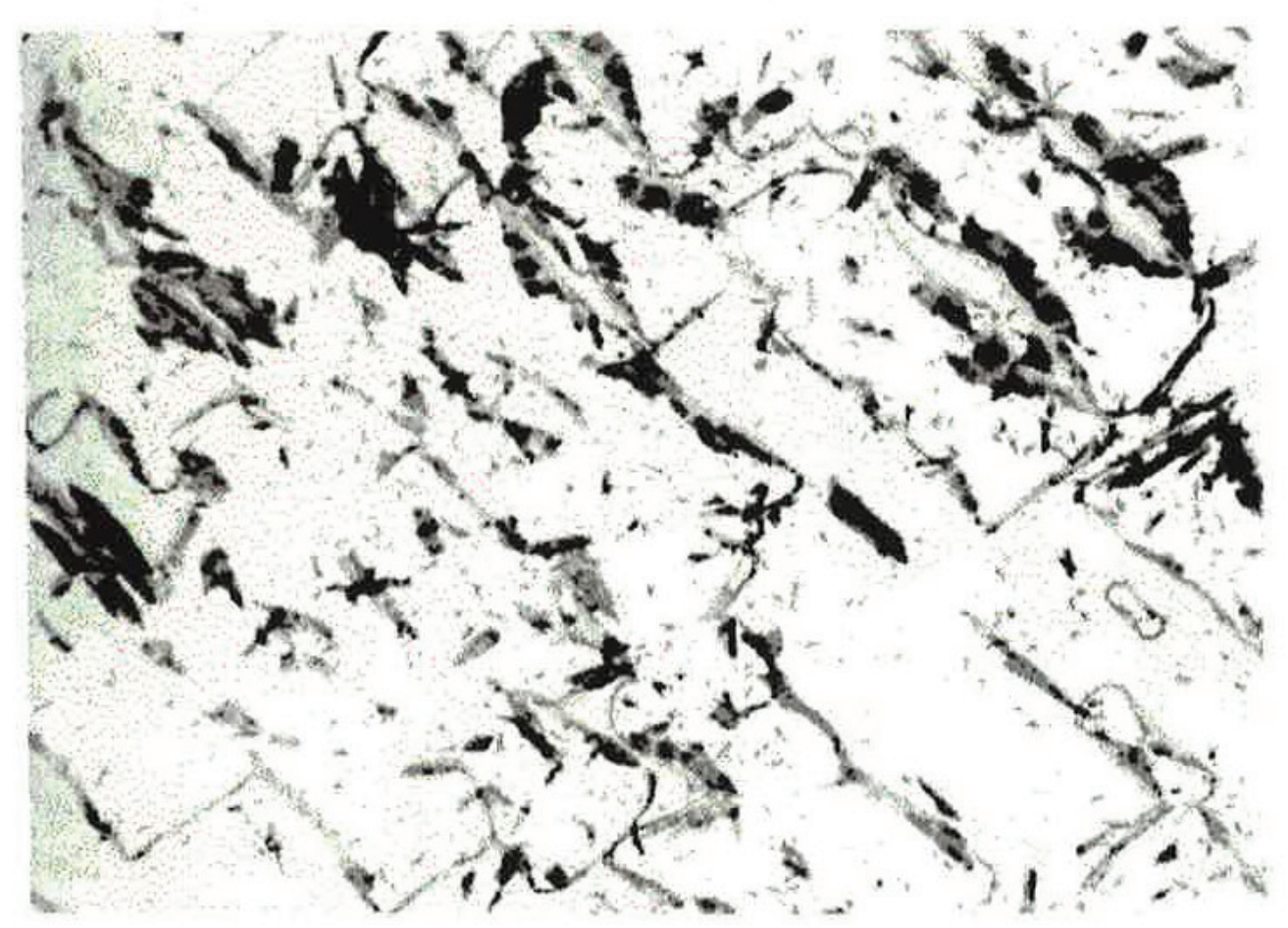

Figura 5.5: Superfície da amostra \# 921 (AlAs/GaAs) vista no microscópio óptico com um aumento de $\sim 60 \mathrm{x}$.

Uma lasca do filme retirado da superfície, foi colocado sobre um suporte de vidro sob microcópio para medição do espectro Raman tanto na região Stokes como na Anti-Stokes. Os espectros são apresentados na Figura-5.6. Neste espectros as estruturas são semelhantes àquelas mostradas na Figura5.2. O espectro contém um pico correspondente ao modo LO do GaAs e mais uma banda larga que é a soma de diversas contribuições induzidas pela erosão devido ao laser. Os picos correspondentes aos fônons do AlAs 
não aparecem nestes espectros. Estruturas resolvidas aparecem nas posições $w \cong 200 \mathrm{~cm}^{-1}$ e $w \cong 150 \mathrm{~cm}^{-1}$. Como todas as estruturas estão presentes tanto na componente Stokes quanto na anti-Stokes, elas são originadas por efeito de vibração da rede. Para interpretar o espectro, é feita a seguir uma análise mais detalhada dos efeitos de oxidação em decorrência da extração do filme de AlAs e excitação com uso de feixe intenso de laser.
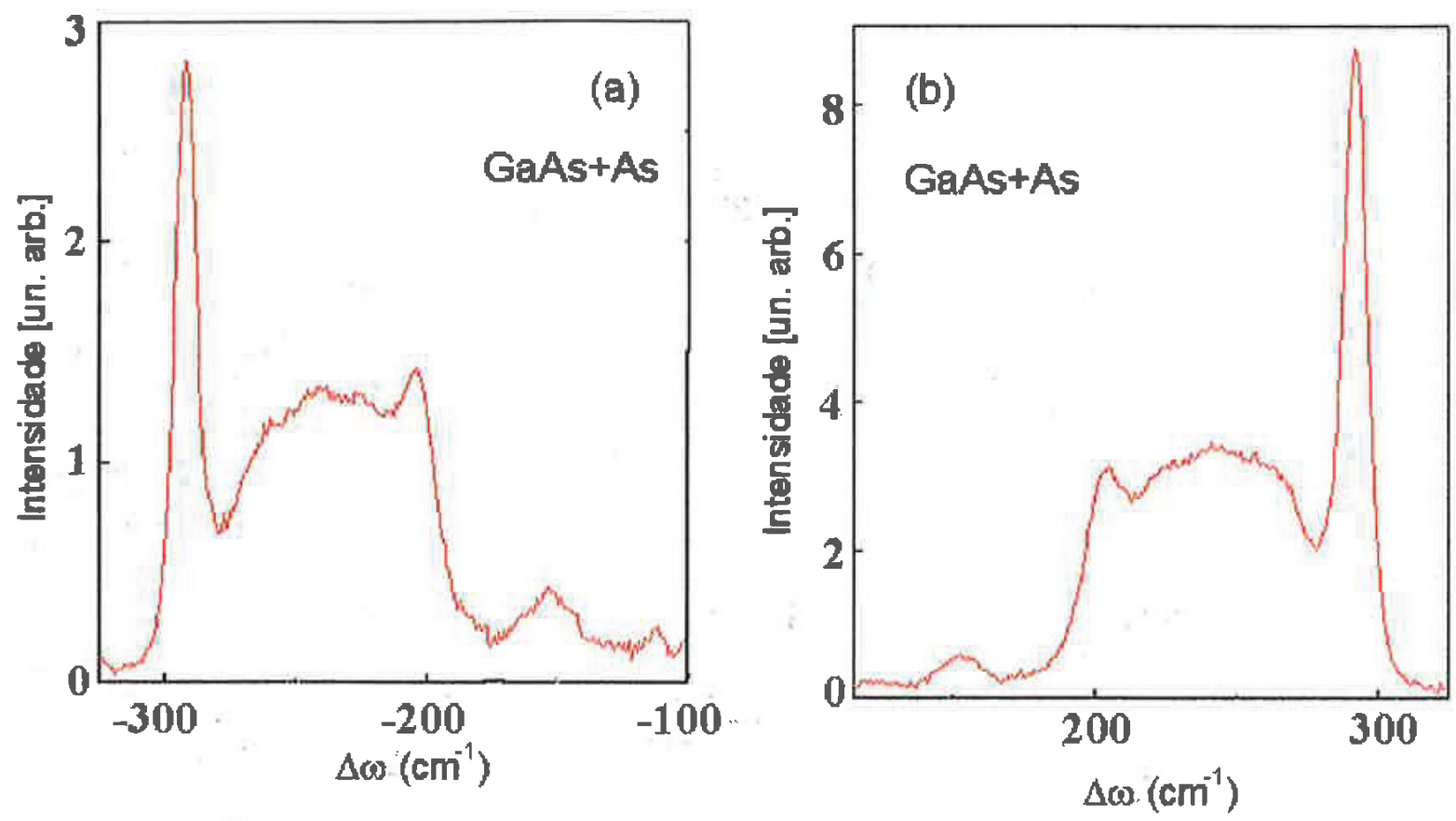

Figura 5.6: Espectro Raman da amostra \# 921 (casquinha) nas regiões Anti-Stokes (a) e Stokes (b).

A temperatura local serve de índice de fusão ou composição de material com o oxigênio do ar formando óxidos que poderiam dar contribuição ao espalhamento Raman. Conhecendo as intensidades dos picos Raman e suas posições é possível estimar a temperatura local na amostra durante a medida utilizando o método descrito a seguir.

O método é usual e consiste em dividir a intensidade Raman de primeira ordem no processo Stokes pela intensidade Raman no processo Anti-Stokes. [36] A intensidade no processo Stokes é dada por: 


$$
I_{s}=A\left[\frac{n(w, T)+1}{w}\right] C(w) g_{a}(w)
$$

onde A é uma constante sobre todas as frequências; $g_{a}(w)$ é a densidade de estados vibracionais do material; $C(w)$ é uma função de acoplamento entre a radiação incidente e os modos vibracionais e $n(w, T)$ é o fator estatístico de Bose-Einstein, que é escrito como:

$$
n(w, T)=\frac{1}{\exp \left(\frac{\hbar w}{k T}\right)-1}
$$

onde $\hbar$ é a constante de Planck e $k$ é a constante de Boltzmann.

No processo Anti-Stokes a intensidade Raman é obtida através da mesma equação escrita para o processo Stokes, diferindo apenas no fator estatístico de Bose-Einstein que nesse caso é proporcional a $n(w, T)$. Dividindo a intensidade Stokes $\left(I_{s}\right)$ pela Anti-Stokes $\left(I_{a s}\right)$ obtém-se a expressão:

$$
\frac{I_{s}}{I_{a s}}=\frac{n(w, T)+1}{n(w, T)} .
$$

Desta relação é possível isolar a temperatura como:

$$
T=\left[\frac{\hbar w}{k \ln \left(\frac{I_{s}}{I_{a s}}\right)}\right] .
$$

Analisando os espectros da Figura-5.6 foi possível obter os dados das posiçôes e intensidades dos picos. Isso foi feito, ajustando os picos através de formas de linha Lorentzianas. Com esses dados foi estimado o valor da temperatura local, como $\mathrm{T}=374 \mathrm{~K}$. O valor de $\mathrm{T}$, mostra que a temperatura atingida não foi suficiente para produzir fusão. (Os pontos de fusão do GaAs e do AlAs são, respectivamente, 1513 e 2013 K). No entanto essa temperatura pode ter favorecido oxidação superficial nas amostras, com formação de As em excesso. Para testar esta hipótese, o espectro do As deve ser comparado com o espectro da Figura-5.6. Para isso, foi incluída a 
Figura-5.7 obtida da ref. [37]. Nesta figura, o espectro superior, para As cristalino, mostra os picos referentes aos modos LO e TO nas posições 257 $\mathrm{cm}^{-1}$ e $198 \mathrm{~cm}^{-1}$. O espectro inferior, mostra uma banda larga compreendida entre 170 e $220 \mathrm{~cm}^{-1}$ correspondente ao espectro do arsênio amorfo além dos picos do óxido de arsênio. A banda larga da Figura-5.6 apresenta uma forma muito semelhante à do espectro do Arsênio amorfo. Dado esta semelhança é possível concluir que o material da lasca de filme contém As amorfo. A presença do pico dominante em $292 \mathrm{~cm}^{-1}$ é devido à camada de proteção de GaAs. É provável que o pico na posição $204 \mathrm{~cm}^{-1}$, corresponda ao modo TO do arsênio cristalino. A diferença de $6 \mathrm{~cm}^{-1}$ entre o valor publicado anteriormente e o valor observado por nós pode ser consequência de tensões internas. Baseado nesta discussão, é possível inferir a presença de arsênio, provavelmente por oxidação do AlAs, o qual em contato com o ar forma óxido de $\mathrm{Al}$ e gera excesso de As. O excesso de As é parcialmente precipitado na forma cristalina e parcialmente amorfo. A presença do As na amostra \#911 vêm do fato da superfície rica em Ga se oxidar formando uma camada de $\mathrm{Ga}_{2} \mathrm{O}_{3}$. Nesse processo o As é precipitado na forma sólida pois sua temperatura de fusão é de $1090 \mathrm{~K}$, e esta não foi alcançada no experimento. Uma hipótese similar pode ser formulada para explicar o aparecimento de estruturas relacionadas ao As nos espectros apresentados nas Figuras-5.2 e 5.3. A presença do sinal Raman do As amorfo é devido ao Arsênio intersticial que fica preso na rede do GaAs quando o Ga se oxida.

A título de comparação qualitativa foi acrescentada a Figura-5.8 que é uma sobreposição dos espectros que foram apresentados nas Figuras 5.2 (GaAs/GaAs) e 5.3 (AlAs/GaAs) com o espectro da lasca de filme que é composto de As + GaAs.

É possivel observar uma certa similaridade entre os espectros obtidos para camadas de GaAs e AlAs com furo com aqueles obtidos para o filme oxidado, indicado na Figura-5.8 como As+GaAs. A Figura-5.8 mostra que a banda proveniente do As amorfo do filme oxidado se extende para mais altas frequências que a banda larga das camadas de GaAs e AlAs, de tal forma que não aparecem os picos do fônon TO nos espectros. Embora a forma de linha tenha sofrido alteração, as diferenças não são grandes o suficiente para permitir interpretar os espectros das camadas de GaAs e AlAs em termos de fônons de $q \neq 0$, exclusivamente. Por outro lado, o espectro do filme oxidado não contém os picos de AlAs que estavam presentes antes da 


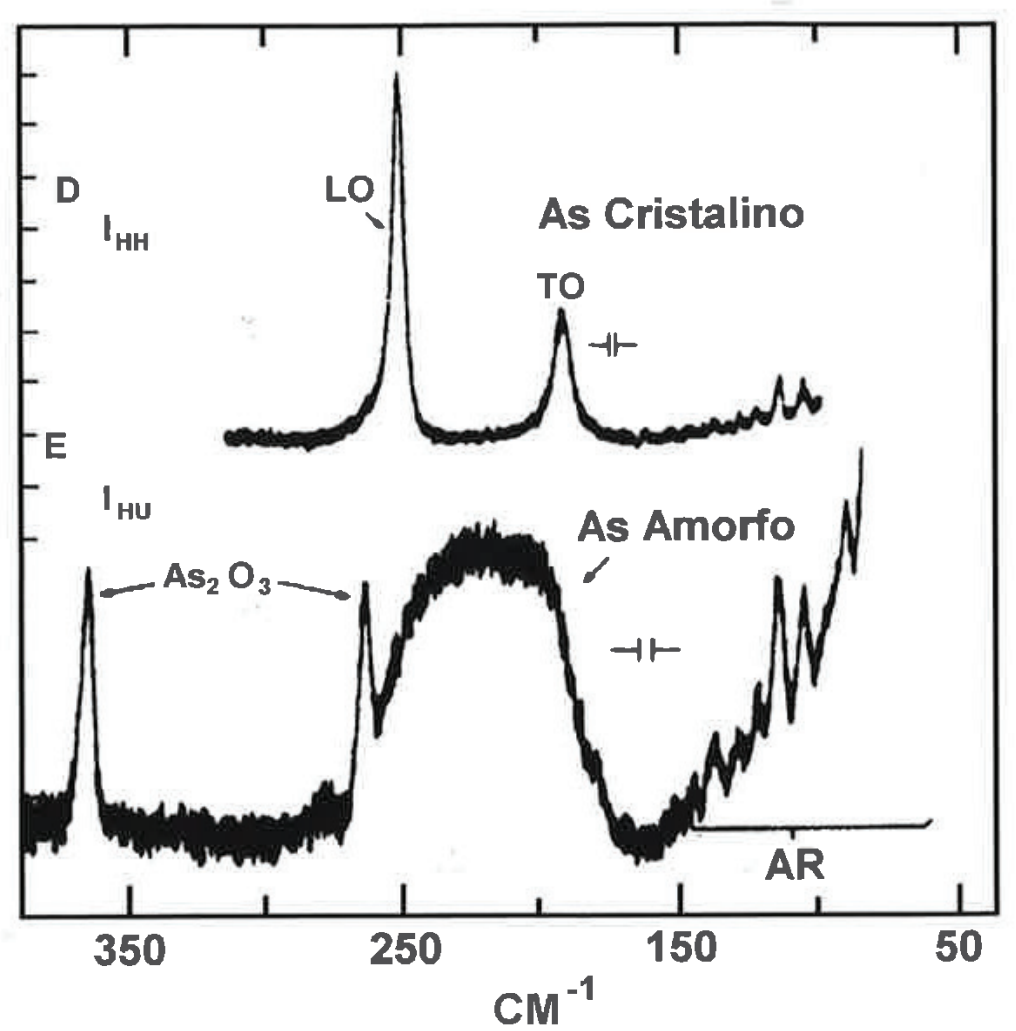

Figura 5.7: Espectro Raman do Arsênio na forma cristalina e amorfa. Ref. [37]

oxidação e eram os picos mais intensos. Isto é uma indicação de que não há AlAs mais, e consequentemente não pode haver contribuição de fônons de $q \neq 0$ do AlAs. Pode haver contribuição dos fônons de $q \neq 0$ do GaAs, porque trata-se da camada de cobertura. Como a camada de cobertura é muito fina, é possível que a contribuição predominante ao espectro Raman seja devido ao excesso de arsênio. Como o arsênio pode estar presente tanto na forma cristalina como amorfa em proporções arbitrárias, não é possível uma análise quantitativa. Além disso, as contribuições de As no espectro ocorrem na mesma região de que os fônons de borda de zona. Desta forma é possível que os espectros resultem da contribuição mista dos fônons do As e dos fônons do GaAs, incluindo os fônons de borda de zona proibidos por conservação de momento. 

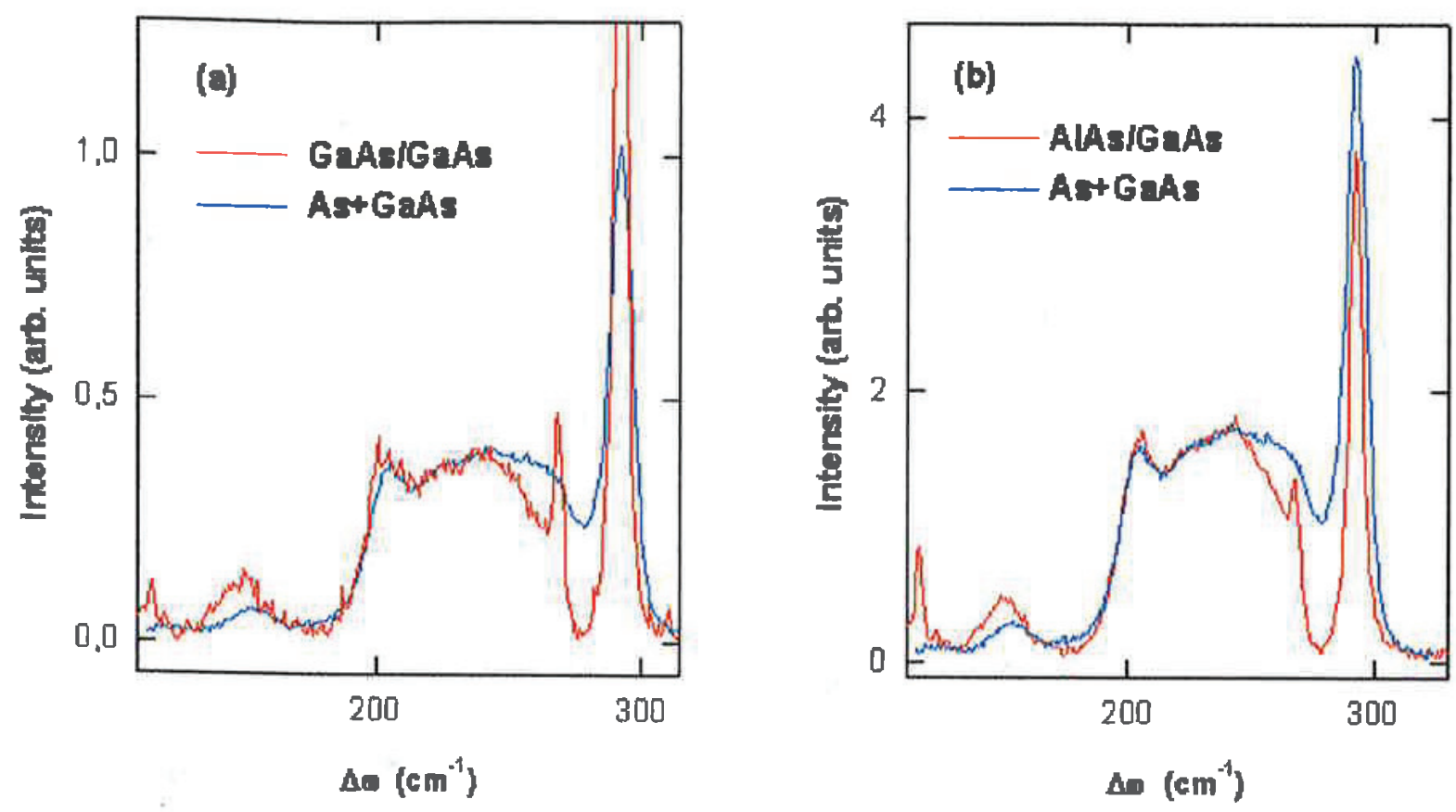

Figura 5.8: a) Superposição do espectro Raman do GaAs (\#911) e GaAs+As (lasca de filme). b) Superposição do espectro Raman do AlAs/GaAs (\#923) e GaAs+As (lasca de filme).

\subsection{Conclusões}

Neste trabalho foi realizada uma medição de espalhamento Raman em camadas de GaAs e AlAs depositadas sobre substrato de GaAs. O espectro Raman em ambos os casos mostra estruturas adicionais aos modos LOs permitidos e TOs proibidos. Estas estruturas foram interpretadas como provenientes de vibrações de As e vibrações de GaAs e AlAs correspondentes a regiões da zona de Brillouin com $q \neq 0$. O As aparece em excesso devido à oxidação do GaAs no ponto focal da radiação incidente. Foi verificado que uma potência incidente da ordem de $3 \mathrm{~mW}$ focalizada com a lente de abertura 0,95 produz queima na superfície. $O$ defeito local pode produzir a quebra de conservação de momento e neste caso fônons de borda de zona, normalmente proibidos, podem dar origem a estruturas no espectro. Uma indicação de que estes fônons contribuem, é o fato da banda larga nos es- 
pectros das camadas de GaAs e AlAs ter largura de linha menor que aquela observada para o As amorfo. Desta forma, nos espectros das camadas o modo TO aparece bem resolvido enquanto que no espectro do As amorfo + GaAs, este modo não é resolvido. Talvez, para evitar a oxidação e consequente formação de $\mathrm{As}$, seja necessário distribuir a potência incidente. A conclusão é qualitativa por várias razões. Uma delas é o fato de ser impossível produzir um espectro padrão de As contendo cristal e amorfo nas mesmas proporções que aquela encontrada no volume de espalhamento da erosão produzida nas camadas. Outra razão, é a dificuldade de reproduzir um espectro de As com polarização definida, porque o As produzido na erosão é provavelmente um policristal. 


\section{Capítulo 6}

\section{Conclusões}

Neste trabalho foi proposto um modelo que permitiu identificar em primeira instância o modo de vibração de pontos quânticos de $I n_{x} G a_{1-x} A s$ com $x=0,25$. O modelo proposto para caracterização das contribuições aos espectros Raman consistiu das seguintes etapas: (i) identificação das vibrações provenientes do substrato; (ii) estudos dos efeitos de tensão e confinamento; (iii) estudos dos modos ativados por desordem.

Primeiramente, foram observados e identificados os modos LO e TO provenientes do substrato. Considerações de regras de seleção indicam que esse modos são, respectivamente, permitidos e proibidos para a geometria e polarização utilizada. A aparição do modo TO é atribuida a desordem superficial do substrato devido à presença dos pontos. Outra característica importante que aparece nos espectros refere-se a um pico centrado em $w=222 \mathrm{~cm}^{-1}$ e que permanece sempre na mesma posição dentro do erro experimental nos espectros. Esse pico foi interpretado como fônon da borda de zona de Brillouin devido ao espalhamento ativado por desordem. A camada de molhagem, que é o depósito inicial de onde se originam os pontos quânticos, também não contribuiu para o espalhamento.

De acordo com resultados teóricos para pontos quânticos esféricos, foi verificado que efeitos de confinamento não podem influenciar na frequência dos pontos estudados por esses serem grandes. Para pontos esféricos os efeitos de confinamento só aparecem quando a dimensão do raio é menor que $15 \AA$. Os efeitos de tensão em pontos quânticos de InAs/GaAs com a forma piramidal são conhecidos. Os pontos que foram estudados nesta tese possuem uma forma similar que permite comparações. Foi verificado que 
o deslocamento da banda associada aos pontos quânticos de $\operatorname{In}_{x} G a_{1-x} A s$ aumenta com a fração molar de In, deslocando-se para altas frequências. O máximo valor esperarado para $x=1$ corresponde ao valor encontrado na literatura. Esse valor máximo produz uma mudança na energia do fônon estimada em 2,2 meV. Com base nesse valor, conclui-se então que o modo de vibração para pontos quânticos de $I n_{x} G a_{1-x} A s$ está contido no intervalo 233,6 $\mathrm{cm}^{-1} \lesssim w_{i} \lesssim 251,3 \mathrm{~cm}^{-1}$. Assim, a banda centrada em $w \approx 245 \mathrm{~cm}^{-1}$ foi identificada como proveniente dos pontos quânticos de $I n_{0,25} G a_{0,75} A s$ e o deslocamento da banda para altas frequências com o aumento da fração molar de In foi atribuído a efeitos de tensão.

Como um subproduto da tese foram incluídas as medidas de espalhamento Raman em camadas de GaAs e AlAs depositadas sobre substrato de GaAs que sofreram queima por laser. As estruturas que aparecem nos espectros foram interpretadas como provenientes de vibraçóes de As e vibrações de GaAs e AlAs correspondentes a regiões da zona de Brillouin com $q \neq 0$. $O$ arsênio aparece em excesso devido à oxidação do GaAs no ponto focal da radiação incidente. Foi verificado que a queima produz na superfície um defeito local que provoca a quebra da conservação de momento e neste caso fônons de borda de zona, normalmente proibidos, podem dar origem a estruturas no espectro. Uma indicação de que estes fônons contribuem, é o fato da banda larga nos espectros das camadas de GaAs e AlAs ter largura de linha menor que aquela observada para o As amorfo. Desta forma, nos espectros das camadas o modo TO aparece bem resolvido enquanto que no espectro do As amorfo + GaAs, este modo não é resolvido. A conclusão para o estudo das camadas é qualitativo por várias razões. Uma delas é o fato de ser impossível produzir um espectro padrão de As contendo cristal e amorfo nas mesmas proporções que aquela encontrada no volume de espalhamento da erosão produzida nas camadas. Outra razão, é a dificuldade de reproduzir um espectro de As com polarização definida porque o As produzido na erosão é provavelmente um policristal.

O estudo dessas camadas foi importante para verificar o possível aparecimento de estruturas provenientes da borda de zona de Brillouin no espectro dos pontos quânticos. 
Apêndices 


\section{Apêndice A}

\section{Detectores}

\section{A.1 Medidas de Energia}

A maior parte dos experimentos realizados em estado sólido tem o interesse de medir a energia envolvida no processo. Quando são estudadas as propriedades ópticas dos semicondutores os interesses se voltam para a medida da energia dos fótons envolvidos no processo ou indiretamente será medida a energia dos modos de vibração da rede. Assim, é de extrema importância ter um sistema óptico muito bem otimizado com medidores de energia que permitam a melhor resolução possível. O presente apêndice apresenta alguns tipos de medidores juntamente com suas características. Dentre os medidores podemos citar alguns exemplos ilustrativos. Por exemplo, as energias dos fótons de raio-X podem ser determinadas em contadores proporcionais ao número de fótons que são detectados por ele. Todo dispositivo que absorve totalmente uma partícula que chega também mede sua energia se ela for depositada em uma parte do volume sensível do detector. As medidas de altas energias na faixa de $1 \mathrm{GeV}$ são geralmente determinadas por métodos calorimétricos. [38] A maior parte das medidas relacionadas às propriedades ópticas dos materiais estão na escala de baixas energias (eV - MeV). A espectroscopia Raman se caracteriza por trabalhar com energias baixas, por isso nessas escalas de energia são utilizados com mais frequência os chamados detectores de estado sólido. Esses tipos de detectores permitem medidas altamente precisas. Dentre esses detectores os mais utilizados são as fotomultiplicadoras e os sistemas CCD (Charge Coupled Device). Esses dispositivos funcionam com base no efeito fotoelétrico, 
ou seja, eles geram uma carga elétrica que é proporcional à intensidade de luz que chega até eles.

\section{A.2 Detectores de Estado Sólido}

A maior parte dos detectores de estado sólido são essencialmente câmaras ionizáveis que utilizam sólidos como meio de absorção da energia que recebem e transformam essa energia em um sinal mensurável. Partículas carregadas ou fótons produzem pares elétrons-buracos nos materiais semicondutores. Um campo elétrico é aplicado cruzando o cristal semicondutor, isso permite que os portadores de carga gerados no processo não se recombinem formando uma corrente de portadores que será medida por um sistema externo. A principal vantagem dos detectores de estado sólido é que a energia disponível para a produção de um par elétron-buraco é pequena quando comparada com outros sistemas de deteç̧ão. Para o silício e o germânio a energia necessária para a produção de um par elétron-buraco são respectivamente 3,6 e 2,8 eV. A título de comparação temos que o gap de energia entre a banda de valência e a banda de condução para o silício e o germânio à temperatura ambiente são, respectivamente, $1,14 \mathrm{e} 0,67 \mathrm{eV}$. Devido ao baixo gap de energia, esses detectores geralmente devem ser resfriados através de sistemas de nitrogênio líquido ou termóeletricamente para evitar o ruído térmico. Outro ponto importante nos detectores de estado sólido é o baixo valor da função trabalho que se encontra entre 1 e $2 \mathrm{eV}$ aproximadamente, o que fornece uma excelente resolução em energia, pois é muito fácil retirar elétrons destes materiais. O princípio de operação dos detectores de estado sólido pode ser melhor entendido a partir da estrutura de banda dos sólidos. O silício cristalino torna-se portador de cargas negativas quando impurezas doadoras de elétrons são introduzidas na rede. $\mathrm{O}$ silício tem quatro elétrons na sua camada de valência. Assim podemos introduzir átomos com cinco elétrons na última camada. Estes átomos passam a agir como impurezas doadoras. Da mesma forma o silício pode tornarse portador de cargas positivas se átomos trivalentes forem introduzidos na sua rede. Estes passam a agir como impurezas aceitadoras. A FiguraA.1 mostra a estrutura de bandas dos semicondutores com a presença de impurezas doadoras e aceitadoras. [38]

O fósforo e o arsênio agem como doadores de elétrons. Nas vizinhanças 


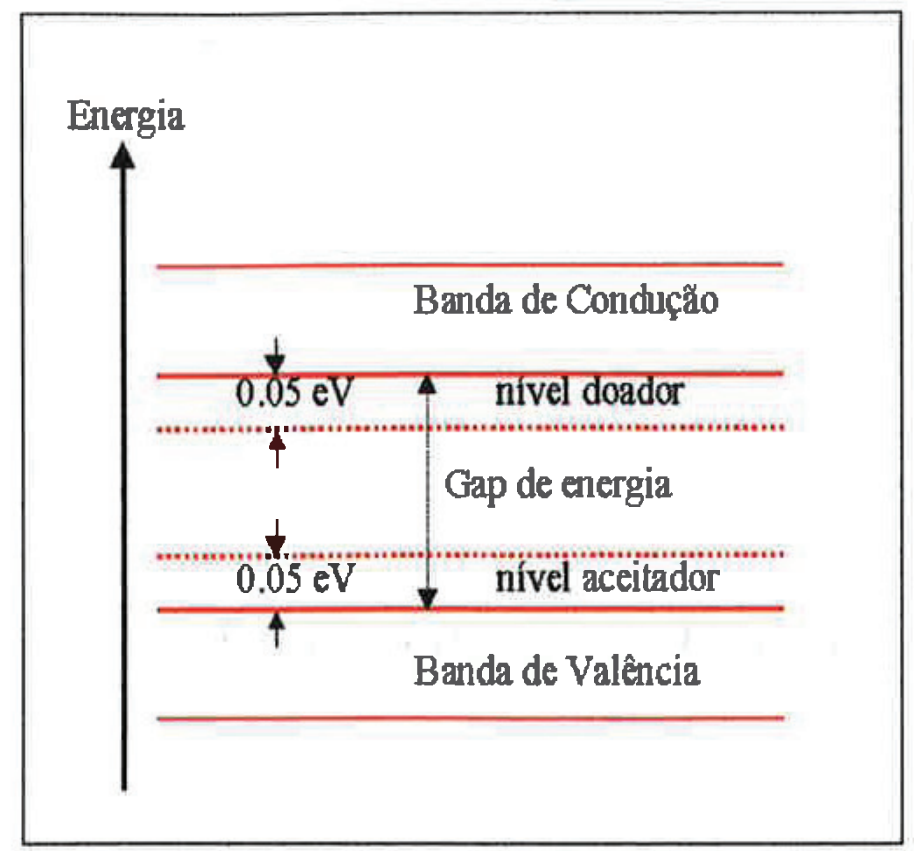

Figura A.1: Diagrama de bandas de um detector de estado sólido. [38]

do silício os átomos podem ligar-se apenas a quatro elétrons. O quinto elétron da impureza doadora de elétrons está fracamente ligado e pode alcançar facilmente a banda de condução. Os níveis doadores estão localizados a aproximadamente $0.05 \mathrm{eV}$ abaixo da banda de condução. Se átomos trivalentes como o boro e o lítio são introduzidos na rede do silício a banda de valência deste fica incompleta criando um nível aceitador de elétrons. Este nível aceitador, que está cerca de $0.05 \mathrm{eV}$ acima da banda de valência, tenta atrair um elétron a partir das vizinhanças do átomo de silício. Como consequência, os buracos podem migrar através do cristal provocando uma corrente de buracos. Se uma partícula carregada atravessa um cristal condutor tipo p ou tipo n, ela produzirá ao longo de seu trajeto pares elétron-buraco. Além disso os elétrons primários podem produzir outros pares de elétrons ou excitar as vibrações da rede. É produzido então um plasma ao longo do trajeto da partícula ou fóton que apresenta uma concentração de portadores de carga de cerca de $10^{15}$ até $10^{17} / \mathrm{cm}^{3}$.

Assim com base nos dispositivos de estado sólido exploraremos um pouco mais as características das fotomultiplicadoras e do CCD nos itens abaixo. O princípio de funcionamento dos detectores de estado sólido consiste da coleta de portadores de carga através da aplicação de um campo externo 
antes que eles tenham chance de se recombinar com os buracos. Se todo esse processo ocorrer com sucesso suficiente, então a medida do sinal de carga é proporcional à energia perdida pela partícula ou fóton ou, se a partícula depositar toda sua energia sobre um volume sensível do detector, a energia da partícula será proporcional à energia absorvida pelo detector. Os detectores geralmente feitos de semicondutores devem operar com uma voltagem de polarização reversa para produzir um campo elétrico suficientemente alto no cristal para poder coletar os elétrons liberados no processo.

\section{A.3 Sobre as Fotomultiplicadoras}

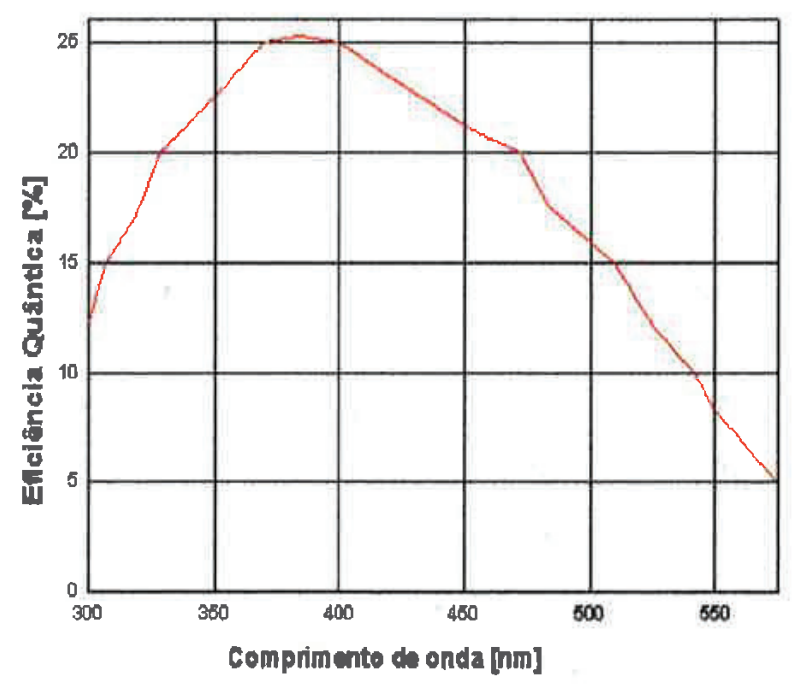

Figura A.2: Eficiência Quântica de uma fotomultiplicadora com catodos fabricados a partir de materiais bi-alcalinos. [38]

A fotomultiplicadora é o intrumento mais comum utilizado em medidas espectroscópicas. Com esses instrumentos é possível medir sinais luminosos na escala do visível ao ultravioleta, a partir de cintiladores. Como foi dito anteriormente temos que o princípio de funcionamento desses dispositivos está baseado no efeito fotoelétrico. Assim temos que a luz incidente atinge um fotocatodo geralmente feito de metal alcalino por possuir uma baixa função trabalho. Assim conforme a energia da radiação 


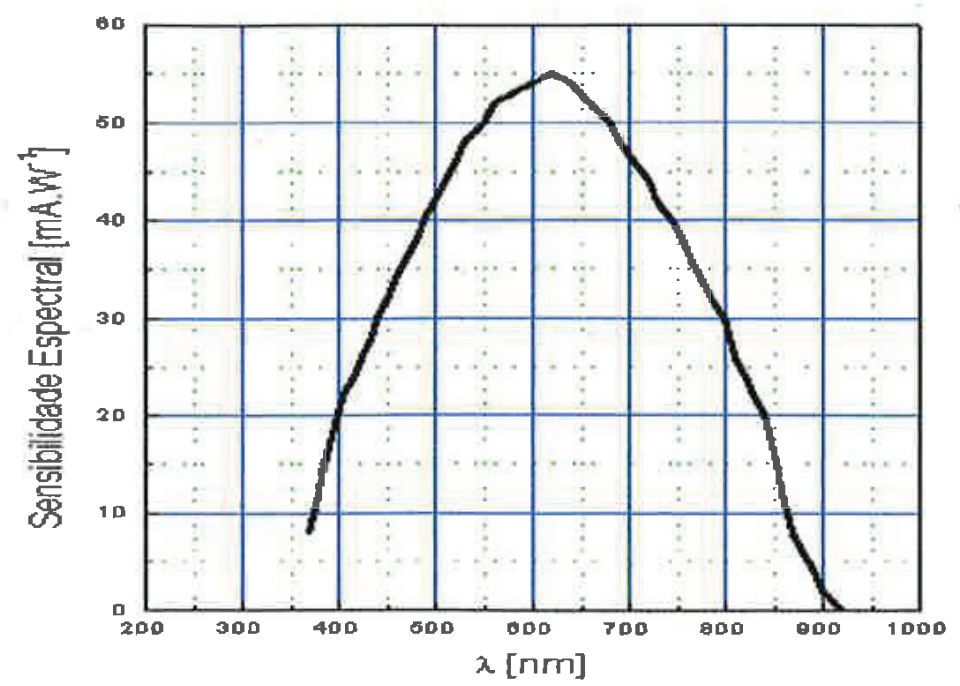

Figura A.3: Curva de sensibilidade espectral típica de um fotocatodo, modelo S $20 \mathrm{~F}$.

incidente, temos que os elétrons são liberados deste alvo. A maior parte das fotomultiplicadoras apresentam uma alta tensão negativa para que os elétrons liberados sejam impulsionados na direção de um primeiro dinodo. Os elétrons são focalizados sobre o primeiro dinodo através da aplicação de um campo elétrico. O anodo é normalmente um potencial aterrado. A voltagem entre o fotocatodo e o anodo é geralmente subdividida por uma bateria de resistores. Esta voltagem subdividida alimenta outros dinodos entre o fotocatodo e o anodo de tal forma que a alta tensão negativa é subdividida linearmente. Um parâmetro importante de uma fotomultiplicadora é a sua eficiência quântica (EQ). A eficiência quântica é definida como o número médio de fotoelétrons produzidos em relação ao número de fótons incidentes. Para catodos fabricados com materiais bi-alcalinos como por exemplo os feitos de $\mathrm{Cs}-\mathrm{K}$ com $\mathrm{Sb}$ a eficiência quântica alcança valores em torno de $25 \%$ para comprimentos de onda de cerca de $400 \mathrm{~nm}$, conforme podemos ver na Figura-A.2. [38] A eficiência quântica diminui para baixos comprimentos de onda devido à transparência da janela diminuir com o aumento da frequência. A Figura-A.3 mostra a sensibilidade espectral de um dos fotocatodos mais utilizados em medidas Raman na faixa do visível. $O$ modelo é chamado de S $20 \mathrm{~F}$. 


\section{A.4 Sobre o CCD}

Os detectores CCDs são compostos por várias centenas de milhares de "pixels" quadrados que são arranjados em uma matriz retangular, onde cada. pixel pode ser considerado como um detector discreto. O princípio de funcionamento do CCD também está baseado no efeito fotoelétrico, assim cada pixel gera uma carga elétrica que é proporcional à intensidade de luz que chega até eles. Essas cargas elétricas geradas são acumuladas nos pixels e em seguida são levadas através de um circuito elétrico até algum registrador externo que digitaliza o sinal. O CCD utilizado em nossos experimentos foi fornecido juntamente com o espectrômetro da Jobin-Yvon. O detector era feito de silício e sua sensibilidade estava entre aproximadamente $400 \mathrm{~nm}$ e $1100 \mathrm{~nm}$. Com uma cobetura ultra-violeta especial poderíamos estender sua sensibilidade para a região UV. O CCD que foi utilizado em nossos experimentos possui um conjunto de 1024 x 256 pixels em uma área de 27.6 x 7 mm. Para a maior parte das aplicações espectroscópicas o chip é orientado de tal forma que seu maior eixo seja paralelo à dispersão em comprimento de onda do espectrômetro. Este procedimento é feito para maximizar a escala espectral que pode ser analizada ao mesmo tempo. Dessa forma o eixo mais curto é paralelo às fendas de entrada do espectrômetro. Uma das vantagens de se usar o CCD é que ele permite monitorar simultaneamente toda região espectral de interesse, esse procedimento permite integrar o sinal com constantes de tempo muito curtas. Contrariamente, as fotomultiplicadoras trabalham com um sistema de foto-contagem acoplado a um sistema de varredura mecânico. Assim, em alguns casos há uma desvantagem com relação à velocidade de varredura. Por ser lenta ela não permite o uso de constantes de tempo muito baixas como no sistema CCD. Um tempo de varrredura muito alto faz aumentar a razão sinal-ruído drasticamente.

Por outro lado a fotomultiplicadora tem algumas vantagens em relação ao CCD quando queremos varrer grandes regiões espectrais. Além da vantagem citada, o sistema CCD apresenta outras características importantes na deteç̧ão de energia. Na escolha de um detector espectrométrico, é necessário levar em conta algumas características que maximizam a sensibilidade do detector. Assim, a seguir são citadas algumas dessas características.

Uma das principais características do CCD é uma alta eficiência quântica 


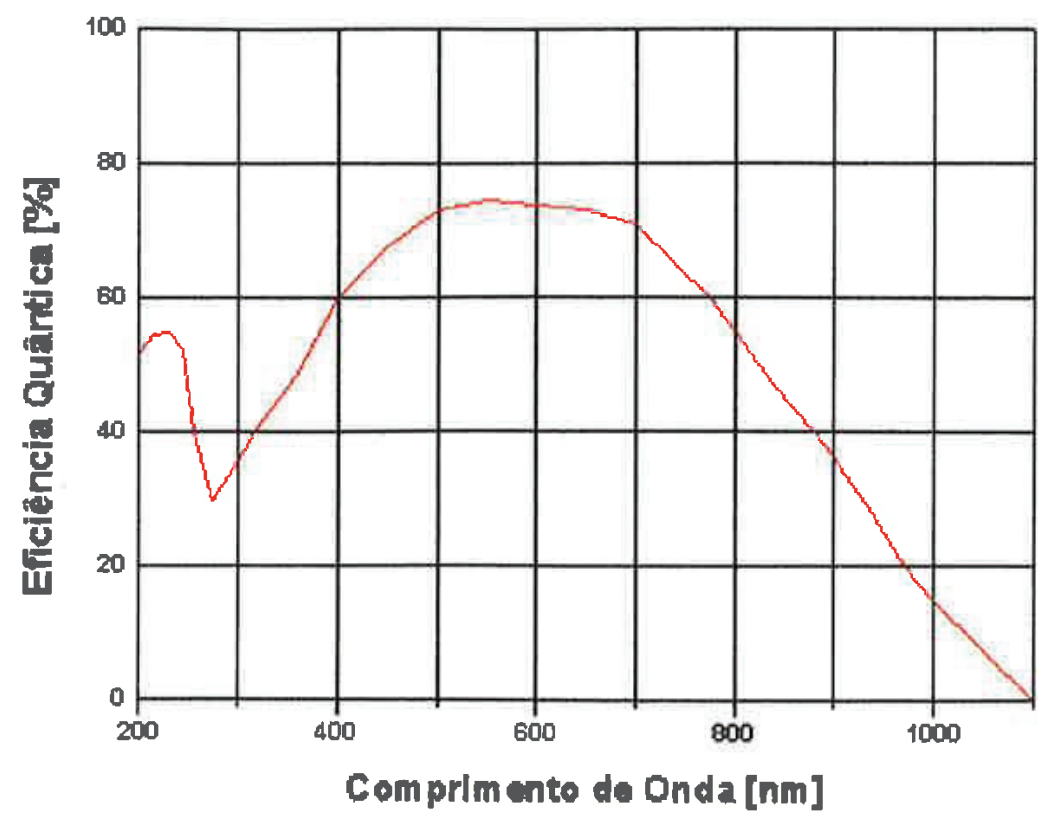

Figura A.4: Eficiência Quântica do CCD.

(EQ) que melhora sensivelmente a razão sinal-ruído de duas maneiras. Ele aumenta o nível de sinal e reduz a porcentagem de ruído balístico. É apresentada na Figura-A.4 uma curva típica de eficiência quântica para o CCD. $[39]$

Um baixo nível de ruído é uma característica crucial em muitas aplicações Raman, onde sinais extremamente fracos são superpostos por um grande ruido de fundo devido à luminescência. É possível também através de uma cobertura com filme ultravioleta expandir a escala do CCD para regiões fora do visível. Esse tipo de filme permite cobrir uma larga região espectral com um EQ de cerca de 50-70 \% no visível e infra-vermelho próximo e cerca de 20-30 \% no ultra-violeta. É possível também negligenciar o ruído térmico quando o CCD é suficientemente resfriado. Por essas e outras razões o CCD é de alto valor para a espectroscopia Raman quando se trata da medida de baixos níveis de energia. 


\section{Apêndice B}

\section{Espalhamento Raman Ativado por desordem}

\section{B.1 Introdução}

Durante o desenvolvimento e crescimento de novos compostos artificiais, surgiram materiais que não tinham a forma quase perfeita dos cristais encontrados na natureza. Nestes materiais foram observadas algumas estruturas as quais foram nomeadas de defeitos ou impurezas que poderiam aparecer durante o crescimento do material. Esses defeitos ocasionam desordem na rede cristalina modificando as propriedades físicas (ópticas, elétricas, etc) dos materiais. Devido a essa desordem surgem novas características nos espectros ópticos desses materiais. Assim nosso interesse neste trabalho é estudar esses defeitos à luz da Espectroscopia Raman enfatizando principalmente algumas ligas ternárias com o grupo de materiais III-V e com estrutura do tipo Zincblende. Seram dadas algumas das possíveis origens dos novos modos Raman ativados por desordem que surgem devido ao fato da não conservação do momento $(q \neq 0)$, o que provoca uma quebra nas regras de seleção para cristais perfeitos.

A espectroscopia Raman é uma das melhores técnicas de se medir os modos vibracionais da rede cristalina. De maneira bem geral e simplificada o espalhamento Raman consiste da interação da radiação com a matéria : a luz incidente de frequência $w_{i}$ pode interagir com um cristal criando ou destruindo um ou mais modos vibracionais da rede (fônons) e a energia $\hbar w$ ganha ou perdida pela rede é compensada por uma diminuição ou aumento 
na frequência da radiação espalhada $w_{s}\left(w_{s}=w_{i} \pm w\right)$. A diferença entre a radiação incidente e espalhada é chamada de deslocamento Raman. A maior parte dos fônons excitados durante o processo Raman em sólidos são ditos de centro da zona de Brillouin ou de $q=0$. Há outros processos Raman mais sofisticados que envolvem outros tipos de interações mas que não serão discutidos no momento. Para materiais perfeitamente cristalinos o espalhamento Raman obedece algumas regras de seleção que são determinadas pelas simetrias de translação do cristal. [40]

As técnicas de medição Raman não servem apenas para materiais cristalinos mas também para sólidos amorfos e desordenados onde aparecem os modos ativados por desordem que são de nosso interesse neste trabalho. Nos sólidos cristalinos é possível saber rapidamente quais são os modos vibracionais permitidos e proibidos, para isto basta saber qual é o tensor Raman $(\overleftrightarrow{R})$ associado à simetria do cristal em questão e à polarização das radiações incidente e espalhada em relação às direções cristalinas. [40]

Nos sólidos amorfos e desordenados as regras de seleção são quebradas e podem aparecer espectros contínuos onde todos os modos são permitidos. Estes modos ativados por desordem podem ser ocasionados por diversos tipos de defeitos intrínsecos e extrínsecos, tais como: impurezas, vacâncias, interstícios, antisítios, substituição, etc. Dentre os materiais usados para esse tipo de estudo encontram-se diversas ligas de materiais com estrutura tipo zincblende e um dos mais estudados é o GaAs que serve na maioria das vezes como substrato para o crescimento $\mathrm{MBE}$ de diversas estruturas semicondutoras de baixa dimensionalidade como as superredes e os pontos quânticos.

\section{B.2 Observação prévia de modos ativados por desordem}

Nas últimas décadas muitos trabalhos surgiram para tentar explicar os modos Raman ativados por desordem (MRAD). Para se conhecer esses novos MRAD é necessário primeiramente conhecer muito bem os modos para os compostos puros, a partir daí é possível a comparação com os materiais desordenados. Uma forma de se estudar os defeitos intrínsecos da rede é através da técnica de "Electron Spin Ressonance", mas neste caso 
as estruturas obtidas são muito largas e fica complicado obter informaçôes a respeito dos defeitos. Assim, a espectroscopia Raman é usada, pois as mudanças nas formas de linha são bem aparentes e as estruturas são mais finas.

O processo de espalhamento por desordem se dá da seguinte forma: os fônons de um cristal perfeito ao serem excitados por alguma radiação incidente (fótons) viajam pela rede cristalina em direções privilegiadas sem serem espalhados. Por exemplo numa incidência ao longo de uma direção $x$ de um cristal puro, os átomos que estão ao longo deste eixo vibram longitudinalmente formando os modos LO e LA do cristal, enquanto os que vibram em direções perpendiculares, formam os chamados modos transversais ou TO e TA. Numa situação de desordem onde aparecem defeitos e impurezas na estrutura cristalina os fônons são espalhados por esses defeitos e interagem com outros modos em direções variadas. Isso explica os novos modos ativados por desordem.

Como exemplo de modos desordenados, podemos citar os modos ópticos e acústicos locais que aparecem em condições de ressonância na presença de defeitos. Há também alguns defeitos que podem ocasionar modos Raman coletivos e de superfície que normalmente são proibidos em compostos sem defeitos, isso ocorre devido à quebra das regras de seleção do momento cristalino e os espectros desses materiais muitas vezes formam um contínuo. Quando não há uma conservação do momento cristalino os fônons da borda da zona podem contribuir para o processo de espalhamento Raman.

Para exemplificar, será discutido brevemente um trabalho interessante feito por Berg and Yu [30], onde são criados alguns defeitos intrínsecos irradiando uma amostra de GaAs com radiações de diversas energias tais como: feixe iônico, feixe de elétrons e nêutrons. Medidas Raman das amostras são feitas logo após a irradiação. Os resultados mostraram o aparecimento de diversos modos de vibração que não apareciam antes e nas medidas em condições de ressonância ocorre um aumento da seção de choque Raman aumentando a amplitude do sinal.

O estudo do espalhamento Raman ativado por desordem é importante pois nos últimos anos com o aparecimento das ligas semicondutoras que apresentam uma série de defeitos é de extrema importância entender os processos de espalhamento e suas propriedades ópticas. As ligas se dividem em dois tipos: as ligas ordenadas que obedecem os cálculos estequiométricos 
durante a mistura de dois elementos e as ligas desordenadas que misturam os elementos em porcentagens que não levam em conta os cálculos estequiométricos. Um trabalho interessante onde aparece desordem substitucional foi publicado por Kawamura e colaboradores [41] onde é feito um estudo da substituição de $\mathrm{Ga}$ por $\mathrm{Al}$ em ligas do tipo $\mathrm{Ga}_{1-x} \mathrm{Al}_{x} A s$ usando espalhamento Raman, cujos resultados foram interpretados como modos longitudinais acústicos ativados por desordem (DALA). Algumas ligas semicondutoras de especial interesse são as do tipo ternária como o $\mathrm{Ga}_{1-x} \mathrm{Al}_{x} \mathrm{As}$, o $\mathrm{In}_{1-x} \mathrm{Al}_{x}$ As e o $\mathrm{GaAl}_{1-x} \mathrm{P}_{x}$ que devido ao confinamento, apresentam mudanças nas suas propriedades ópticas servindo para diversas aplicações na produção de novos dispositivos eletrônicos e Lasers. Por exemplo no sistema $\mathrm{Ga}_{1-x} \mathrm{Al}_{x} \mathrm{As}$, as constantes referentes à força do $\mathrm{Ga}-\mathrm{As}$ e do Al-As são quase iguais e isto permite um casamento quase perfeito das constantes da rede, assim podemos estudar seus modos vibracionais como se fossem um cristal perfeito, mas como há diferenças nas funções de onda dos caroços atômicos do $\mathrm{Ga}$ e do $\mathrm{Al}$ é esperado que a incerteza na localização da função de onda dos elétrons possa causar uma quebra nas regras de seleção fazendo aparecer modos que antes eram proibidos. Muitas vezes nas ligas apresentadas acima aparecem modos que eram proibidos no cristal puro e esses novos modos aparecem possivelmente devido à desordem na rede e têm sua intensidade proporcional à densidade de estado dos fônons sendo mais uma forma de caracterizar a desordem da rede.

No espectro Raman de materiais semicondutores III-V distinguimos geralmente dois tipos de linhas. Essas linhas correspondem aos modos ópticos longitudinais ( $\mathrm{LO}$ ) e transversais (TO) do centro da zona de Brillouin. No caso das ligas ternárias do tipo $\mathrm{Ga}_{1-x} \mathrm{Al}_{x} \mathrm{As}$ há dois acoplamentos dos modos LO e TO, um para o tipo-GaAs e outro para o tipo-AlAs, onde por exemplo o tipo-GaAs tem frequência de fônons que se aproxima do GaAs quando x vai a zero. Assim podemos estudar os efeitos da anarmonicidade e os efeitos da desordem induzida através de um estudo da largura de linha e da mudança de perfil do espectro [32]. Na Figura-B.1 é mostrado um gráfico que relaciona a frequência dos modos LO e TO na heteroestrutura de $\mathrm{Ga}_{1-x} \mathrm{Al}_{x}$ As crescidas por diversos métodos em função da concentração de Al.

No caso das ligas os modos LO para o GaAs e para o AlAs tornam-se assimétricos, conforme o perfil visto na Figura-B.2. Uma explicação que 


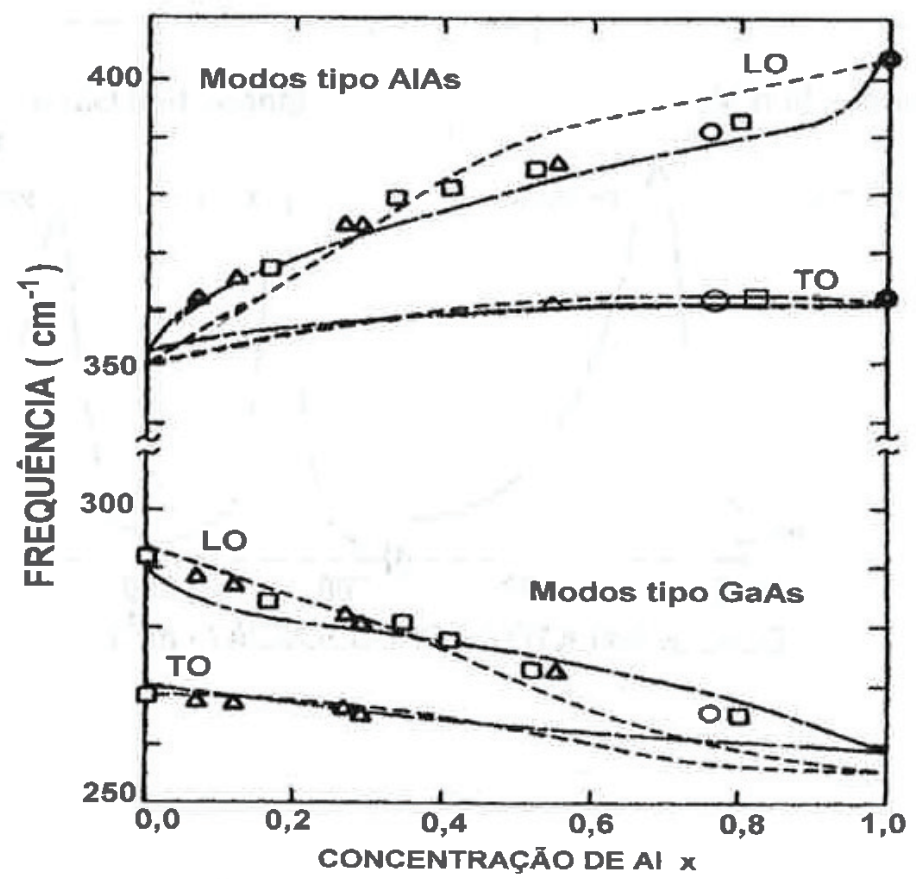

Figura B.1: Variação da frequência versus composição das linhas Raman de primeira ordem em ligas de $\mathrm{Ga}_{1_{-x}} \mathrm{Al}_{x} \mathrm{As}$. Os pontos experimentais são representados por triângulos (MBE), quadrados (LPE), e círculos (VPE). A figura ainda mostra os resultados teóricos obtidos pelo modelo de Bonneville [42] (linhas interrompidas), bem como os valores experimentais obtidos por Tsu [43] (linhas pontilhadas).

foi dada para o alargamento da assimetria da linha Raman foi dada como efeito induzido por desordem.

\section{B.3 Conclusões}

O que se percebe de importante nessas heteroestruturas desordenadas é que durante as medidas de espalhamento Raman não há conservação do momento e consequentemente as regras de seleção são quebradas, aparecendo modos que antes eram proibidos no cristal puro. Essas novas bandas têm intensidade proporcional à densidade de estados de fônons. Em conclusão, através da observação do espectro Raman é possível ver como se degradam os modos quando passam de uma fase cristalina para a fase amorfa. É 


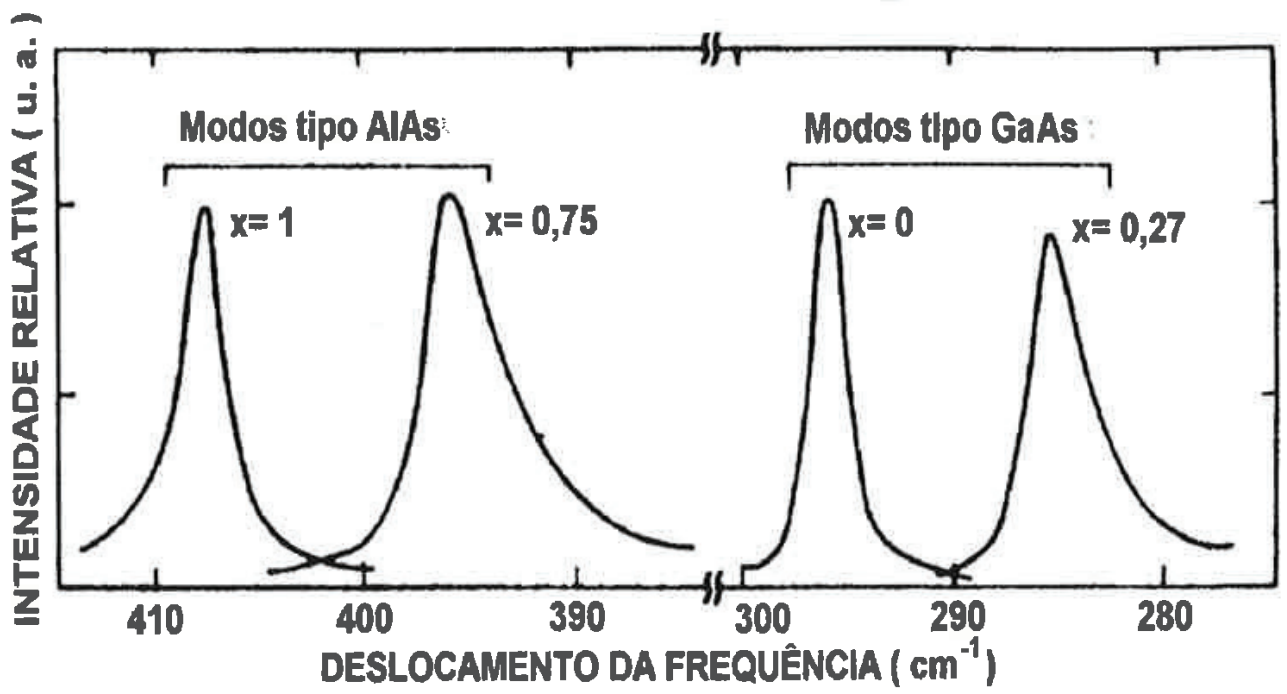

Figura B.2: Perfil do modo LO em $\mathrm{Ga}_{1_{-x}} \mathrm{Al}_{x} \mathrm{As}$, com diversas composições.

possível também medir as energias vibracionais na presença de desordem permitindo a criação de dispositivos que trabalhem nessas escalas de energia. 


\section{Referências Bibliográficas}

[1] S. Nakamura, J. Vac. Sci. Technol. A 13, 705 (1995).

[2] T. Uenoyama, Phys. Rev. B 51, 10228 (1995).

[3] Y. Narukawa, Y. Kawakami, M. Funato, S. Fupita, and S. Nakamura, Appl. Phys.Lett. 70, 981 (1997); Y. Narukawa, Y. Kawakami, M. Funato, S. Fupita, and S. Nakamura, Phys. Rev. B 55, R1938 (1997).

[4] K.P. O'Donnell, R.W. Martin and P.G. Middleton, Phys. Rev. Lett. 82, 237 (1999); K.P. O'Donnell, R.W. Martin and P.G. Middleton, Appl. Phys. Lett. 74, 263 (1999).

[5] P.M. Petroff and S.P. Denbaars, Superlattices Microstruct. 15, 15 (1994).

[6] F. Hatami, N.N. Ledentsov, M. Grundmann, J. Bhrer, F.Heinrichsdorff, M. Beer, D. Bimberg, S.S. Ruvinov, P. Werner, U. Gsele, J. Heydenreich, U. Richter, S.V. Ivanov, B. Ya. Meltser, P.S. Kop 'ev, and Zh.I. Alferov, Phys. Rev. Lett. 67, 656 (1995).

[7] B.R. Bennett, R. Magno, and B.V. Shanabrook, Appl. Phys. Lett., vol. 68, 505 (1996)

[8] D.J. Bottomley, Appl. Phys. Lett., 72, 783 (1998).

[9] B.R. Bennett, B.V. Shanabrook, and R. Magno, Appl. Phys. Lett., 68, 958 (1996).

[10] E. Silveira, A. Tabata, J.R. Leite, R. Trentin, V. Lemos, T. Frey, D.J. As, D. Shibora, and K. Lischike, Appl. Phys. Lett. submetido July (1999) 
[11] E. Roca, C. Trallero-Giner and M. Cardona, Phys. Rev. B 49, 13704 (1994)

[12] M. Grundmann, O. Stier and D.Bimberg, Phys. Rev. B 52, 11969 (1995)

[13] R. Fuchs and K.L. Kliewer, Phys. Rev. 140, A2076 (1970)

[14] M.C.Klein, F. Hache, D. Ricard, and C. Flytzanis, Phys. Rev. B 42, $11123(1990)$

[15] K.Imamura, Y. Sugiyama, Y. Nakata, S. Muto and N. Yokoyama, Jpn. J. Appl. Phys. 34, 1445 (1995)

[16] A.F.Tsatsul'nikov, N.N. Ledentsov, M.V. Maksimov, B.Ya.Mel'tser, P.V. Neklyudov, S.V. Shaposhnikov, B. V Volovik, I.L. Krestnikov, A.V. Sakharov, N.A. Bert, P.S. Kop'ev, Zh.I. Alferov and D. Bimberg, Semiconductors 31, 55 (1997)

[17] A.A. Quivy, M.A. Cotta and J.R. Leite, Braz. J. Phys 27A, 154 (1997)

[18] M. Grundmann, J. Christen, N.N. Ledentsov, J. Bhrer, D. Bimberg, S.S. Ruvinov, P. Werner, U. Richter, U. Gsele, J. Heydenreich, V.M. Ustinov, A. Yu. Egorov, A.E. Zhukov, P.S. Kop 'ev and Zh.I. Alferov, Phys. Rev. Lett. 74, 4043 (1995).

[19] R. Trommer and M. Cardona, Phys. Rev. B 17, 1875 (1978)

[20] D. Leonard, M. Krishnamurthy, S. Fajard, J.L. Merz, and P.M. Petroff, J. Vac. Sci. Technol. B 12, 1063 (1994)

[21] W. Li, Z. Wang, J. Liang, Q. Liao, B. Xu, Z. Zhu, and B. Yang, Appl. Phys. Lett. 66, 1080 (1995)

[22] M.J. da Silva, A.A. Quivy, E.C.F. da Silva, M.T. Moshegov, P. Gonzales-Borrero, and P. Basmaji, resultados a serem submetidos a publicação.

[23] S. Emura, A.E. Gonda, Y. Matsui and H. Hayashi, Phys. Rev. B 38, $3280(1988)$ 
[24] B. Jusserand and M. Cardona in: Light Scattering in Solids V, vol.66 of Topics in Applied Physics, edited by M. Cardona and G. Gntherodt (Springer-Verlag, Berlin Heildelberb 1989) pag.49

[25] P.Y.Yu and M. Cardona Fundamentals of Semiconductors, Physics and Materials Properties, (Springer-Verlag, Berlin Heildelberb, 1995).

[26] O. Madelung, Physics of III-V Compounds, (John Wiley and Sons, 1964).

[27] J.-Y. Marzin, J.-M. Gerard, O. Cabrol, B. Jusserand and B. Sermage, Il Nuovo Cimento, 17D, 1285 (1995).

[28] J. Groenen, A Mlayah, R. Carles, A. Ponchet, A. Le Corre and S. Salaün, Appl. Phys. Lett., vol. 69, 943 (1996).

[29] C. García, J. Ramos, A.C. Prieto, J. Jiménez, C. Geertsen, J.L. Lacour and P. Mauchien, Applied Surface Science 96-98, 370 (1996).

[30] R.S. Berg and P.Y.Yu, Appl. Phys.Lett., vol. 47, pag. 515 (1985).

[31] B. Monemar, Phys. Rev. B 8, 5711 (1973)

[32] B. Jusserand and J. Sapriel, Phys. Rev B, vol. 24, 7194 (1981)

[33] N.C.Craig and I.W. Levin, Appl. Spectroscopy, vol. 33, 476 (1979)

[34] P. Giannozzi, S. de Gironcoli, P. Pavone and S. Baroni, Phys. Rev. B 43, 7231 (1991).

[35] J.I. Pankove, Optical processes in semiconductors(Dover, New York 1971) (cap.3)

[36] A. Chehaidar, A. Zwick, R.Carles and J. Bandet, Phys. Rev. B 50, 5345 (1994)

[37] G.P. Schwartz, B. Schwartz, D. DiStefano, G.J. Gualtieri and J.E. Griffiths, Appl. Phys. Lett. 34(3), 205 (1979).

[38] C. Grupen, Particle Detectors, Cambridge Monographs on Particle Physics, Cambridge University Press (1996)

[39] Princeton Instruments Publication, Outubro (1994 
[40] M. Cardona in: Light Scattering in Solids II, vol.50 of Topics in Applied Physics, edited by M. Cardona and G. Gntherodt (Springer-Verlag, New York 1982)

[41] H. Kawamura, R.Tsu, and L.Esaki, Phys. Rev. Lett. 29, 1397 (1972)

[42] R. Bonneville, Phys. Rev. B, vol. 24, 1987 (1981)

[43] R. Tsu, H. Kavamura, and L.Esaki, in Proceedings of the Eleventh International Conference on the Physics of Semiconductors, Warsaw, 1972, edited by M. Miasek (P.W.N.-Polish-Scientific, Warsaw, 1972), 1135 . 